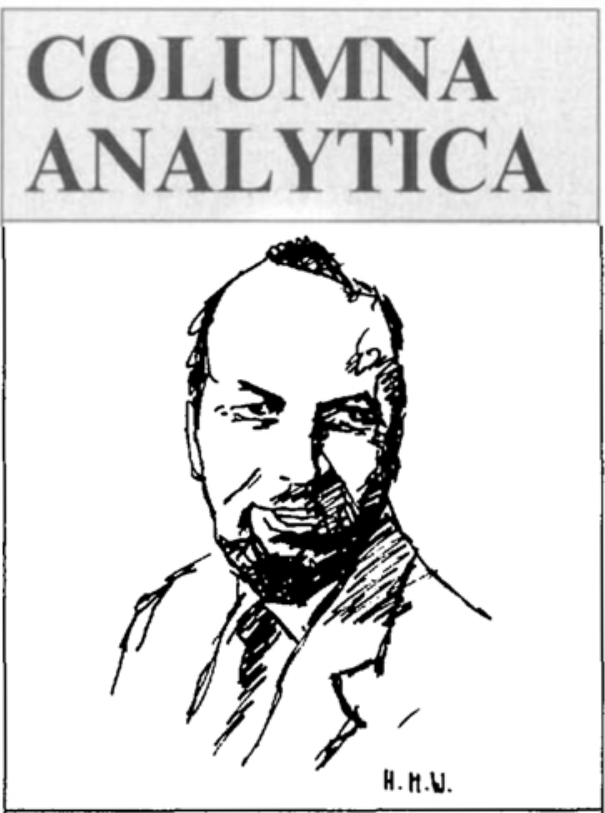

In dieser Kolumne schreibt Prof. Dr. H.M. Widmer

Forschung Analytik

Ciba-Geigy $A G$, FO 3.2

CH 4002 Basel

regelmässig eigene Meinungsurtikel oder lädt Gäste ein, allgemein interessierende Angelegenheiten der modernen Analytik zu kommentieren. Einwendungen aus dem Leserpublikum sind nicht unerwünscht (Adresse: siche oben) und werden in angemessener Weise berücksichtigt.

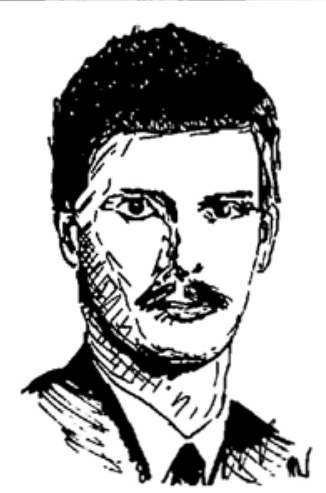

Dr. Klans Olaf Börnsen is the laser program project leader in the Central Analytical Research Depart ment of Ciba-Geigy Ltd., Basel. He studied at the Christian-Albrechts University in Kiel. Under Prof. Edu'ard M. Schlag at the Technical University in Munich, he received his Ph. D. in 1987. He joined Ciha-Geigy in 1988 as a postdoctoral fellow and became a permanent cmployee in 1989.

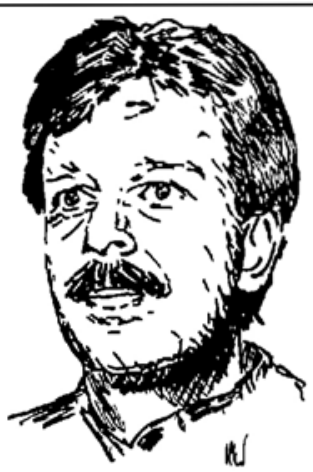

k

Dr. Marlin Schür reccived his Ph. D in 1988 from the University of Berne, where he studied under Prof. Ernst Schumacher. He spent a postdoctoral year at the California Institute of Technology in Pasadena, where he investigated the photoelectronic spectra of van der Waals clusters in molecular beams. He joined the Laser Laboratory of the Ciha-Geigy, Central Analytical Rescarch Department, in July 1990 (c) Schweiz. Chemiker-Verhand; ISSN 00094293

\title{
Recent Progress in Laser Analytics
}

Analytical methods are on their way to penetrate the biological sciences. In this trend, laser technology plays an important role, especially in the form of laser-desorption mass spectrometry (LD-MS).

The remarkable progress made in this field is nicely demonstrated by a statement made in 1986 by Frank H. Field, a specialist in the mass spectrometric investigation of biomolecules and Professor at Rockefeller University in New York. Citing Professor Field: 'The mass region of real interest for proteins lies between 40000 and 100000 $\mathrm{Da}$, and one can only speculate as to whether such monster gaseos ions could be produced. My personal feeling is that to do so may well require the discovery of some new technique.'

This statement represented the state-ofthe-art in 1986, but only less than two years later the predicted new discovery was made. The novel method is called matrixassisted laser desorption/ionization (LDI), and was introduced by Michael Karas and Franz Hillenkamp (Institute for Medical Physics, University of Münster) in 1987/ 88. Their invention made it possible to investigate biomolecules up to $300000 \mathrm{Da}$ in the gas phase of a time-of-flight mass spectrometer (TOF-MS).

It is interesting to recall the different steps that made this success come true. It is again one of these cases demonstrating the necessity of interdisciplinary influences for the advancement of analytical methodologies. At the same time, it is a typical model case for the instrumental developments from a complicated physical instrument to a widely used analytical tool. It needed a fine-tuning through chemical experience to improve the efficiency of the method and to simplify the instrumental device, so that it became economical and may be operated by relative unskilled personnel, a prerequisite for the wide-spread use of a technology, especially in medical applications.

Laser techniques have long been used in analytical research, but seldom has a laser method reached whide applications. It remained the domain of specialists, partially due to the fact, that for many years lasers remained expensive and delicate to handle. However, in the last few years, novel laser instruments became available, among them the simple diode and semiconductor lasers, which found many applications in fiber optical sensors and other analytical fields.

The most important analytical applications of laser methods are connected with mass spectrometry (MS). In 1946, William E. Stephens (University of Pennsylvania in Philadelphia) described a mass spectrometer with time dispersion, followed by the ion velocitron of A.E. Cameron and D.F. Eggers. These devices represented early forms of the time-of-flight mass spectrometer (TOF-MS) first described by the Swiss R. Keller in 1949.

The first commercially successful TOFMS was introduced by Bendix Corporation, and it was based on the design reported in 1955 by William C. Wiley and I. H. McLaren (Bendix Aviation Corporation). In these early days of TOF-MS, the ions were generated by electron impact (EI). The Bendix instrument had a $2 \mathrm{~m}$ long flight tube and its mass range was limited to $400 \mathrm{Da}$ when operated at $10 \mathrm{kHz}$. Originally this instrument was used to study ion-molecule and molecule-molecule interactions.

An important improvement in the TOFMS instrumentation was introduced in 1973 by B.A. Mamyrin, V.J. Karatajev, D.V. Shmikk, and V. Zagulin (Physical Technical Institute Ioffe, Leningrad) the inventors of the reflectron. Their mass reflector enabled the focussing of ions with the same mass, and, therefore, inhanced the mass resolution of TOF-MS.

Parallel to these instrumental developments, attempts were made to desorb and ionize nonvolatile and polar substances to make them accessible for MS. The idea was to desorb such molecules directly from the solid state into the gas phase and to ionize them in a second step in the gas phase.

In 1960, Hans D. Beckey and P. Schultz (University of Bonn) introduced the fielddesorption (FD) technique. Field desorption creates a direct and combined desorption and ionization from the condensed phase. The primary excitation is achieved through low-energy ions and neutral particles such as $\mathrm{Xe}^{+}$and $\mathrm{Xe}$.

In 1964, Joseph Berkowitz and William A. Chupka used a laser beam directed at the surface of graphite to study the mass spectrum of the vapor ejected from the solid material. Kenneth A. Lincoln (Naval Radiological Defense Laboratory, San Francisco) also used laser radiation to flash evaporate solid materials for mass spectrometric investigations. Other desorption methods followed shortly. In 1976, D. MacFarlane and D.F. Torgerson (Cyclotron Institute, Texas A and M University, College Station) published work on the plasma desorption (PD) of large molecules, based on the analyte surface 
bombardment with high-energy heavy particle fission products of ${ }^{252} \mathrm{Cf}$, and in the same year Alfred Benninghoven, D. Jaspers, and $W$. Sichtermann (University of Köln) used lighter particles, such as fast alkali or rare-gase ions, to desorb ions form the solid surface. The method was called secondary-ion mass spectrometry (SIMS). An extension of these techniques was introduced in 1981 by Michael Barber, Robert $S$. Bordoli, R. Donald Sedgwick, and Andrew N. Tyler (Chemistry Department University of Manchester), called fastatom-bombardment (FAB). For many years, SIMS and FAB were the most popular methods for the desorption of large and nonvolatile molecules, since these techniques were easily adapted to the existing sector and quadrupole mass spectrometers of numerous MS laboratories. Although FAB and SIMS were extended to desorb compounds above $10000 \mathrm{Da}$, these investigations were generally handicapped by the resulting week signals and the sensitivity remained unsatisfactory for this upper mass range.

Around 1975 laser microprobe instruments became available and were widely used. Their characteristics is that they focus the laser to a very small spot size on a thin foil on which the sample is deposited on the opposite side of the foil. Heraeus successfully commercialized an instrument (LAMMA 500 and 1000) which became very popular among the specialists. The LAMMA 500 used a Nd/YAG laser focussed to a spot size of $0.1-1.0 \mu \mathrm{m}$ $\left(10^{8}-10^{11} \mathrm{~W} \cdot \mathrm{cm}^{-2}\right)$.

Another approach evolving around 1978 by was the resonant and non-resonant multiphoton ionization (MPI). Originally, the sample was introduced from the vapor phase over a liquid effluents through a thin nozzle to generate a supersonic molecular beam by expansion into the vacuum. The molecules of interest were then ionized through a two photon process and extracted into a TOF-MS. The two-step laser ionization was preferred over a direct ionization, because only two photons have enough energy to ionize the molecule. Using two photons of different color it is possible to ionize in an extremly soft mode. However, the target molecule must contain a chromophore to ionize. Maximum resolution of the wavelength spectra was obtained, when the evaporated molecules were cooled in an expanding beam of neutral gas. Pioneers in this field were groups around Richard N. Zare (Chemistry Department, Stanford University), David $M$. Lubman (Chemistry Department, University of Michigan, Ann Arbor), and Edward W. Schlag and Jürgen Grotemeyer (Technical University of Munich).

Later, two-step laser procedures were also performed with solid samples. In these experiments, a $\mathrm{CO}_{2}$-laser was used to desorb the species deposited on a flat surface. The desorbed molecules were subsequently introduced into a supersonic molecular beam with carrier gas and then ionized by
MPI and analyzed in a TOF-MS system. In an earlier Columna Analytica article (Chimia, 1988, 42, 147), Renato Zenobi, Jong Hoon Hahn, and Richard N. Zare (Department of Chemistry, Stanford University) reviewed and illustrated the feasibility of such technologies.

The classical ionization, i.e. electron-impact (EI) and chemical-ionization (CI) techniques for gas-phase molecules are suitable only for relatively small species. In contrast, the laser desorption techniques are applicable to large polar and thermolabile molecules, such as antibiotica, enzymes, and carbohydrates.

In the early 1980's, laser desorption of intact organic molecules evolved. Although various mass analyzers were used for this purpose, the time-of-flight analyzer proved to be the most suitable, since TOF-MS can record ions over a broad mass range, therefore, extending the mass range of previous laser-desorption mass spectrometry. However, laser desorption also fits well with ion-cyclotron-resonance (ICR). David A. McCreary, E. B. Ledford, Jr., and M.L Gross conducted some of the very first experiments in which samples were analyzed by ICR, also called FourierTransform MS (FT-MS).

In 1987, Kuni Tanaka, Y. Ido, S. Akita, $Y$. Yoshida, and T. Yoshida reported the mass-spectral analysis of oligomers in lysozyme with masses far above $10000 \mathrm{Da}$, using laser desorption from a matrix of metal powder (Ni), finely dispersed in glycerol. Laser mass spectrometry for the examination of large molecules, thus, came to ages, supported by improvement in laser technology and high-speed electronic recording techniques.

Lasers may desorb neutral species, including intact molecules, an advantage that was fully realised when matrix-assisted laser desorption/ionization was introduced by Michael Karas and Franz Hillenkamp in 1988, using a time-of-flight microprobe instrument (LAMMA 1000) with a frequency-quadrupled ND/YAG laser at 266-nm wavelength for ion desorption/ ionization. The sample solutions $\left(5 \times 10^{-6}\right.$ to $10^{-7} \mathrm{M}$ ) were mixed with equal amounts of $5 \times 10^{-2} \mathrm{M}$ solutions of nicotinic acid as matrix. Less than $1 \mu$ l of the combined solution were dripped onto an $\mathrm{Ag}$ target and dried under vacuum. This rather simple sample preparation lead to a final sample-matrix solid mixture covering 1 to $5 \mathrm{~mm}^{2}$ of the probe metal surface. The probe was then introduced into the vacuum system of the microprobe analyzer and irradiated with the laser light. The total time for sample preparation, insertion into the vacuum chamber, and recording of the spectra amounted to several minutes, and single spectra could be registered at a rate of $\sim 5-10$ per min.

This technique represented a remarkable technological breakthrough, since it al. lowed the mass spectral investigations of biopolymers in the mass range up to $300000 \mathrm{Da}$. Several groups adopted the technology. The most astonishing results were published by the groups around Michael Karas and Franz Hillenkamp and by Ronald C. Beavis and Brian T. Chait (Department of Mass Spectrometry and Gas Phase Ion Chemistry, The Rockefeller University, New York) and Robert J. Cotter (Department of Pharmacology of Molecular Sciences, The John Hopkins University, Baltimore).

Matrix-assisted LDI-MS is characterized by several typical features. Singly charged molecular ions are in all cases the base peak of the analyte signal, and no fragments are observed above $1000 \mathrm{Da}$. Sometimes, multiple charged ions are observed, which has not been reported before for the laser desorption, though for plasma desorption MS of high-mass proteins. Multimers and doubly charged molecular ions generally improve the molecular ion detection. A remarkable sensitivity is demonstrated and only small samples are required for multiple analysis (subnanogram range). Furthermore, matrixassisted LDI is also characterized by a low chemical-noise level.

The matrix material plays a crucial role in the successful desorption and ionization of the macromolecules. Whereas Michael Karas and Franz Hillenkamp used nicotinic acid as matrix material, Ronald $C$. Beavis and Brian T. Chait improved the ionization efficiency for certain analytes by the use of sinapinic acid.

The matrix should be chosen so that it is able to absorb light. Aromatic systems nicely fulfill this requirements. But until now only a few molecules are known which explode in crystalline form when exposed to laser light. Under these conditions, a collective evaporation of the irradiated micro volume occurs. Obviously, in the laser process the lattice vibration of the matrix is excited after the relaxation of the deposited energy, leading to a desintegration of the crystal lattice. At the same time protontransfer reactions occur through photoionization processes in the condensed phase leading to a simultaneous desorption and ionization. However, the theoretical process is still unknown.

Carbohydrates, i.e. polysaccharides, polypeptides and proteins, and oligonucleotides have been successfully investigated by this matrix-assisted LDI-MS technique.

Karas et al. published investigations of lysozyme with a molecular weight of 14306 $\mathrm{Da}, \beta$-lactoglobulin A (18277 Da), porcine trypsin $(23463 \mathrm{Da})$, and albumin $(67000$ Da). In 1990, Ronald C. Beavis and Brian $T$. Chait published a study on the rapid and sensitive analysis of protein mixtures including commercial bovine milk and human breast milk.

Most recently, $K$. Olaf Boernsen, Martin Schär, and H. Michael Widmer (Analytical Research, Ciba-Geigy Ltd., Basel) using sinapinic acid as matrix material, demonstrated that this technique also works for sulfonic-acid compounds. With other mass spectrometric methods this substance class 
could not be efficiently ionized. With most analytes, they observed the positive and negative ions, depending only on the direction of the applied field in the TOF-MS.

Basic research in molecular biology and experience from biotechnology ask for more accurate and sensitive analytical methods for high-molecular weight compounds such as proteins (enzymes), carbohydrates (polysaccharides), and nucleic acids (oligonucleotides). The main problem is to form intact ions in the gas phase of thermolabile biomolecules. The use of laser techniques opened new horizons, and matrix-assisted laser desorption especially will assume an important position in analytical biotechnology and analytical molecular biology.

These promising aspects need further development. Matrix-assisted LDI TOFMS may become an easy-to-handle future technology, which may be expanded to fulfill additional needs of biotechnology and molecular biology, such as a simple sequence analysis or real-time measurements in polypeptide synthesis and biotechnological processes.

\section{Literature Survey On Recent Progress in Laser Mass Spectrometry}

- W. E. Stephens, Phys. Rev. 1946, 69 , 691: 'A Pulsed Mass Spectrometer with Time Dispersion'.

- A. E. Cameron, D. F. Eggers, Rev. Sci. Instrum. 1948, 19, 605: 'An Ion «Velocitron'”'.

- R. Keller, Helv. Phys. Acta 1949, 22, 386: 'Mass Spectra Obtained from Measurement of the Time of Flight'.

- W. C. Wiley, I.H. McLaren, Rev. Sci. Instrum. 1955, 26, 1150: 'Time-of-Flight Mass Spectrometer with Improved Resolution'.

D. B. Wetlaufer, in 'Advances in Protein Chemistry', Eds. C. B. Anfinsen, Jr., M. L. Anson, K. Bailey, and J.T. Edsall, Academic Press, New York, 1962, p. 326: 'Ultraviolet Spectra of Proteins and Amino Acids'.

R. S. Lehrle, J.C. Robb, D. W. Thomas, J. Sci. Instrum. 1962, 39, 458: 'A Modified Time-of-Flight Mass Spectrometer for Studying Ion-Molecule or Neutral Particle-Molecule Interactions'

- G. Junk, H. Svec, J. Am. Chem. Soc 1963, 85, 839: 'The Mass Spectra of the Amino Acids'.

J. Berkowitz, W.A. Chupka, J. Chem Phys. 1964, 40, 2735: 'Mass Spectrometric Study of Vapor Ejected from Graphite and other Solids by Focused Laser Beams'.

- K.A. Lincoln, Anal. Chem. 1965, 37, 541: 'Flash Vaporisation of Solid Materials for Mass Spectrometry by Intense Thermal Radiation'

- H.D. Beckey, D. Schulze, Z. Naturforsch., $A$ 1965, 20 : 'Field Ionization Mass Spectra of Organic Molecules'.
- N.C. Fenner, N.R. Daly, Rev. Sci. Instrum. 1966, 37, 1068: 'Laser Used for Mass Analysis'

- H.J. Svec, G.A. Junk, J. Am. Chem. Soc. 1967, 89, 790: 'Electron-Impact Studies of Substituted Alkanes'.

- M.A. Slifkin, A.C. Allison, Nature (London) 1967, 215, 949: 'Measurement of Ionization-Potentials from Contact Charge Transfer Spectra'.

- J.H. Futrell, T.O. Tiernan, F.P. Abramson, C. D. Miller, Rev. Sci. Instrum. 1968, 39, 340: 'Modification of a Time-ofFlight Mass Spectrometer for Investigation of Ion-Molecule Reactions at Elevated Pressure'.

- A. Benninghoven, Z. Phys. 1970, 230 , 403: 'Analysis of Monomolecular Surface Layers of Solids by Secondary Ion Emission'.

- F.J. Vastola, R.O. Mumma, A.J. Pirone, Org. Mass Spectrom. 1970, 3, 101: 'Use of Laser-Micropyrolysis-Mass Spectrometer in Studying the Pyrolysis of Coal'.

- F. J. Vastola, A.J. Pirone, P.H. Giver, R. R. Dutcher, in 'Spectrometry of Fuels', Ed. R.A. Friedel, Plenum Press, New York, 1970, p. 29.

- W. P. Poschenrieder, Int. J. Mass. Spectrom. Ion Phys. 1971, 6, 413: 'Multiple-Focusing Time of Flight Mass Spectrometers. Part I. TOFMS with Equal Momentum Acceleration'.

- I. C. Paul, D. Y. Curtin, Acc. Chem. Res. 1973, 6, 219: 'Thermally Induced Organic Reactions in the Solid State'

- B. A. Mamyrin, V.J. Karatajev, D.V. Shmikk, V.A. Zagulin, Sov. Phys. JETP 1973, 37, 45: 'Mass Reflection. New NonMagnetic Time-of-Flight High-Resolution Mass Spectrometer'.

- D.F. Torgerson, R.P. Skowronski, R. D. McFarlane, Biochem. Biophys. Res. Commun. 1974, 60, 616: 'New Approach to the Mass Spectrometry of Nonvolatile Compounds'.

- F. Hillenkamp, E. Unsöld, R. Kaufmann, R. Nitsche, Appl. Phys. 1975, 8, 341: 'High-Sensitivity Laser Microprobe Mass Analyzer'.

- F. Hillenkamp, E. Unsöld, R. Kaufmann, R. Nitsche, Nature (London) 1975, 256, 119: 'Laser Microprobe Mass Analysis of Organic Materials'.

- R. D. MacFarlane, D. F. Torgerson, Int J. Mass Spectrom. Ion Phys. 1976, 21, 81 : "252 Cf-Plasma Desorption Time-of-Flight Mass Spectrometry'

- A. Benninghoven, D. Jaspers, W. Sichtermann, Appl. Phys. 1976, 11, 35: 'Secondary-Ion Emission of Amino Acids'.

- R.D. MacFarlane, D.F. Torgerson, Science 1976, 191, 920: “252Cf-Plasma Desorption Mass Spectrometry'.

- R.M. Gandy, R. Ampulski, J. Prusaczyk, R.H. Johnen, Int. J. Mass Spectrom. Ion Phys. 1977, 24, 363: 'Modification of a Time-of-Flight Mass Spectrometer for Studies in Collisionally Induced Dissociation'.
- H.D. Beckey, 'Principles of Field Ionization and Field Desorption Mass Spectrometry', Pergamon Press, Oxford, 1977.

- U. Boesl, H.J. Neusser, E. W. Schlag, Z. Naturforsch., A 1978, 33, 1546: 'Two-Photon Ionization of Polyatomic Molecules in a Mass Spectrometer'.

- R. Nitsche, R. Kaufmann, F. Hillenkamp, E. Unsold, H. Vogt, R. Wechsung, Israel J. Chem. 1978, 17, 181: 'Mass Spectrometric Analysis of Laser-Induced Microplasmas from Organic Samples'.

- M. A. Posthumus, P.G. Kistemaker, H. L.C. Meuzelaar, M.C. Ten Noever de Brauw, Anal. Chem. 1978, 50, 985: 'Laser Desorption-Mass Spectrometry of Polar Nonvolatile Bio-Organic Molecules'.

- R. Stoll, F. W. Röllgen, Org. Mass Spectrom. 1979, 14, 642: 'Laser Desorption Mass Spectrometry of Thermally Labile Compounds Using a Continuous Wave Carbon Dioxide Laser'.

- R. J. Donovan, Prog. React. Kinet. 1979 10, 253: 'Electronic to Vibrational Energy Transfer and Infrared Lasers'.

- G.S. Hurst, M. G. Payne, S. D. Kramer, J.P. Young, Rev. Mod. Phy's. 1979, 51, 767: 'Resonance Ionization Spectroscopy with Amplification'.

- C.R. Blakley, J.J. Carmody, M.L. Vestal, Anal. Chem. 1980, 52, 1636: 'Liquid Chromatograph Mass Spectrometer for Analysis of Nonvolatile Samples'.

- R. J. Cotter, Anal. Chem. 1980, 52, 1767:

'Laser Desorption Chemical Ionization Mass Spectrometry'.

- F. Heresch, E. R. Schmid, J. F. K. Huber, Anal. Chem. 1980, 52, 1803: 'Repetitive Laser Desorption Mass Spectrometry for Nonvolatile Organic Compounds'.

- D.W. Beekman, T.A. Callcott, S.D. Kramer, E. T. Arakawa, G.S. Hurst, E. Nussbaum, Int. J. Mass Spectrom. Ion Phys. 1980, 34, 89: 'Resonance Ionization Source for Mass Spectrometry'.

- R. J. Conzemius, J.M. Capellen, Int. J. Mass Spectrom. Ion Phys. 1980, 34, 197: 'A Review of the Applications to Solids of the Laser Ion Source in Mass Spectrometry'.

- B. Schueler, R. F. Krueger, Org. Mass Spectrom. 1980, 15, 295: 'Comparative Study of Pulsed Laser and Fission Fragment Induced Desorption with Nucleotic Compounds'.

- D. M. Lubman, R. Naaman, R. N. Zare, J. Chem. Phys. 1980, 72, 3034: 'Multiphoton Ionization of Azulene and Naphthalene'.

- J. Silberstein, R. D. Levine, Chem. Phys. Lett. 1980, 74, 6: 'Fragmentation Patterns in Multiphoton Ionization: A Statistical Interpretation'.

- P.M. Johnson, Acc. Chem. Res. 1980. 13, 20: 'Molecular Multiphoton lonization Spectrometry'.

- J.A. Gardella, D. M. Hercules, H.J. Heinen, Spectrosc. Lett. 1980, 13, 347:

'Mass Spectrometry of Molecular Solids: Laser Microprobe Mass Analysis (LAMMA) of Selected Polymers'.

- R.J. Beuhler, F. Friedman, Nucl. Instrum. Meth. 1980, 170, 309: 'Threshold 
Studies of Secondary Electron Emission Induced Macro-Ion Impact on Solid Samples'.

- M. Bassin, in 'Physical Processes in Laser-Materials Interactions', Ed. M. Bertolotti, Plenum Press, New York, 1980. - E. D. Hardin, M. L. Vestal, Anal. Chem. 1981, 53, 1492: 'Laser Ionization Mass Spectrometry of Nonvolatile Samples'.

- C. E. Klots, Int. J. Mass Spectrom. Ion Phys. 1981, 37, 195: 'The Time-of-Flight Mass Spectrometer: A Poor Man's SIMS Device'.

- H. Wollnik, T. Matsuo, Int. Mass Spectrom. Ion Phys. 1981, 37, 209: 'A Q-Value for Energy-Focussed, Time-of-Flight Mass Spectrometers'.

H. J. Heinen, Int. J. Mass Spectrom. Ion Phys. 1981, 38, 309: 'On Ion Formation in Laser Desorption Mass Spectrometry with LAMMA'

B. T. Chait, K. G. Standing, Int. J. Mass Spectrom. Ion Phys. 1981, 40, 185: 'A Time-of-Flight Mass Spectrometer for Measurement of Secondary Ion Mass Spectra'.

- G.J.Q. van der Peyl, K. Isa, J. Haverkamp, P. G. Kistemaker, Org. Mass Spectrom. 1981, 16, 416: 'Gas Phase Ion/ Molecule Reactions in Laser Desorption Mass Spectrometry".

- J. Silberstein, R.D. Levine, J. Chem. Phys. 1981, 75, 5735: 'Statistical Fragmentation Patterns in Multiphoton Ionization: A Comparison with Experiment'.

- M. Barber, R.S. Bordoli, R.D. Sedgwick, A. N. Tylor, Nature (London) 1981 , 293, 270: 'Fast Atom Bombardment of Solids as an Ion Source in Mass Spectrometry".

- M. Barber, R.S. Bordoli, R.D. Sedgwick, N. Tylor, Biomed. Mass Spectrom. 1981, 8, 492: 'Fast Atom Bombardment Mass Spectrometry of Cobalamines'.

- G.J.Q. Van der Peyl, K. Isa, J. Haverkamp, P. G. Kistemaker, Org. Mass Spectrom. 1981, 16, 416: 'Gas Phase Ion/ Molecule Reactions in Laser Desorption Mass Spectrometry'.

- M. Barber, R.S. Bordoli, R. D. Sedgwick, A.N. Tyler, J. Chem. Soc., Chem Commun. 1981, 325: 'Fast Atom Bombardment of Solids (FAB): A New Source for Mass Spectrometry'.

- R.P. Lattimer, G.E. Hansen, Macromolecules 1981, 14, 776: 'Determination of Molecular Weight Distributions of Polyglycerol Oligomers by Field Desorption Mass Spectrometry'.

- R. J. Colton, J. Vac. Sci. Technol. 1981 18, 731: 'Molecular Secondary Ion Mass Spectrometry (SIMS)'

- E. Denoyer, R. Van Griecken, F. Adams, D.F.S. Natusch, Anal. Chem. 1982, 54 264A: 'Laser Microprobe Mass Spectrometry: 1. Basic Principles and Performance Characteristics'

- D. M. Hercules, R. J. Day, K. Balasanmugam, T. A. Dang, C.P. Li, Anal. Chem. 1982, 54, 280A: 'Laser Microprobe Mass Spectrometry: 2. Applications to Structural Analysis'.
- N. H. Turner, R. J. Colton, Anal. Chem. 1982, 54, 293R: 'Surface Analysis: X-Ray Photoelectron Spectroscopy, Auger Electron Spectroscopy, and Secondary Ion Mass Spectrometry'.

- M. Barber, S. Bordoli, G. J. Elliot, R. D. Sedgwick, A. N. Tayler, Anal. Chem. 1982 54, 645A: 'Fast Atom Bombardment Mass Spectrometry'

- S.W. Graham, P. Dowd, D. M. Hercules, Anal. Chem. 1982, 54, 649: 'Laser Desorption Mass Spectrometry of Some Cobalamins'

- D. A. McCrery, E. B. Ledford, Jr., M. L. Gross, Anal. Chem. 1982, 54, 1437: 'Laser Desorption Fourier Transform Mass Spectrometry'.

- W. Aberth, K.M. Straub, A. L Burlingame, Anal. Chem. 1982, 54, 2029 'Secondary Ion Mass Spectrometry with Cesium Ion Primary Beam and Liquid Target Matrix for Analysis of Bioorganic Compounds'.

- R. Stoll, F.W.Z. Röllgen, Z. Naturforsch., $A$ 1982, 37, 9: 'Cationization by Alkali Ion Attachment in Laser Desorption Mass Spectrometry'.

- B. Joest, B. Schueler, F. R. Krueger, Z. Naturforsch., $A$ 1982, 37, 18: 'Ion Formation from Alkali Halide Solids by High Power Pulsed Laser Irradiation'.

- P. Moesta, U. Seydel, B. Lindner, H Grisebach, Z. Naturforsch., C 1982, 37, 748: 'Detection of Glyceollin on the Cellular Level in Infected Soybean by Laser Microprobe Mass Analysis'

- G. J.Q. Van der Peyl, J. Haverkamp, P.G. Kistemaker, Int. J. Mass Spectrom. Ion Phys. 1982, 42, 125: 'Thermal Aspects of Laser Desorption Mass Spectrometry'

- F. Hillenkamp, Int. J. Mass. Spectrom. 1982, 45, 305: 'Laser Desorption Techniques for Nonvolatile Organic Substances'.

- R. B. Bernstein, J. Phys. Chem. 1982, 86 1178: 'Systematics of Multiphoton Ionization-Fragmentation of Polyatomic Molecules'.

- G.J.Q. Van der Peyl, K. Isa, J. Haverkamp, P.G. Kistemaker, Nucl. In strum. Meth. Phys Res 1982, 198, 125 'Cationization in Laser Desorption Mass Spectrometry'.

- F. Holland, C. G. Enke, J. Allison, J.T Stults, J. D. Pinkston, B. Newcombe, J.T Watson, Anal. Chem. 1983, 55, 997A 'Mass Spectrometry on the Chromatographic Time Scale: Realistic Expectations'.

- N. E. Vanderborgh, J. E. R. Jones, Anal. Chem. 1983, 55, 527: 'Laser Microprobe Mass Analysis Studies on Coal and Shale Samples'.

- I. Dimicoli, J. Jaraudias, J. Le Maire, R. Botter, Int. J. Mass Spectrom. Ion Phys. 1983, 46, 281: 'Resonant Two Photon Ionization of Polyatomic Molecules by TOF Mass Spectrometry'.

- G.J.Q. van der Peyl, W.J. van der Zande, K. Bederski, A.J.H. Boerboom, P. G. Kistemaker, Int. J. Mass Spectrom. Ion Phys. 1983, 47, 7: 'Kinetic Energy Dis- tribution Measurement of Laser Produced Ions'.

- G.J.Q. van der Peyl, J. Haverkamp, P.G. Kistemaker, Int. J. Mass Spectrom. 1983, 47, 11: 'Thermal Aspects of Laser Desorption Mass Spectrometry (LDMS)'.

- P. Feigl, B. Schueler, F. Hillenkamp, Int. J. Mass Spectrom. Ion. Phy's. 1983, 47, 15: 'LAMMA 1000, A New Instrument for Bulk Microprobe Mass Analysis by Pulsed Laser Irradiation'

- H. J. Heinen, S. Meier, H. Vogt, R. Wechsung, Int. J. Mass Spectrom. Ion Phys. 1983, 47, 19: 'LAMMA 1000, A New Laser Microprobe Mass Analyzer for Bulk Samples'.

- R. B. Van Breemen, M. Snow, R. J. Cotter, Int. J. Mass Spectrom. Ion Phy's. 1983, 49, 35: 'Time-Resolved Laser Desorption Mass Spectrometry. I. Desorption of Preformed Ions'

- B. T. Chait, Int. J. Mass Spectrom. Ion Phys. 1983, 53, 227: 'Prompt and Metastable Decomposition in ${ }^{252} \mathrm{Cr}$ Fission Fragment Ionization Mass Spectrometry' - J.-C. Tabet, R. J. Cotter, Int. J. Mass Spectrom. Ion Processes 1983, 54, 151: 'Time-Resolved Laser Desorption Mass Spectrometry. II. Measurement of the Energy Spread of Laser Desorbed Ions'.

- M. M. Ross, J. R. Wyatt, R. J. Colton, J.E. Campana, Int. J. Mass Spectrom. Ion Processes 1983, 54, 237: 'Fast-Atom Molecular Secondary-Ion Mass Spectrometry'.

- R. J. Beuhler, J. Appl. Phys. 1983, 54, 4118: 'A Comparison of Secondary Electron Yields from Accelerated Water Cluster Ions $(\mathrm{M} / \mathrm{z}=50000)$ Striking Aluminium Oxide and Copper Surfaces'.

- F. Hillenkamp, in 'Ion Formation from Organic Solids II, Ed. A. Benninghoven, Springer, Berlin, 1983, p. 190: 'Laser-Induced Ion Formation from Organic Solids'.

- R.J. Cotter, M. Snow, M. Colvin, in 'Ion Formation from Organic Solids II', Ed. A. Benninghoven, Springer, Berlin, 1983, p. 206: 'Time Resolved Laser Desorption'

- H.H. Heinen, S. Meier, H. Vogt, in 'Ion Formation from Organic Solids II', Ed. A. Benninghoven, Springer, Berlin, 1983, p. 229: 'LAMMA 1000, A New ReflectionMode Laser Microprobe Mass Analyzer and Its Application to EDTA and Diolen'. - U. Seydel, B. Lindner, in 'Ion Formation from Organic Solids II', Ed. A. Benninghoven, Springer, Berlin, 1983, p. 240: 'Mass Spectrometry of Organic Compounds $(<2000 \mathrm{amu})$ and Tracing of Organic Molecules in Plant Tissue with LAMMA'.

- R. Cotter, Anal. Chem. 1984, 56, 485A: 'Lasers and Mass Spectrometry'.

- R. Cotter, Anal. Chem. 1984, 56, 1256A 'Exchange of Comments on Lasers and Mass Spectrometry'.

- E. D. Hardin, T.P. Fan, C. R. Blakley, M. L. Vestal, Anal. Chem. 1984, 56, 2: 'Laser Desorption Mass Spectrometry with Thermospray Sample Deposition for 
Determination of Nonvolatile Biomolecules'.

J.C. Tabet, R. Cotter, Anal. Chem. 1984, 56, 1662: 'Laser Desorption Timeof-Flight Mass Spectrometry of High Mass Molecules'.

- J.A. Vergey, R. J. Cotter, D. Heller, C. Fenselau, Anal. Chem. 1984, 56, 2262: 'Resolution Requirements for MiddleMolecule Mass Spectrometry'.

- D. N. Heller, C. Fenselau, J. Vergey, R. J. Cotter, D. Larkin, Anal. Chem. 1984, 56, 2274: 'Large Cluster Ions Desorbed from Organic Salts Under Particle Bombardment'.

- J.E. Campana, R. B. Freas, J. Chem Soc., Chem. Commun. 1984, 1414: 'Chemical Ionization-Fast Atom Bombardment Mass Spectrometry: A Novel Ionization Method'.

B.J. Garrison, R. Srinivasan, Appl. Phys. Lett. 1984, 44, 849: 'Laser Ablation of Organic Polymers: Microscopic Models for Photochemical and Thermal Processes'.

- T. Mauney, F. Adams, Int. J. Mass Spectrom. Ion Processes 1984, 59, 103: 'Ion Kinetic Energy Measurements on LaserInduced Plasmas in Laser Microprobe Mass Analysis (LAMMA). Part I. Methodology'.

- U. Seydel, B. Lindner, U. Zähringer, E.T. Rietschel, S. Kusumoto, T. Shiba, Biomed. Environ. Mass. Spectrom. 1984, 11, 132: 'Laser Desorption Mass Spectrometry of Synthetic Lipid A-like Compound'.

- B. Sundquist, 1. Kamensky, P. Hakansson, J. Kjellberg, M. Salehpour, S. Widdiyasekera, J. Fohlman, P.A. Peterson, P. Roepstorff, Biomed. Environ. Mass. Spectrom. 1984, 11, 242: 'Californium-252 Plasma Desorption Time of Flight Mass Spectrometry of Proteins'.

- H.-R. Schulten, R.P. Lattimer, Mass Spectrom. Rev. 1984, 3, 231: 'Applications of Mass Spectrometry to Polymers'

M. Wink, H.J. Heinen, H. Vogt, H. M Schiebel, Plant Cell Rep. 1984, 3, 230: 'Cellular Localization of Quinolizidine Alkaloids by Laser Desorption Mass Spectrometry (LAMMA 1000)'

H.-H. Wollenweber, U. Seydel, B. Lindner, O. Luderitz, E. Th. Rietschel, Eur. $J$ Biochem. 1984, 145, 265: 'Nature and Location of Amin-Bound (R)-3-Acyloxyacyl Groups in Lipid A of Lipopolysaccharides from Various Gram-Negative Bacteria' - J. Dodt, H.-P. Müller, U. Seemüller, J.Y. Chang, FEBS Lett. 1984, 165, 180: 'The Complete Amino Acid Sequence of Hirudin, A Thrombose Specific Inhibitor. Application of Color Carboxymethylation'.

- R. J. Cotter, J -C. Tabet, Am. Lab. 1984 16, 86: 'Laser Desorption MS for Nonvolatile Organic Molecules'.

- C. L. Wilkins, D. A. Weil, C. L.C. Yang, C. F. ljames, Anal. Chem. 1985, 57, 520: 'High Mass Analysis by Laser Desorption Fourier Transform Mass Spectrometry'.

- B. Lindner, U. Seydel, Anal. Chem.
1985, 57, 895: 'Laser Desorption Mass Spectrometry of Nonvolatiles under Shock Wave Conditions'.

- D.A. McCrery, D.A. Peake, L.M Gross, Anal. Chem. 1985, 57, 1181: 'Fast Atom Bombardment and Laser Desorption Mass Spectrometry for Determination of Alkyltriphenylphosphonium Salts'.

- R. J. Cotter, B. S. Larsen, D. N. Heller, J.E. Campana, C. Fenselau, Anal. Chem. 1985, 57, 1479: 'Wide Mass Range Scanning for the Fast Atom Bombardment Mass Spectrometry of Very Large Compounds'.

- R.B. Opsal, K.G. Owens, J.P. Reilly, Anal. Chem. 1985, 57, 1884: 'Resolution in the Linear Time-of-Flight Mass Spectrometer'

- D.E. Mattern, D. M. Hercules, Anal. Chem. 1985, 57, 2041: 'Laser Mass Spectrometry of Polyglycols: Comparison with Other Mass Spectral Techniques'.

- J.V. Bletsos, D.M. Hercules, D. Greifendorf, A. Benninghofen, Anal. Chem. 1985, 57, 2384: 'Time-of-Flight Secondary Ion Mass Spectrometry of Nylons: Detection of High Mass Fragments'

- N.S. Nogar, R.C. Estler, C. M. Miller, Anal. Chem. 1985, 57, 2441: 'Pulsed Laser Desorption for Resonance Ionization Mass Spectrometry'.

- M. Karas, D. Bachmann, F. Hillenkamp, Anal. Chem. 1985, 57, 2935: 'Influence of the Wavelength in High-Irradiance Ultraviolet Laser Desorption Mass Spectrometry of Organic Molecules'.

- R.E. Shomo, II, A. G. Marshall, C. R. Weisenberger, Anal. Chem. 1985, 57, 2940: 'Laser Desorption Fourier Transform Ion Cyclotron Resonance Mass Spectrometry vs. Fast Atom Bombardment Magnetic Sector Mass Spectrometry for Drug Analysis'

- R. B. Cody, J. A. Kinsinger, S. Ghaderi, I. J. Amster, F.W. McLafferty, C.E. Brown, Anal. Chim. Acta 1985, 178, 43: 'Developments in Analytical Fourier Transform Mass Spectrometry'.

- B. Sundqvist, A. Hedin, P. Hakansson, I. Kamensky, M. Salehpour, G. Säwe, Int . J. Mass Spectrom. Ion Processes 1985, 65, 69: 'Plasma Desorption Mass Spectrometry (PDMS). Limitations and Possibilities'. - J.-C. Tabet, M. Jablonski, R. J. Cotter, J. E. Hunt, Int. J. Mass Spectrom. Ion Processes 1985, 65, 105: 'Time-Resolved Laser Desorption Mass Spectrometry. III. The Metastable Decomposition of Chlorophyll- and Some Derivatives'

- B. T. Chait, F. H. Field, Int. J. Mass Spectrom. Ion Processes 1985, 65, 169: 'A Study of the Metastable Fragmentation of Ions Produced by ${ }^{252} \mathrm{Cf}$ Fission Fragment Bombardment of Bovine Insulin'.

- T. Sakurai, Y. Fujita, T. Matsuo, H. Matsuda, I. Katakuse, K. Mireki, Int. J. Mass Spectrom. Ion Processes 1985, 66, 283: 'A New Time-of-Flight Mass Spectrometer'.

- J. Rosmarinowsky, M. Karas, F. Hillenkamp, Int. J. Mass Spectrom. Ion Phys. 1985, 67, 109: 'Metastable Decay of Laser-
Desorbed Ions from Aromatic Organic Compounds'

- S. A. Carr, V. N. Reinhold, B. G. Green, J. R. Hass, Biomed. Mass Spectrom. 1985. 12,288: 'Enhancement of Structural Information in FAB Ionized Carboxyhydrate Samples by Neutral Gas Collision'.

- M.L. Coates, C.L. Wilkins, Biomed. Mass Spectrom. 1985, 12, 424: 'Laser Desorption Fourier Transform Mass Spectra of Malto-Oligosaccharides'.

- A.H. Verbueken, F. J. Bruynseels, R.E Van Griecken, Biomed. Mass. Spectrom. 1985, 12, 438: "Laser Microprobe Mass Analysis: A Review of Applications in the Life Sciences'.

- B. U.R. Sunquist, R.D. MacFarlane, Mass Spectrom. Rev. 1985, 4, 421: "252CfPlasma Desorption Mass Spectrometry'. - B. Fain, S.H. Lin, Chem. Phys. Lett. 1985, 114, 497: 'Effect of Vibrational Energy Transfer on Laser-Induced Desorption'.

- A.L. Burlingame, T.A. Baillie, P.J. Derrick, Anal. Chem. 1986, 58, 165R: 'Mass Spectrometry'.

- C.D. Parker, D.M. Hercules, Anal Chem. 1986, 58, 25: 'Intermolecular Proton Transfer Reactions in the Laser Mass Spectrometry of Organic Acids'.

- G.P. Jonsson, A. B. Hedin, P. L. Hakansson, B. U. R. Sundquist, B.G.S. Säve, P.F. Nielsen, P. Roepstorff, K.E. Johansson, I. Kamensky, M.S. Lindberg. Anal. Chem. 1986, 58, 1084: 'Plasma Desorption Mass Spectrometry of Peptides and Proteins Adsorbed on Nitrocellulose'. - M. Alai, P. Demirev, C. Fenselau, R. J. Cotter, Anal. Chem. 1986, 58, 1303: 'Glutathione as a Matrix for Plasma Desorption Mass Spectrometry of Large Peptides'.

- R.L.M. Dobson, A.P. D'Silva, S.J. Weeks, V.A. Fassel, Anal. Chem. 1986, 58 , 2129: 'Multidimensional, Laser-Based Instrumentation for the Characterization of Environmental Samples for Polycyclic Aromatic Compounds'

- R.M. Caprioli, T. Fan, J.S. Cottrell, Anal. Chem. 1986, 58, 2949: 'Continuous Flow Sample Probe for Fast Atom Bombardment Mass Spectrometry'.

- F. Hillenkamp, M. Karas, D. Holtkamp, P. Klüsener, Int. J. Mass. Spectrom. Ion Processes 1986, 69, 265: 'Energy Desorption in Ultraviolet Laser Desorption Mass Spectrometry of Biomolecules'.

- I. Jardine, S. W. Hunter, P. J. Brennan. C.J. McNeal, R. D. MacFarlane, Biomed. Environ. Mass Spectrom. 1986, 13, 273: 'Heterogeneity of Bacterial Antigenic Lipooligosaccharide, Determined by Californium-252 Plasma Desorption Mass Spectrometry'.

- P. Roepstorff, P. Hojrup, B. U. R. Sunqvist, G. Jonsson, P. Hakansson, S. O. Andersen, K. E. Johanson, Biomed. Environ. Mass. Spectrom. 1986, 13, 689: 'Application of Plasma Desorption Mass Spectrometry to Molecular Weight Determination of Structural Protein from Insect Cuticle'. 
J. Grotemeyer, U. Boesl, K. Walter, E. W. Schlag, Org. Mass Spectrom. 1986, 21. 645: 'A General Soft Ionization Method for Mass Spectrometry: Resonance-Enhanced Multi-Photon Ionization of Biomolecules'.

- T. R. Rizzo, Y.D. Park, L. A. Peteanu, D. H. Levy, J. Chem. Phys. 1986, 84, 2534: 'The Electronic Spectrum of the Amino Acid Tryptophan in the Gas Phase'.

E. Sutcliffe, R. Srinivasan, J. Appl. Phys. 1986, 60, 3315: 'Dynamics of UV Laser Ablation of Organic Polymer Surfaces'.

- K. Takayama, N. Qureshi, K. Hyver, J. Honovich, R.J. Cotter, P. Mascagni, H. Schneider, J. Biol. Chem. 1986, 261, 10624 'Characterization of a Structural Series of Lipid A Obtained from the Lipopolysaccharides of Neisseria Gonorrhoeae'.

- N. Qureshi, R. J. Cotter, K. Takayama, J. Microbiol. Meth. 1986, 5, 65: "Applications of Fast Atom Bombardment Mass Spectrometry and Nucelar Magnetic Resonance on the Structural Analysis of Purified Lipid A'

R.S. Brown, D.A. Weil, C. L. Wilkins, Macromolecules 1986, 19, 1255: 'Laser Desorption Fourier Transform Mass Spectrometry for the Characterization of Polymers'.

- R.J. Cotter, J. Honovich, R.P. Lattimer, Macromolecules 1986, 19, 2996: 'Laser Desorption Time-of-Flight Mass Spectrometry of Low-Molecular Weight Polymers'.

M. Karas, U. Bahr, $\operatorname{Tr} A C$ 1986, 5, 90 : 'Laser Desorption Mass Spectrometry'.

- S. Della-Negra, Y. Le Beyec, in 'Ion Formation from Organic Solids III, Ed. A Benninghoven, Springer, Berlin, 1986, p. 42: 'Metastable Ion Studies with a Californium-252 Time-of-Flight Mass Spectrometer'.

- J.V. Bletsos, D.M. Hercules, D. van Leyen, E. Niehuis, E. Benninghoven, in 'Ion Formation from Organic Solids III', Ed. A. Benninghoven, Springer, New York, 1986, p. 74: 'TOF-SIMS of Polymers in the High Mass Range'.

H. Wollnik, in 'Ion Formation from Organic Solids III', Ed. A. Benninghoven, Springer, Berlin, 1986, p. 184: 'Design of Modern Time-of-Flight Mass Spectrometer'.

- B. Lindner, U. Seydel, in 'Ion Formation from Organic Solids III', Ed. A. Benninghoven, Springer, Berlin, 1986, p. 240: 'On Different Desorption Modes'

- F. Hillenkamp, in 'Ion Formation from Organic Solids III', Ed. A. Benninghoven, Springer, Berlin, 1986, p. 471: 'Laser Desorption Mass Spectrometry'.

- A. Benninghoven, E. Niehues, D. Greifendorf, D. van Leyen, W. Lange, in 'Secondary Ion Mass Spectrometry (SIMS)', Eds. A. Benninghoven, R.J. Colton, and D.S. Simons, Springer, New York, 1986, p. 497: 'Analytical Application of High Performance TOF-SIMS'.

- J. V. Bletsos, D. M. Hercules, A. Benninghoven, D. Greifendorf, in 'Secondary Ion Mass Spectrometry (SIMS)', Eds. A.
Benninghoven, R. J. Colton, and D.S. Simons, Springer, New York, 1986, p. 538 'TOF-SIMS of Polymers in the Range of $\mathrm{M} / \mathrm{Z}=50$ to $5000^{\prime}$.

- R. D. MacFarlane, J.C. Hill, D. L. Jacobs, R. G. Phelps, in 'Mass Spectrometry in the Analysis of Large Molecules', Ed. C.J. McNeal, Wiley, Chichester, 1986 , p. 1: 'Fundamental Studies in the Californium-252-PDMS of Small Proteins'.

- F.H. Field, in 'Mass Spectrometry in the Analysis of Large Molecules', Ed. C.J. McNeal, Wiley, Chichester, 1986, p. 213.

- L. Grotjahn, in 'Mass Spectrometry in Biomedical Research', Ed. S.J. Gaskell, Wiley, New York, 1986, p. 215: 'Oligonucleotide Sputtering from Liquid Matrixes'. - M. Karas, D. Bachmann, F. Hillenkamp, in 'Proc. International Mass Spectrometry Conference', Ed. J.F.J. Todd, Wiley, Chichester, 1986, p. 969.

- U. Bahr, M. Karas, F. Hillenkamp, in 'Proc. 3rd International Laser Microprobe Mass Spectrometry Workshop', University of Antwerp, 1986, p. 17.

- B. Schueler, R. W. Odom, in 'Proc. 24th Annual Conference on Mass Spectrometry \& Allied Topics', 1986

- J. Grotemeyer, V. Boesl, K. Walter, E.W. Schlag, in 'Proc. 24th Annual Conference on Mass Spectrometry \& Allied Topics', 1986.

- R. Frey, M. Weiss, H. Kaminski, G. Weiss, in 'Proc. 24th Annual Conference on Mass Spectrometry \& Allied Topics', 1986.

- M. L. Coates, L. Nuwagsir, C. L. Wilkins, in 'Proc. 24th Annual Conference Mass Spectrometry \& Allied Topics', 1986. - R. Holm, M. Karas, H. Vogt, Anal. Chem. 1987, 59, 371: 'Polymer Investigation with the Laser Microprobe'.

- F. Engelke, J.H. Hahn, W. Henke, R. N. Zare, Anal. Chem. 1987, 59, 909: 'Determination of Phenylthiohydantoin-Amino Acides by Two-Step Laser Desorption/ Multiphoton Ionization'.

- J. K. Olthoff, J.P. Honovich, R. J. Cotter, Anal. Chem. 1987, 59, 999: 'Liquid Secondary Ion Time-of-Flight Mass Spectrometry'.

- R. Tembreull, D.M. Lubman, Anal Chem. 1987, 59, 1082: 'Pulsed Laser Desorption of Biological Molecules in Supersonic Beam Mass Spectrometry with Resonant Two-Photon Ionization Detection'.

- C.H. Watson, G. Baykut, J. R. Eyler, Anal. Chem. 1987, 59, 1133: 'Laser Photodissociation of Gaseous Ions Formed by Laser Desorption'.

- F.R. Verdun, G. Krier, J.F. Müller, Anal. Chem. 1987, 59, 1383: 'Increased Sensitivity in Laser Microprobe Mass Analysis by Using Resonant Two-Photon Ionization Processes'.

- P. Demirev, J. K. Olthoff, C. Fenselau R. J. Cotter, Anal. Chem. 1987, 59, 1951 'High-Mass Ion Fragmentation as a Function of Time and Mass'.

- J.S. Cottrell, S. Evans, Anal. Chem 1987, 59, 1990: 'Characteristics of a Multichannel Electrooptical Detection System and Its Application to the Analysis of Large Molecules by Fast Atom Bombardment Mass Spectrometry'.

- R. J. Cotter, Anal. Chim. Acta 1987, 195. 45: 'Laser Mass Spectrometry: An Overview of Techniques, Instruments and Applications'.

- G.E. Ewing, J. Phys. Chem. 1987, 91 . 4662: 'Selection Rules for Vibrational Energy Transfer. Vibrational Predissociation of Van der Waals Molecules'.

- B. Spengler, M. Karas, U. Bahr, F. Hillenkamp, J. Phys. Chem. 1987, 91, 6502: 'Excimer Laser Desorption Mass Spectrometry of Biomolecules at 248 and 193 nm'.

- A. Hedin, P. Hakansson, B. U. R. Sundqvist, Int. J. Mass Spectrom. Ion Processes 1987, 75, 275: 'On the Detection of Large Organic Ions by Secondary Electron Production'.

- M. Karas, D. Bachmann, U. Bahr, F. Hillenkamp, Int. J. Mass Spectrom. Ion Processes 1987, 78, 53: "Matrix-Assisted Ultraviolet Laser Desorption of NonVolatile Compounds'

- B. T. Chait, Int. J. Mass Spectrom. Ion Processes 1987, 78, 237: 'A Study of the Fragmentation of Singly and Multiply Charged Ions Produced by ${ }^{252} \mathrm{Cf}$ Fission Fragment Bombardment of Polypeptides Bound to Nitrocellulose'.

- R.E. Johnson, Int J Mass Spectrom Ion Processes 1987, 78, 357: 'Mechanisms for the Desorption of Large Organic Molecules'

- L. I. Grace, B. T. Chait, F. H. Field, Biomed. Environ. Mass Spectrom. 1987, 14, 295: 'A System for Collecting High-Resolution Time-of-Flight Mass Spectrometric Data'.

R. J. Cotter, J. Honovich, N. Qureshi, K. Takayama, Biomed. Environ. Mass Spectrom. 1987, 14, 591: 'Structural Determination of Lipid A from Gram Negative Bacteria Using Laser Desorption Mass Spectrometry'

- J. Grotemeyer, E.W. Schlag, Org. Mass Spectrom. 1987, 22, 758: 'Biomolecules in the Gasphase. IV. Multiphoton Ionization Mass Spectrometry of Bovine Insulin/1/'.

- M. Barber, B. N. Green, Rapid Commun. Mass Spectrom. 1987, I, 80: 'The Analysis of Small Proteins in the Molecular Weight Range 10-24 kDa by Magnetic Sector Mass Spectrometry'

- F. LaFortune, R. Beavis, X. Tang, K. G. Standing, B.T. Chait, Rapid Commun Mass. Spectrom. 1987, 1, 114: 'Fission Fragment Secondary Ion Yield with Nitrocellulose'

- 1. Kamensky, A.G. Craig, Anal. Instrum. 1987, 16, 71: 'Californium-252 Plasma Desorption Mass Spectrometry: Recent Advances and Applications'

- J.K. Olthoff, I. Lys, P. Demirev, R.J. Cotter, Anal. Instrum. 1987, 16. 93: 'Modification of Wiley-McLaren TOF Analyzers for Laser Desorption'

- U. Boesl, J. Grotemeyer, K. Walter, E. W. Schlag, Anal. Instrum. 1987, 16, 151: 'A High-Resolution Time-of-Flight Mass 
Spectrometer with Laser Desorption and a Laser Ionization Source'.

K. B. Standing, R.C. Beavis, G. Bollbach, W. Ens, F. Lafortune, D. E. Main, B. Schueler, X. Tang, J. Westmore, Anal. Instrum. 1987, 16, 173: 'Secondary Ion Timeof-Flight Mass Spectrometers and Data Systems'.

- R. N. Zare, R. D. Levine, Chem. Phys. Lett. 1987, 136, 593: 'Mechanism for Bond-Selective Processes in Laser Desorption'.

- C. Fenselau, R.J. Cotter, Chem. Rev. 1987, 87, 501: 'Middle-Molecules: Molecular and Fragment lons at 1000 to 14000 amu'.

T. Mizuochi, J. Hamako, T. Titani, Arch. Biochem. Biophys. 1987, 257, 387: 'Structure of the Sugar Chains of Mouse Immunoglobulin G'.

- M. von Allmen, 'Laser-Beam Interactions with Materials, Physical Principles and Applications', Springer, Berlin, 1987

- B. T. Chait, T. Chaudhary, F. H. Field, 'Methods in Protein Sequence Analysis', Ed. K. A. Walsh, Humana Press, Clifton, New Jersey, 1987.

- K. Tanaka, Y. Ido, S. Akita, Y. Yoshida, T. Yoshida, in 'Proc. 2nd JapanChina Joint Symposium on Mass Spectrometry', Osaka, Japan, 1987, p. 185.

- A.G. Craig, A. Engstrom, H. Bennich, 1. Kamensky, in 'Proc. 35th Conference on Mass Spectrometry \& Allied Topics', Denver, 1987, p. 528

- R.J. Cotter, Anal. Chem. 1988, 60 , 781A: 'Plasma Desorption Mass Spectrometry: Coming to Ages'.

L. M. Nuwaysir, C.L. Wilkins, Anal. Chem. 1988, 60, 279: 'Laser Desorption Fourier Transform Mass Spectrometry of Polymers: Comparison with Secondary Ion and Fast Atom Bombardment Mass Spectrometry'.

- I. Jardine, G. F. Scanlan, A. Tsarbopoulos, D. J. Liberato, Anal. Chem. 1988, 60, 1086: 'Plasma Desorption Mass Spectrometry of Peptides Adsorbed on Nitrocellulose from a Glutathione Matrix'.

W. Ens, D.E. Main, K. G. Standing, B. T. Chait, Anal. Chem. 1988, 60, 1494 'Comparison of Relative Quasi-Molecular Ion Yields for 8-keV Ion and ${ }^{252} \mathrm{Cf}$ Fission Fragment Bombardment'.

- M. Karas, F. Hillenkamp, Anal. Chem. 1988, 60, 2299: 'Laser Desorption Ionization of Proteins with Molecular Masses Exceeding 10000 Daltons'.

- P.C. Andrews, M. Alai, R. J. Cotter Anal. Biochem. 1988, 174, 23: 'The Use of Plasma Desorption Time-of-Flight Mass Spectrometry to Screen for Products of Prohormone Processing in Crude Tissue Extracts'.

- R.C. Beavis, J. Lindner, J. Grotemeyer, E. W. Schlag, Z. Naturforsch., A 1988, 43, 1083: 'Infrared Desorption of Neutral Molecules Embedded in Transparent Matrices'.

- R.C. Beavis, J. Lindner, J. Grotemeyer, E. W. Schlag, Chem. Phys. Lett. 1988, 146, 310: 'Sample-Matrix Effects in Infrared
Laser Neutral Desorption, MultiphotonIonization Mass Spectrometry'.

- B. Spengler, U. Bahr, M. Karas, F. Hillenkamp, Anal. Instrum. 1988, 17, 173: 'Postionization of Laser-Desorbed Organic and Inorganic Compounds in a Time-of-Flight Mass Spectrometer'. - P. Roepstorff, P.F. Nielsen, K. Klarskov, P. Hojrup, Biomed. Environ. Mass Spectrom. 1988, 16, 9: 'Applications of Plasma Desorption Máss Spectrometry in Peptide and Protein Chemistry'.

- P.F. Nielsen, K. Klarskov, P. Hojrup, P. Roepstorff, Biomed. Environ. Mass Spectrom. 1988, 17, 355: 'Optimization of Sample Preparation for Plasma Desorption Mass Spectrometry of Peptides and Proteins Using a Nitrocellulose Matrix'.

- J. Grotemeyer, E. W. Schlag, Org. Mass Spectrom. 1988, 23, 388: 'Peptides Investigated by Laser Desorption Multiphoton Ionization Mass Spectrometry'.

- R. Wang, R. J. Cotter, T.-Y. Lin, M. Laskowski, Jr., Rapid Commun. Mass Spectrom. 1988, 2, 71.

- R. Grix, R. Kutscher, G. Li, U. Gruner, H. Wollnik, Rapid Commun. Mass Spectrom. 1988, 2, 83.

- K. Tanaka, H. Waki, Y. Ido, S. Akita, Y. Yoshida, T. Yoshita, Rapid Commun. Mass Spectrom. 1988, 2, 151

- J. K. Olthoff, I. Lys, R. J. Cotter, Rapid Commun. Mass Spectrom. 1988, 2, 171.

- K.-H. Chen, R.J. Cotter, Rapid Commun. Mass Spectrom. 1988, 2. 237: 'A Continuous-Flow Probe High Performance Liquid Chromatography Interface to a Liquid Secondary-Ion Time-of-Flight Mass Spectrometer'

- T.R. Covey, R.F. Bonner, B.I Shushan, J. Henion, Rapid Commun. Mass Spectrom. 1988, 2, 249: 'The Determination of Protein, Oligonucleotide, and Peptide Molecular Weights by Ion-Spray Mass Spectrometry'

- K. Tanaka, H. Waki, Y. Ido, S. Akita, Y. Yoshida, T. Yoshida, Rapid Commun. Mass Spectrom. 1988, 8, 151 .

- N. Qureshi, J.P. Honovich, H. Hara, R. J. Cotter, K. Takayama, J. Biol. Chem. 1988, 263, 5502 .

- C. K. Meng, M. Mann, J. B. Fenn, Z. Phys. D 1988, 10, 361: 'Of Protons or Proteins'.

- A.D. Frankel, R. Chen, R. J. Cotter, C. O. Pabo, Proc. Natl. Acd. Sci. U.S.A. 1988, 85, 6297: 'Dimerization of the TAT Protein from Human Immunodeficiency Virus: A Cysteine-Rich Peptide Mimics the Normal Metal-Linked Dimer Interface'.

- B. Spengler, U. Bahr, F. Hillenkamp, Inst. Phys. Conf. Ser. No. 94 ; Sect. 1988, p. 307: 'Excimer Laser Desorption and UVMPI of Neutral Bio-Organic Molecules'.

- R. Zenobi, J.H. Hahn, R. N. Zare, Chimia 1988, 42, 147: 'Two-Step LaserMass Spectrometry for the Direct Analysis of Mixtures'.

- M. Mann, C. K. Meng, J. B. Fenn, Anal. Chem. 1989, 61, 1702: 'Interpreting Mass Spectra of Multiply Charged Ions'.
- M. Karas, U. Bahr, F. Hillenkamp, Int. J. Mass Spectrom. Ion Processes 1989, 92, 231 : 'UV Laser Matrix Desorption/Ionization Mass Spectrometry of Proteins in the 100000 Dalton Range'.

- J.A. Loo, H. R. Udseth. R. D. Smith, Anal. Biochem. 1989, 179, 404: 'Solvent Effects on the Charge Distribution Observed with Electrospray Ionization-Mass Spectroscopy of Large Molecules'

- J. Grotemeyer, E. W. Schlag, Acc. Chem. Res. 1989, 22, 399: 'Biomolecules in the Gas Phase: Multiphoton Ionization Mass Spectrometry'.

- J. B. Fenn, M. Mann, C. K. Meng, S. F. Wong, C.M. Whitehouse, Science 1989 , 246, 64: 'Electrospray Ionization for Mass Spectrometry of Large Biomolecules'.

- R.W. Nelson, M.J. Rainbow, D.E. Lohr, P. Williams, Science 1989, 246, 1585: 'Volatilization of High Molecular Weight DNA by Pulsed Laser Ablation from Frozen Aqueous Solutions'.

- M. Karas, U. Bahr, A. Ingendoh, F. Hillenkamp, Angen'. Chem. 1989, 28, 760: 'Laser Desorption/Ionization Mass Spectrometry of Proteins of Mass 100000 to 250000 Dalton'

- A. Vertes, P. Juhasz, M. De Wolf, R. Gijbels, Int. J. Mass Spectrom. Ion Processes 1989, 94, 63: 'Hydrodynamic Modelling of Laser Plasma Ionization Processes'.

- R.J. Cotter, Biomed. Environ. Mass Spectrom. 1989, 18, 513: Time-of-Flight Mass Spectrometry: An Increasing Role in the Life Sciences'.

- M. Karas, A. Ingendoh, U. Bahr, F. Hillenkamp, Biomed. Environm. Mass Spectrom. 1989, 18, 841: 'Ultraviolet-Laser Desorption/Ionization Mass Spectrometry of Femtomolar Amounts of Large Proteins'.

- G. Jonsson, A. Hedin, P. Hakansson, B. U. R. Sundqvist, H. Beennich, P. Roepstorff; Rapid Commun. Mass Spectrom. $1989,3,190$.

- R.C. Beavis, B.T. Chait, Rapid Commun. Mass Spectrom. 1989, 3, 233: 'Factors Affecting the Ultraviolet Laser Desorption of Proteins'.

- M. Selehpour, I. Perera, J. Kjellberg, A Hedin, M.A. Islamian, P. Hakansson, B. U. R. Sundquist, Rapid Commun. Mas. Spectrom. 1989, 3, 259: 'Laser-Induced Desorption of Proteins'

- M.P. Lacey, T. Keough, Rapid Commun. Mass Spectrom. 1989, 3, 40: 'The Effects of Gas-Phase Basicity and Surface Activity on the Formation of Fast-AtomBombardment Mass Spectra'.

- R.C. Beavis, B.T. Chait, Rapid Commun. Mass Spectrom. 1989, 3, 432: 'Cinnamic Acid Derivatives as Matrices for Ultraviolet Laser Desorption Mass Spectrometry of Proteins'

- R.C. Beavis, B.T. Chait, Rapid Commun. Mass Spectrom. 1989, 3, 436: 'Matrix-Assisted Laser-Desorption Mass Spectrometry Using $355 \mathrm{~nm}$ Radiation?.

- H. Masuhara, S. Eura, H. Fukumura, A. Itaya, Chem. Phys. Lett. 1989, 156, 446: 
'Laser Ablation Dynamics of Poly(NVinylcarbazole) Film as Revealed by TimeResolved Fluorescence Spectroscopy'.

- B. Fain, S. H. Lin, Chem. Phys. Lett. 1989, 157, 233: 'Avalanche Phenomenon in UV Laser-Induced Desorption'.

- M. Karas, F. Hillenkamp, in 'Microbeam Analysis - 1989', Ed. P.E. Russell, San Francisco Press, Inc., 1989: 'Prospects for Laser Molecular Microprobing'.

- F. Hillenkamp, in 'Advances in Mass Spectrometry', Ed. P. Longevialle, Heyden \& Son, London, 1989, p. 354.

- F. Hillenkamp, M. Karas, in 'Proc. 37th. ASMS Conference on Mass Spectrometry \& Allied Topics', Amer. Soc. Mass Spectrom., East Lansing, Michigan, 1989 , p. 1168

- B. Spengler, R.J. Cotter, Anal. Chem. 1990, 62, 793: 'Ultraviolet Laser Desorption/Ionization Mass Spectrometry of Proteins above 100000 Daltons by Pulsed Ion Extraction Time-of-Flight Analysis'. - B. Spengler, J.W. Dolce, R. J. Cotter, Anal. Chem. 1990, 62, 1731: 'Infrared Laser Desorption Mass Spectrometry of Oligosaccharides: Fragmentation Mechanisms and Isomer Analysis".

- R.C. Beavis, B.T. Chait, Anal. Chem.
1990, 62, 1836: 'High-Accuracy Molecular Mass Determination of Proteins Using Matrix-Assisted Laser Desorption Mass Spectrometry'.

- J. A. Loo, C. G. Edmonds, R. D. Smith, M. P. Lacey, T. Keough, Biomed. Environ. Mass Spectrom. 1990, 19, 286: 'Comparison of Electrospray Ionization and Plasma Desorption Mass Spectra of Peptides and Proteins'.

S. K. Chowdhury, V. Katta, B. T. Chait, Rapid Commun. Mass Spectrom. 1990, 4 , 81: 'An Electrospray-Ionization Mass Spectrometer with New Features'.

- B. Spengler, Y. Pan; R. J. Cotter, L.S. Kan, Rapid Commun. Mass Spectrom. $1990,4,99$

- M. Karas, Phys. Bl. 1990, 46, 149: 'New Perspectives in Mass Spectrometry of BioMacromolecules'.

- J. Grotemeyer, Angew. Chem. 1990, 102, A-298: 'Matrix-Assisted Laser-Desorption in Mass Spectrometry'.

- A. Vertes, R. D. Levine, Chem. Phys. Lett. 1990, 171, 284: 'Sublimation versus Fragmentation in Matrix-Assisted Laser Desorption'.

- R. C. Beavis, B.T. Chait, Proc. Natl. Acad. Sci. U.S.A. 1990, 87, 6873: 'Rapid, Sensitive Analysis of Protein Mixtures by
Mass Spectrometry'

- M. Karas, E.P. Magomedbekov, G.H. Sicking, J. Less-Common Met. 1990, 159. 307: 'Determination of Hydrogen Isotope Separation-Factors on a Microscope Scale by 'Laser Desorption'.

- R.C. Beavis, B.T. Chait, Proc. Natl. Acad. Sci. U.S.A. 1990, 87, 6873: 'Rapid, Sensitive Analysis of Protein Mixtures by Mass Spectrometry'.

- K.O. Boernsen, M. Schär, H. M. Widmer, Chimia 1990, 44, 412: 'Matrix-Assisted Laser Desorption and Ionization Mass Spectrometry and Its Application in Chemistry'.

- F. Hillenkamp, M. Karras, A. Ingendoh, B. Stahl, in 'Proc. 2nd International Symposium on Mass Spectrometry in the Health and Life Sciences', Eds. A. Burlingame and J.A. McCloskey, Elsevier, Amsterdam, 1990.

- R.C. Beavis, B.T. Chait, in 'Proc. 38th ASMS Conference on Mass Spectrometry \& Allied Topics', Tuscon, 1990.

- K. O. Boernsen, M. Schär, V. Steiner, E. Gassmann: 'Analytical Applications of Laser Desorption Ionization Mass Spectrometry'.

\section{Astrochem}

What do the stars have in store for chemists next month? As a service to its readers and as a bold attempt to boost circulation, Chimia is now introducing a new feature - Astrochem. The connection between astrology and chemistry goes back centuries, to the very beginnings of alchemy. Alchemists in medieval times would never undertake an experiment without having first ascertained that the constellations were favourable. More recent research has discovered highly significant correlations between the time of birth of successful chemists and the positions of the planets. Now we have persuaded that eminent scientist and scholar Dr. Wolfgang von Hochnebel to cast a horoscope for our readers for the coming month. Here are his results.

Aries 21.3 - 20.4

Too hasty acid extraction may cause you to lose much of your yield.

㳻 Taurus 21.4. - 20.5.

Hindered rotation about a single bond could lead to a surprising result.

Gemini 21.5. - 21.6.

Unexpected difficulties in a well planned synthesis can probably be overcome by attention to detail.

300 Cancer 22.6. - 22.7.

A misunderstanding with a colleague could cause irritation on both sides.

2-5 Leo 23.7. - 23.8.

Two short communications may be more advantageous than one full paper. Do not postpone a decision any longer.

A V Virgo 24.8. - 23.9.

A harmonious time for Beckmann rearrangements. But special care with the hydrolysis step may be advisable.
St Libra 24.9. - 23.10.

An organophosphorus compound may turn out to be an unexpectedly poor nucleophile.

tos Scorpio 24.10. - 22.11.

Distrust a result that seems to fit your theory. There may be a mistake somewhere. Try to seek it out.

$\Leftrightarrow$ Sagittarius 23.11. - 21.12.

Your enantiomeric excess may be disappointing, but do not give up too easily.

Ex Capricorn 22.12. - 20.1.

React calmly if your manuscript is judged harshly by a referee. It may lead to an unforeseen advantage for you in the end.

Aquarius 21.1. - 18.2.

Attendance at a seminar may give you an interesting idea. Follow it up.

Pisces 19.2. - 20.3.

An enzymatic reaction may turn out to be much more complicated than it seemed at first sight. Inadequate purification may be the cause. 


\section{Prelog-Vorlesung 1990}

\section{Laboratorium für Organische Chemie, ETH Zürich}

Am 19. November 1990 erfolgte die Übergabe der Prelog-Medaille 1990 an Prof. Henri Boris Kagan (Université de Paris-Sud, Orsay, France). Der Titel des anschlicssenden Vortrags lautete: 'Recent developments in asymmetric synthesis of sulfoxides'.

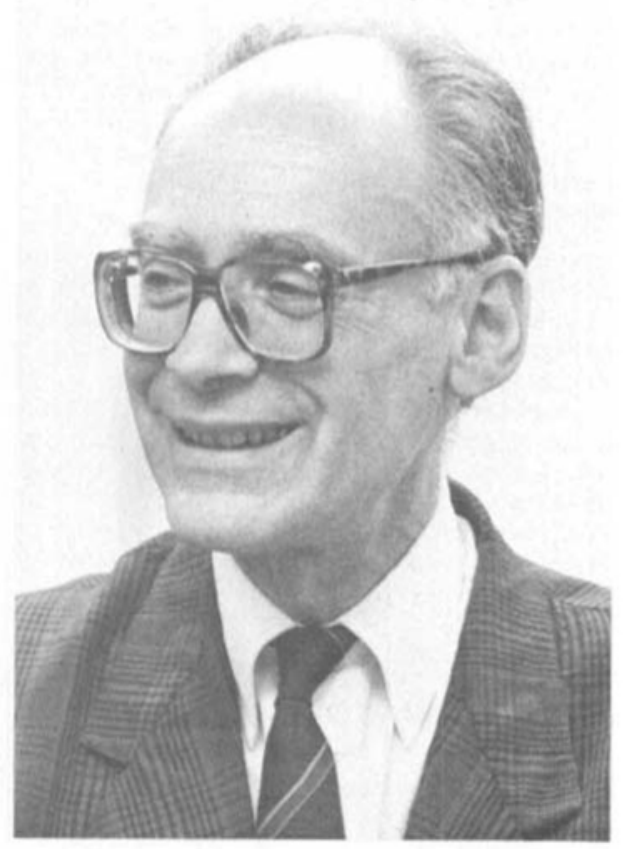

Henri Boris Kagan, 1930 in Boulogne an der Seine geboren, studierte Chemie in Paris, promovierte mi ciner unter J. Jacques durchgeführten Doktorarbeit 'Les Stérö̈des inversés' 1960 am Collège de France und arbeitete bis 1967, durch cin Postdoktorandenjahr (Prof. T. Mabry, University of Texas, Austin) unterbrochen, im Laboratorium von A. Horeau, wo er Coautor zahlreicher wichtiger Arbeiten war. Seit 1968 leitet er die Laboratoires de Synthèse Asymmétrique et de Coordination Organique an der Universität von Paris (Orsay).

Dic Stereochemie zieht sich wie ein roler Faden durch dic Arbeiten von Kagan. Zunächst machte er durch enantioselektive Reaktionen mit Hilfe von circular po- larisiertem Licht auf sich aufmerksam. Dann war er einer der ersten, dem es gelang, mit einem chiralen Wilkinson-Katalysator, jetzt bekannt als DIOP, seh hohe Enantioselektivitäten bei der Hydrierung von Doppelbindungen zu erreichen, und zwar speziell be der Herstellung von Aminosäuren aus Dehydro-aminosäurederivaten. Später folgten dann Arbeiten über die Herstellung enantiomerenreiner Sulfoxide und übe enantioselektiv katalysierte Epoxidierungen und DielsAlder-Reaktionen. Neben den synthetischen Fragestellungen, für die sich Kagan bis hin zu industriellen Anwendungen interessiert, hat er aber immer wieder grundlegende Erkenntnisse über den stereochemischen Verlauf von Reaktionen zu gewinnen versucht; so hat er kürzlich nicht-lineare Effekte bei zahlreichen stereoselektiven Reaktionen entdeckt, was teilweise zu einer Revision des angenommenen Mechanismus zwang. Schliesslich hat Kagan als erster die Bedeutung von organischen Derivaten der Lanthanide für die Synthese erkannt (seine erste Arbeit zu diesem Thema datiert aus dem Jahre 1970), heute ein nicht nur in seiner Gruppe intensiv bearbeitetes Gebiet. Zusätzlich enthält seine über 200 Arbeiten umfassende Publikationsliste Veröffentlichungen über so verschiedenartige Themen wie Reaktionen in flüssigem $\mathrm{SO}_{2}$ und in cholesterischen Phasen, Graphiteinschlussverbindungen oder Lichtenergiespeicherung.

Neben den Originalveröffentlichungen hat Kagan ungewöhnlich viele Übersichtsartikel und Buchkapite und ein in fünf Sprachen übersetztes kurzes Lehrbuch 'Stéréochimie Organique' geschrieben sowie als Editor fünf Bände 'Stereochemistry, Fundamentals and $\mathrm{Me}$ thods' im Thieme-Verlag' herausgebracht und dadurch eine breite Wirkung auf den von ihm bearbeiteten Gebicten erzeugt. Seine bescheidene, nicht prätentiöse Art hat Zusammenarbeiten mit anderen französischen und ausländischen Laboratorien ermöglicht, wie gemeinsame Veröffentlichungen, z. B. mit Ourisson, Salem, Snatzke oder Schurig, belegen. Auch im Wirken seine Schüler, deren prominentester vielleicht J. L. Luche ist, spiegelt sich die Vielfalt seines Wissens und sciner Interessen wider.

Die Leistungen Kagans auf wissenschaftlichem Gebiet haben dazu geführt, dass er verantwortliche Aufgaben in seiner Universität und in der französischen chemischen Gesellschaft übertragen bekam (Präsident de Division für Organische Chemie und Vizepräsident der Gesellschaft, Herausgeber des Nouveau Journal de Chimie). Neben zahlreichen Gastprofessuren auf der ganzen Welt zeugen die ihm verliehenen Preise und Auszeichnungen von der Anerkennung, die seine Arbeiten erfahren: Prix Le Bel (1967), Prix Cahours (1968), Médaille d'argent du CNRS (1974), Prix Raymond Berr (1976), korrespondierendes Mitglied der Académie des Sciences (seit 1978), Prix du Rayonnement Français (1989)

\section{Schweizerisches Komitee für Chemie Comité Suisse de la Chimie (CSC)}

\section{Jahresbericht 1990 \\ (1. 10.8930 .9 .90$)$}

Delcgiertenversammlungen wurden am 25 . Oktober 1989 in Fribourg und am 16. Februar 1990 in Bern abgehalten.

\section{Mutationen}

Die Amtszeit von Prof. A. v. Zelewsky als Präsident und Dr. R. Darms als Sekretär des CSC wurde von der Delcgiertenversammlung vom 16. Februar 1990 für einc Periode von weiteren 3 Jahren vcrlängert.

Dr. U. Schenk wurde als Nachfolger von Dr. P.A Böhler als Vizepräsident in den Vorstand des CSC gewählt.

Prof. U. Schlunegger wurde als Vertreter des CSC in die SANW gewählt.

Prof. W. v. Philipsborn wurde als Nachfolger von Prof A. Eschenmoser neuer Präsident der SCG.
Dr. R. Battaglia wurde als Nachfolger von Prof. $J$. Solms neuer Präsident der SGAAC.

Dr. H. Sigrist wurde als Delegierter der SGB ernannt.

Prof. E. Haselbach wurde neuer Präsident und Beobachter der EPA-Schweiz

\section{Strukturänderungen CSC}

Eine Abstimmung unter den Mitgliedern der SCG und des SChV über eine 'Absichtserklärung' betreffend Zusammenschluss der beiden Gesellschaften fiel sehr positiv aus. Es wurde beschlossen, in einer zweijährigen Kooperationsphase die Fusion vorzubereiten.

\section{Internationale Beziehungen}

FECS (Federation of European Chemical Societies)
Die Generalversammlung fand am 12./13. Juni 1990 in Frankfurt statt. Dr. R. Darms nahm als Delegierte des CSC daran teil.

Council Meetings fanden anlïsslich der Generalversammlung sowie am 15. März in Florenz statt.

Dr. R. Darms nahm als Council-Mitglied am Meeting in Frankfurt teil.

Am Meeting der Working Party on Electrochemistry in Prag nahm Dr. O. Haas teil.

Dr. R. Battaglia besuchte die Jahressitzung der Working Party on Food Chemistry vom 26. Augus 1990 in Wien.

Die FECS Lecture 1990 hielt Prof. J.-M. Lehn Strasbourg, anlässlich des 100-Jahr-Jubilïums der Universität Fribourg am 12. Dezember 1989.

IUPAC

Dr. M. Cosandey nahm als Mitglied des Comnittee on Teaching of Chemistry an der Sitzung vom 3./4. September 1990 in Moskau teil und besuchte dor vom 5.-7.September das Symposium 'Environment and Chemistry Teaching'.

\section{EUCHEM}

Am Mceting des EUCHEM Komites vom 20. Oktober 1989 in Paris nahmen Prof. H. Dutler als Delegierter des CSC und Dr. R. Darms als Vertreter der FECS teil.

Chemie-Olympiade

Unter der Leitung von $\mathrm{Dr} . M$. Cosandey besuchte eine Schülergruppe aus Schweizer Gymnasien vom 8.-17.7.90 die Chemie-Olympiade in Paris und brachte eine Bronzemedaille nach Hause - die erste Medaille einer Schweizerdelegation.

Dr. M. Cosandey wohnte der 1. Internationalen Konferenz für Chemische Olympiaden vom 10.-12. September 1990 in Kiew bei.

\section{Nationale Koordinationstätigkeit}

$K f U$ (Kommission für Unterrichtsfragen)

Die von Prof. $P$. Müller veleitete Kommission Doktorate in der Chemie' hat nach einem ersten Zwischenbericht ihre Tätigkeit wieder aufgenommen. Es wurde eine Arbeitsgruppe gebildet, bestehend aus Vertretern aller Hochschulen und drei Vertretern der Chemischen Industrie, mit dem Ziel, ein Konzept für das Doktorat zu erarbeiten.

Die Gruppe 'Computer Assisted Teaching' hat sich an der Herbstversammlung der SCG 1989 in Bern mi Demonstrationen von Lehrprogrammen vorgestellt.

$K f O$ (Kommission für Öffentlichkeitsarbeit)

Dic von Dr. $A$. Fürst organisicrte und geleitete Tagung 'Chemie, Chemiker, Chemikernachwuchs' des CSC mit den akademischen Berufsberatern vom 22./23. März 1990 in Fribourg wurde von Gymnasialund Hochschullehrern, von Vertretern der Industric der CSC-Mitgliedgesellschaften sowie der Berufsberatung rege zu Diskussionen genutzt, die wertvolle Beiträge zur Erkennung der möglichen Gründe für den Nachwuchsmangel erbrachten. Ein erster Bericht ist im Maiheft des $\mathrm{c}+\mathrm{b}$ erschienen.

Eine Programmkommission unter der Leitun von $\operatorname{Dr} A$. Fürst hat das Programm zur CSC Veranstaltung an der ILMAC 1990 ausgearbeitet. Das Thema lautet 'Chemische Signale und ihre Empfänger'.

\section{IFS (Informationsstelle)}

Die Statistik über Chemiestudierende in der Schweiz wurde erstellt und in der Chimia publiziert.

\section{$S A N W$}

An den Sitzungen des Zentralvorstandes hat Prof. $U$. Schlunegger teilgenommen.

Prof. A. v. Zelewsky (Präsident) Dr. R. Darms $\quad$ (Sekretär) 


\section{Prelog-Vorlesung 1990}

\section{Laboratorium für Organische Chemie, ETH Zürich}

Am 19. November 1990 erfolgte die Übergabe der Prelog-Medaille 1990 an Prof. Henri Boris Kagan (Université de Paris-Sud, Orsay, France). Der Titel des anschlicssenden Vortrags lautete: 'Recent developments in asymmetric synthesis of sulfoxides'.

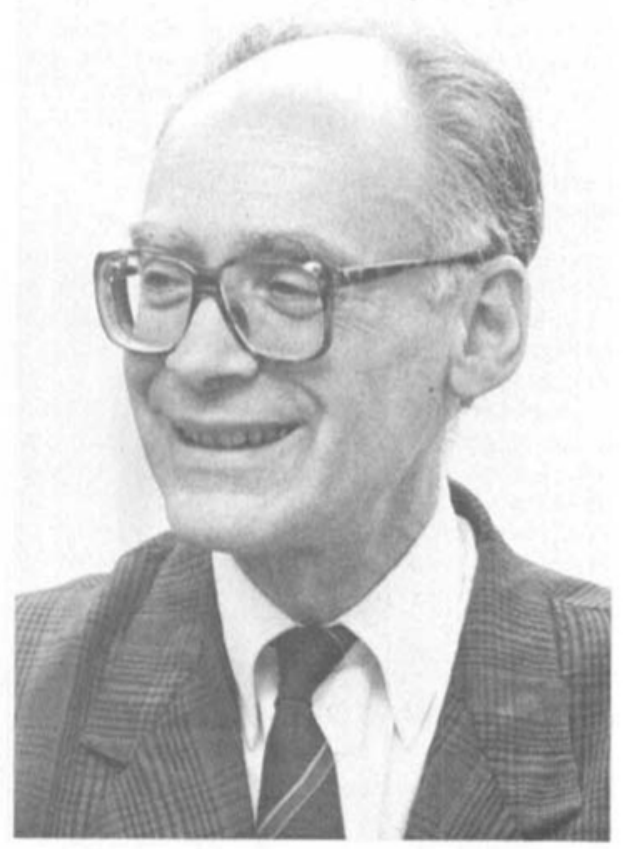

Henri Boris Kagan, 1930 in Boulogne an der Seine geboren, studierte Chemie in Paris, promovierte mi ciner unter J. Jacques durchgeführten Doktorarbeit 'Les Stérö̈des inversés' 1960 am Collège de France und arbeitete bis 1967, durch cin Postdoktorandenjahr (Prof. T. Mabry, University of Texas, Austin) unterbrochen, im Laboratorium von A. Horeau, wo er Coautor zahlreicher wichtiger Arbeiten war. Seit 1968 leitet er die Laboratoires de Synthèse Asymmétrique et de Coordination Organique an der Universität von Paris (Orsay).

Dic Stereochemie zieht sich wie ein roler Faden durch dic Arbeiten von Kagan. Zunächst machte er durch enantioselektive Reaktionen mit Hilfe von circular po- larisiertem Licht auf sich aufmerksam. Dann war er einer der ersten, dem es gelang, mit einem chiralen Wilkinson-Katalysator, jetzt bekannt als DIOP, seh hohe Enantioselektivitäten bei der Hydrierung von Doppelbindungen zu erreichen, und zwar speziell be der Herstellung von Aminosäuren aus Dehydro-aminosäurederivaten. Später folgten dann Arbeiten über die Herstellung enantiomerenreiner Sulfoxide und übe enantioselektiv katalysierte Epoxidierungen und DielsAlder-Reaktionen. Neben den synthetischen Fragestellungen, für die sich Kagan bis hin zu industriellen Anwendungen interessiert, hat er aber immer wieder grundlegende Erkenntnisse über den stereochemischen Verlauf von Reaktionen zu gewinnen versucht; so hat er kürzlich nicht-lineare Effekte bei zahlreichen stereoselektiven Reaktionen entdeckt, was teilweise zu einer Revision des angenommenen Mechanismus zwang. Schliesslich hat Kagan als erster die Bedeutung von organischen Derivaten der Lanthanide für die Synthese erkannt (seine erste Arbeit zu diesem Thema datiert aus dem Jahre 1970), heute ein nicht nur in seiner Gruppe intensiv bearbeitetes Gebiet. Zusätzlich enthält seine über 200 Arbeiten umfassende Publikationsliste Veröffentlichungen über so verschiedenartige Themen wie Reaktionen in flüssigem $\mathrm{SO}_{2}$ und in cholesterischen Phasen, Graphiteinschlussverbindungen oder Lichtenergiespeicherung.

Neben den Originalveröffentlichungen hat Kagan ungewöhnlich viele Übersichtsartikel und Buchkapite und ein in fünf Sprachen übersetztes kurzes Lehrbuch 'Stéréochimie Organique' geschrieben sowie als Editor fünf Bände 'Stereochemistry, Fundamentals and $\mathrm{Me}$ thods' im Thieme-Verlag' herausgebracht und dadurch eine breite Wirkung auf den von ihm bearbeiteten Gebicten erzeugt. Seine bescheidene, nicht prätentiöse Art hat Zusammenarbeiten mit anderen französischen und ausländischen Laboratorien ermöglicht, wie gemeinsame Veröffentlichungen, z. B. mit Ourisson, Salem, Snatzke oder Schurig, belegen. Auch im Wirken seine Schüler, deren prominentester vielleicht J. L. Luche ist, spiegelt sich die Vielfalt seines Wissens und sciner Interessen wider.

Die Leistungen Kagans auf wissenschaftlichem Gebiet haben dazu geführt, dass er verantwortliche Aufgaben in seiner Universität und in der französischen chemischen Gesellschaft übertragen bekam (Präsident de Division für Organische Chemie und Vizepräsident der Gesellschaft, Herausgeber des Nouveau Journal de Chimie). Neben zahlreichen Gastprofessuren auf der ganzen Welt zeugen die ihm verliehenen Preise und Auszeichnungen von der Anerkennung, die seine Arbeiten erfahren: Prix Le Bel (1967), Prix Cahours (1968), Médaille d'argent du CNRS (1974), Prix Raymond Berr (1976), korrespondierendes Mitglied der Académie des Sciences (seit 1978), Prix du Rayonnement Français (1989)

\section{Schweizerisches Komitee für Chemie Comité Suisse de la Chimie (CSC)}

\section{Jahresbericht 1990 \\ (1. 10.8930 .9 .90$)$}

Delcgiertenversammlungen wurden am 25 . Oktober 1989 in Fribourg und am 16. Februar 1990 in Bern abgehalten.

\section{Mutationen}

Die Amtszeit von Prof. A. v. Zelewsky als Präsident und Dr. R. Darms als Sekretär des CSC wurde von der Delcgiertenversammlung vom 16. Februar 1990 für einc Periode von weiteren 3 Jahren vcrlängert.

Dr. U. Schenk wurde als Nachfolger von Dr. P.A Böhler als Vizepräsident in den Vorstand des CSC gewählt.

Prof. U. Schlunegger wurde als Vertreter des CSC in die SANW gewählt.

Prof. W. v. Philipsborn wurde als Nachfolger von Prof A. Eschenmoser neuer Präsident der SCG.
Dr. R. Battaglia wurde als Nachfolger von Prof. $J$. Solms neuer Präsident der SGAAC.

Dr. H. Sigrist wurde als Delegierter der SGB ernannt.

Prof. E. Haselbach wurde neuer Präsident und Beobachter der EPA-Schweiz

\section{Strukturänderungen CSC}

Eine Abstimmung unter den Mitgliedern der SCG und des SChV über eine 'Absichtserklärung' betreffend Zusammenschluss der beiden Gesellschaften fiel sehr positiv aus. Es wurde beschlossen, in einer zweijährigen Kooperationsphase die Fusion vorzubereiten.

\section{Internationale Beziehungen}

FECS (Federation of European Chemical Societies)
Die Generalversammlung fand am 12./13. Juni 1990 in Frankfurt statt. Dr. R. Darms nahm als Delegierte des CSC daran teil.

Council Meetings fanden anlïsslich der Generalversammlung sowie am 15. März in Florenz statt.

Dr. R. Darms nahm als Council-Mitglied am Meeting in Frankfurt teil.

Am Meeting der Working Party on Electrochemistry in Prag nahm Dr. O. Haas teil.

Dr. R. Battaglia besuchte die Jahressitzung der Working Party on Food Chemistry vom 26. Augus 1990 in Wien.

Die FECS Lecture 1990 hielt Prof. J.-M. Lehn Strasbourg, anlässlich des 100-Jahr-Jubilïums der Universität Fribourg am 12. Dezember 1989.

IUPAC

Dr. M. Cosandey nahm als Mitglied des Comnittee on Teaching of Chemistry an der Sitzung vom 3./4. September 1990 in Moskau teil und besuchte dor vom 5.-7.September das Symposium 'Environment and Chemistry Teaching'.

\section{EUCHEM}

Am Mceting des EUCHEM Komites vom 20. Oktober 1989 in Paris nahmen Prof. H. Dutler als Delegierter des CSC und Dr. R. Darms als Vertreter der FECS teil.

Chemie-Olympiade

Unter der Leitung von $\mathrm{Dr} . M$. Cosandey besuchte eine Schülergruppe aus Schweizer Gymnasien vom 8.-17.7.90 die Chemie-Olympiade in Paris und brachte eine Bronzemedaille nach Hause - die erste Medaille einer Schweizerdelegation.

Dr. M. Cosandey wohnte der 1. Internationalen Konferenz für Chemische Olympiaden vom 10.-12. September 1990 in Kiew bei.

\section{Nationale Koordinationstätigkeit}

$K f U$ (Kommission für Unterrichtsfragen)

Die von Prof. $P$. Müller veleitete Kommission Doktorate in der Chemie' hat nach einem ersten Zwischenbericht ihre Tätigkeit wieder aufgenommen. Es wurde eine Arbeitsgruppe gebildet, bestehend aus Vertretern aller Hochschulen und drei Vertretern der Chemischen Industrie, mit dem Ziel, ein Konzept für das Doktorat zu erarbeiten.

Die Gruppe 'Computer Assisted Teaching' hat sich an der Herbstversammlung der SCG 1989 in Bern mi Demonstrationen von Lehrprogrammen vorgestellt.

$K f O$ (Kommission für Öffentlichkeitsarbeit)

Dic von Dr. $A$. Fürst organisicrte und geleitete Tagung 'Chemie, Chemiker, Chemikernachwuchs' des CSC mit den akademischen Berufsberatern vom 22./23. März 1990 in Fribourg wurde von Gymnasialund Hochschullehrern, von Vertretern der Industric der CSC-Mitgliedgesellschaften sowie der Berufsberatung rege zu Diskussionen genutzt, die wertvolle Beiträge zur Erkennung der möglichen Gründe für den Nachwuchsmangel erbrachten. Ein erster Bericht ist im Maiheft des $\mathrm{c}+\mathrm{b}$ erschienen.

Eine Programmkommission unter der Leitun von $\operatorname{Dr} A$. Fürst hat das Programm zur CSC Veranstaltung an der ILMAC 1990 ausgearbeitet. Das Thema lautet 'Chemische Signale und ihre Empfänger'.

\section{IFS (Informationsstelle)}

Die Statistik über Chemiestudierende in der Schweiz wurde erstellt und in der Chimia publiziert.

\section{$S A N W$}

An den Sitzungen des Zentralvorstandes hat Prof. $U$. Schlunegger teilgenommen.

Prof. A. v. Zelewsky (Präsident) Dr. R. Darms $\quad$ (Sekretär) 
Die schweizerische chemische Industrie ist vorerst für den Vollzug der geltenden Luftreinhalte-Verordnung

I.C. - Die geltende Luftreinhalte-Verordnung (LRV) ist seit gut viereinhalb Jahren in Kraft. Dic Unternehmen der chemischen Industrie der Schweiz haben sich von Beginn an voll hinter diese Verordnung gestellt. Sie sind bereit, die notwendigen lnvestitionen von einigen hundert Millionen Franken vorzunehmen Sie benötigen dazu aber die in der Verordnung vorgesehenen Sanierungsfristen von bis zu zehn Jahren und müssen sich auf Rechtsgrundlagen abstützen können dic während der üblichen Abschreibungsfristen ihre Gültigkeit bewahren.

Die chemische Industrie der Schweiz steht voll hinter den Zielen des Umweltschutzes als Ganzem und der Luftreinhaltung im besonderen. Sie bekennt sich auch zum Verursacher- und Vorsorgeprinzip. Beim Vollzus der kostspieligen Verordnungen muss sic sich jedoch auf Rechtsgrundlagen und Normen abstützen können. die mindestens während der landläufig üblichen $\mathrm{Ab}$ schreibungsfristen gültig bleiben.

Die jetzl geltende LRV wurde auf den I. März 1986 in Kraft gesetzt. Je nach dem Mass der Überschreitung der Emissionsgrenzwerte sieht sic realistischerweise Sanierungsfristen von bis zu zehn Jahren vor. Den Kantonen wurde eine Frist für den Erlass der Sanierungsverfügungen von bis zu zwei Jahren eingeräumt. Es kann also bis 1998 dauern, bis Industrie und Gewerbe alle notwendigen, auch die unbedeutenden, Massnahmen vollzogen haben.

Die Zicle der LRV können heule, mitten in der Vollzugsphase, noch gar nicht erreicht sein. Allgemein ist auch bekannt, dass erst etwa ein Drittel der Kantone mit dem Vollzug der LRV auf gutem Weg ist. Zwe Drittel hinken zum Teil noch weit hintennach. Die Schweizerische Gesellschaft für Chemische Industrie (SGCI) vertritt die Auffassung, dass der Vollzug der bestehenden Verordnung in allen Landesteilen etwa den gleichen Stand erreicht haben sollte, bevor neue Vorschriften erlassen werden. Dies gilt in unserem kleinräumigen Land vor allem für die Massnahmen zur Luftreinhaltung.

Dic SGCl erachtet es als falsch, die Luftreinhaltung als isoliertes Ziel des Umweltschutzes zu betrachten Umweltschutz als Ganzes muss der Zweek der Übung sein. Viele der im Entwurf zur Revision der LRV vorgeschlagenen Massnahmen lassen einen solchen gesamtheitlichen Blick jedoch vermissen. Je geringer die $\mathrm{zu}$ entfernenden Schadstoffanteile nämlich sind und je inlensiver Abgase und Waschflüssigkeiten umgewälz werden, desto grösser ist der Stromverbrauch zum Antrieb der Pumpen und Ventilatoren.

Die Schweiz besitzt, auch nach Meinung der Behörden, bereits jetzt eine im internationalen Vergleich sehr strenge Luftreinhalte-Verordnung. Die Frist für deren gänzlichen Vollzug ist aber noch nicht einmal zur Hälfte verstrichen. Im Interesse der Rechtssicherheit verlangt daher die $\mathrm{SGCl}$, es sei mit Revisionen, soweit sie festgeschriebene Grenzwerte betreffen, zuzuwarten, bis die vorgesehenen Fristen abgelaufen sind.

\section{Personalia}

\section{Geburtstage}

Hans Felix, Chemiker HTL, Muttenz, Mitglied des SChV, feiert am 1.1.91 seinen 65. Geburtstag.

Norbert Herzog. Dr. sc.techn., dipl. Ing. Chem., Witterswil, Mitglied des SChV, feiert am 14.1.91 seinen 65. Geburtstag.

Kurt Lew, Dr. phil., Riehen, Mitglied des SChV, feiert am 16.1.91 seinen 70. Geburtstag.

Ernest Merian, Dr. Ing. Chem., Therwil, Mitglied des $\mathrm{SChV}$, feiert am 19.1.91 seinen 70. Geburtstag.

Peter Ludwig, Chemiker HTL, Flüelen, Mitglied des SChV, feiert am 28.1.91 seinen 65. Geburtstag.

R.M. Kunz, Dr., Binningen, Mitglied des SChV, feiert am 2.2.91 seinen 80. Geburtstag.

Max Cruchaud, Dr. ċs sci., Thun, Mitglied des SChV, feiert am 15.2.91 seinen 80. Geburtstag.
Willi G. Stoll, Dr. Ing. Chem., Dr. h.c., Bottmingen, Mitglied des SChV, feiert am 25.2.91 seinen 80. Geburtstag.

\section{Neue Mitglieder}

Hans-Frieder Beer, Dipl. Chem., Dr. phil. nat., Ze]glistrasse 36, 5417 Untersiggenthal.

Cosimo De Caro, Dipl. Chem. ETH, Hofwiesenstrasse, 8050 Zürich.

Peter Hauser, Dr., Hönggerstrasse 10, 8037 Zürich.

Rohert Kuhn, Dr chem., Wiesendamm 10b, 4057 Basel.

André Peter, Cheniker HTL, Bruggwiesenstrasse 8 8307 Effretikon.

Veronique Nery, Ingenieur en chimie ETS, Bugnon 37. 1020 Renens.

\section{Chemie-Aussenhandel Januar bis September 1990}

I.C. - Die Exporte von chemischen Erzeugnissen haben in den ersten neun Monaten dieses Jahres gegen über der entsprechenden Vorjahresperiode um 5,2\% auf SFr. 14,0 Mrd. zugenommen. Gleichzeitig sind di Importe um $0,3 \%$ auf SFr. 8,0 Mrd. gesunken. Im Vergleich mit den Wachstumsraten der Vorjahresperiode (Exporte: $12,8 \%$, Importe: $16,7 \%$ ) ergibt sich eine deutliche Abschwächung der Aussenhandelsdynamik. Der Exportüberschuss der chemischen Industric steigerte sich weiter um 13,3\% auf SFr. 6,0 Mrd.

Infolge der international schwächeren Konjunktu und des wiedererstarkten Schweizer Frankens hat das Ausfuhrwachstum wesentlich an Dynamik eingebüsst. Dies trifft insbesondere für die Ausfuhren nach den USA $(0,1 \%$ nach $15,4 \%$ im Vorjahr) und nach Japan ( $2 \%$ nach $17,1 \%$ im Vorjahr) zu. In geringerem Aus mass hat sich auch das Wachstum der Ausfuhren nach der EG $(7,5 \%$ nach $16,1 \%$ im Vorjahr $)$ abgeschwächt. Eine bemerkenswerte Ausnahme von dieser generellcn Entwicklung bilden die Exporte nach West-Deutschland, die eine mit einem Zuwachs von $11,1 \%$ im Vergleich zum Vorjahr $(7,6 \%)$ sogar steigende Tendenz aufwiesen.

Die Importe von chemischen Produkten haben in der Berichtsperiode um 0,3\% aur SFr. 8,0 Mrd. abgenommen, während sie in der Vorjahresperiode noch um $16.7 \%$ zugenommen haben. Einzig der Import aus dem europäischen Raum weist noch positive Wachs tumsraten auf. Bemerkenswert ist vor allem die Steigerung der Importe aus West-Deutschland um 3,2\% $(+13,9 \%)$

\section{Internationales Farbensymposium 11th International Colour Symposium}

23.-26. September 1991

Montreux

Schweiz/Switzerland

Der Schweizerische Chemiker-Verband, die Schweizerische Chemische Gesellschaft und die Gesellschaft Deutscher Chemiker laden ein zum 11. Internationalen Farbensymposium. Das Farbensymposium wird seit 1960 von deutschen und schweizerischen Farbenchemikern veranstaltet. Es setzt sich zum Ziel, anhand von Erkenntnissen und Entwicklungen die Bedeutung de Farbenchemie auf den verschiedenen Gebieten von Wissenschaft und Praxis darzustellen.

The Swiss Association of Chemists, the Swiss Chemical Society and the Society of German Chemists ar organizing the 11 th International Colour Symposium. The Colour Symposium has been organized by German and Swiss chemical scientists since 1960. The ain is to present the importance of the dyestuff chemistry in science and technology by means of new research results and developments.
Wissenschaftliches Komitec Scientific Committee:

Dr. D. Wyrsch (Chairman), Ciba-Geigy AG Basel Prof. Dr. H Balli, Institut für Farbenchemic Basel; Dr. H. H. Bosshard, Ciba-Geigy AG Basel: Dr. R. Entschel, Sandoz AG Basel; Prof. Dr. P. Müller, Schweiz. Chemiker-Verband: PD Dr. R. Naef, Ciba-Geigy AG Basel:

Dr. R.H. Rupp, Hoechst AG Frankfurt: Prof. Dr. P. Rys, ETH Zürich

Das definitive Programm sowie die Anmeldeunterlagen sind im April 1991 crhältlich bei: The definitive programme and registration documents will be availsble in April 1991 at

Sekretariat Symposien SChV, Instilut für Organische Chemie, Frciestrasse 3, CH 3012 Bern (Tel. 031) 654311 , Fax 031654499 , Telex 912406 unich).

\section{Kurzvorträge und Posters/}

\section{Short Contributions and Posters}

Es ist vorgesehen. Kurzvorträge (20 Minuten) und eine Postersession zu präsenticren. Interessenten für einen Kurzyortrag oder einen Poster sind gebetch. Anmeldung und Abstract (max. I A4-Seite) bis 31. Januar 1991 zu schicken an:

It is planned to present short contributions $(20 \mathrm{minu}$ tes) and a postersession. Applications for a short contribution or a poster and an abstract (max. 1 A4-page) should be sent before January 31, 1991 to:

Prof. Dr. H. Balli

Institute of Colour Chemistry, University of Basle St. Johannsvorstadt 10

$\mathrm{CH}-4056$ Basle

\section{Bei der Redaktion eingetroffene Bücher}

Horst lbelgaufts, Gentechnologie von $A$ bis $Z$. Studienausgabe, VCH, Weinheim-New York- Basel Cambridge, 1990, VIII, 486 S., 290 Abb., 15 Tab., DM 64. -

Robert J. Hurtubise, Phosphorimetry, Theory, Instrumentation, and Applications, VCH, WeinheimNew York-Basel Cambridge, 1990, XII, 370 p., 62 figs., 45 tables, DM 114.-, $£ 45.00$.

Instrumental Surface Analysis of Geologic Materials, Dale L. Perry, VCH, Weinheim New York-Basel-Cambridge, 1990, IX, 373 p., 116 figs., 10 tables. DM 112,--, £40.50

Gerhard Schomburg, Gas Chromatography, A Practical Course, VCH, Weinheim-New York-BaselCambridge, 1990, 318 p., 126 figs., DM 76.-

\section{Ehrungen}

Den Doktortitel ehrenhalber erhielten am ETH-Tag in Zürich (17. November 1990) u. a. Prof. Dr. André Dreiding (Organische Chemie, Universität Zürich) und Prof. Dr. Ernst Schumacher (Anorganische und physikalische Chemie, Universität Bern).

\section{Glossary of bioanalytical nomenclature}

\section{Synopsis}

Many disciplines are involved in the practice of clinical laboratory medicine, with each having its own set of technical terminology. Consequently, the terminology used in the clinical laboratory is often vague, inexact, and in some cases, even in discord with conventional and officially-approved terminology. In order to help rectify this situation, a general set of bioanalytical definitions have been compiled and collated from documents from several national and international organiations with the emphasis on those prepared by the International Federation of Clinical Chemistry (IFCC), the International Union of Pure and Applied Chemistry (IUPAC), and the International Union of Biochemistry (IUB). References are included for each definition included. This document includes section on General Terminology, Body Fluids, Enzymology and Immunology. Other topics will be included in sub- 
Die schweizerische chemische Industrie ist vorerst für den Vollzug der geltenden Luftreinhalte-Verordnung

I.C. - Die geltende Luftreinhalte-Verordnung (LRV) ist seit gut viereinhalb Jahren in Kraft. Dic Unternehmen der chemischen Industrie der Schweiz haben sich von Beginn an voll hinter diese Verordnung gestellt. Sie sind bereit, die notwendigen lnvestitionen von einigen hundert Millionen Franken vorzunehmen Sie benötigen dazu aber die in der Verordnung vorgesehenen Sanierungsfristen von bis zu zehn Jahren und müssen sich auf Rechtsgrundlagen abstützen können dic während der üblichen Abschreibungsfristen ihre Gültigkeit bewahren.

Die chemische Industrie der Schweiz steht voll hinter den Zielen des Umweltschutzes als Ganzem und der Luftreinhaltung im besonderen. Sie bekennt sich auch zum Verursacher- und Vorsorgeprinzip. Beim Vollzus der kostspieligen Verordnungen muss sic sich jedoch auf Rechtsgrundlagen und Normen abstützen können. die mindestens während der landläufig üblichen $\mathrm{Ab}$ schreibungsfristen gültig bleiben.

Die jetzl geltende LRV wurde auf den I. März 1986 in Kraft gesetzt. Je nach dem Mass der Überschreitung der Emissionsgrenzwerte sieht sic realistischerweise Sanierungsfristen von bis zu zehn Jahren vor. Den Kantonen wurde eine Frist für den Erlass der Sanierungsverfügungen von bis zu zwei Jahren eingeräumt. Es kann also bis 1998 dauern, bis Industrie und Gewerbe alle notwendigen, auch die unbedeutenden, Massnahmen vollzogen haben.

Die Zicle der LRV können heule, mitten in der Vollzugsphase, noch gar nicht erreicht sein. Allgemein ist auch bekannt, dass erst etwa ein Drittel der Kantone mit dem Vollzug der LRV auf gutem Weg ist. Zwe Drittel hinken zum Teil noch weit hintennach. Die Schweizerische Gesellschaft für Chemische Industrie (SGCI) vertritt die Auffassung, dass der Vollzug der bestehenden Verordnung in allen Landesteilen etwa den gleichen Stand erreicht haben sollte, bevor neue Vorschriften erlassen werden. Dies gilt in unserem kleinräumigen Land vor allem für die Massnahmen zur Luftreinhaltung.

Dic SGCl erachtet es als falsch, die Luftreinhaltung als isoliertes Ziel des Umweltschutzes zu betrachten Umweltschutz als Ganzes muss der Zweek der Übung sein. Viele der im Entwurf zur Revision der LRV vorgeschlagenen Massnahmen lassen einen solchen gesamtheitlichen Blick jedoch vermissen. Je geringer die $\mathrm{zu}$ entfernenden Schadstoffanteile nämlich sind und je inlensiver Abgase und Waschflüssigkeiten umgewälz werden, desto grösser ist der Stromverbrauch zum Antrieb der Pumpen und Ventilatoren.

Die Schweiz besitzt, auch nach Meinung der Behörden, bereits jetzt eine im internationalen Vergleich sehr strenge Luftreinhalte-Verordnung. Die Frist für deren gänzlichen Vollzug ist aber noch nicht einmal zur Hälfte verstrichen. Im Interesse der Rechtssicherheit verlangt daher die $\mathrm{SGCl}$, es sei mit Revisionen, soweit sie festgeschriebene Grenzwerte betreffen, zuzuwarten, bis die vorgesehenen Fristen abgelaufen sind.

\section{Personalia}

\section{Geburtstage}

Hans Felix, Chemiker HTL, Muttenz, Mitglied des SChV, feiert am 1.1.91 seinen 65. Geburtstag.

Norbert Herzog. Dr. sc.techn., dipl. Ing. Chem., Witterswil, Mitglied des SChV, feiert am 14.1.91 seinen 65. Geburtstag.

Kurt Lew, Dr. phil., Riehen, Mitglied des SChV, feiert am 16.1.91 seinen 70. Geburtstag.

Ernest Merian, Dr. Ing. Chem., Therwil, Mitglied des $\mathrm{SChV}$, feiert am 19.1.91 seinen 70. Geburtstag.

Peter Ludwig, Chemiker HTL, Flüelen, Mitglied des SChV, feiert am 28.1.91 seinen 65. Geburtstag.

R.M. Kunz, Dr., Binningen, Mitglied des SChV, feiert am 2.2.91 seinen 80. Geburtstag.

Max Cruchaud, Dr. ċs sci., Thun, Mitglied des SChV, feiert am 15.2.91 seinen 80. Geburtstag.
Willi G. Stoll, Dr. Ing. Chem., Dr. h.c., Bottmingen, Mitglied des SChV, feiert am 25.2.91 seinen 80. Geburtstag.

\section{Neue Mitglieder}

Hans-Frieder Beer, Dipl. Chem., Dr. phil. nat., Ze]glistrasse 36, 5417 Untersiggenthal.

Cosimo De Caro, Dipl. Chem. ETH, Hofwiesenstrasse, 8050 Zürich.

Peter Hauser, Dr., Hönggerstrasse 10, 8037 Zürich.

Rohert Kuhn, Dr chem., Wiesendamm 10b, 4057 Basel.

André Peter, Cheniker HTL, Bruggwiesenstrasse 8 8307 Effretikon.

Veronique Nery, Ingenieur en chimie ETS, Bugnon 37. 1020 Renens.

\section{Chemie-Aussenhandel Januar bis September 1990}

I.C. - Die Exporte von chemischen Erzeugnissen haben in den ersten neun Monaten dieses Jahres gegen über der entsprechenden Vorjahresperiode um 5,2\% auf SFr. 14,0 Mrd. zugenommen. Gleichzeitig sind di Importe um $0,3 \%$ auf SFr. 8,0 Mrd. gesunken. Im Vergleich mit den Wachstumsraten der Vorjahresperiode (Exporte: $12,8 \%$, Importe: $16,7 \%$ ) ergibt sich eine deutliche Abschwächung der Aussenhandelsdynamik. Der Exportüberschuss der chemischen Industric steigerte sich weiter um 13,3\% auf SFr. 6,0 Mrd.

Infolge der international schwächeren Konjunktu und des wiedererstarkten Schweizer Frankens hat das Ausfuhrwachstum wesentlich an Dynamik eingebüsst. Dies trifft insbesondere für die Ausfuhren nach den USA $(0,1 \%$ nach $15,4 \%$ im Vorjahr) und nach Japan ( $2 \%$ nach $17,1 \%$ im Vorjahr) zu. In geringerem Aus mass hat sich auch das Wachstum der Ausfuhren nach der EG $(7,5 \%$ nach $16,1 \%$ im Vorjahr $)$ abgeschwächt. Eine bemerkenswerte Ausnahme von dieser generellcn Entwicklung bilden die Exporte nach West-Deutschland, die eine mit einem Zuwachs von $11,1 \%$ im Vergleich zum Vorjahr $(7,6 \%)$ sogar steigende Tendenz aufwiesen.

Die Importe von chemischen Produkten haben in der Berichtsperiode um 0,3\% aur SFr. 8,0 Mrd. abgenommen, während sie in der Vorjahresperiode noch um $16.7 \%$ zugenommen haben. Einzig der Import aus dem europäischen Raum weist noch positive Wachs tumsraten auf. Bemerkenswert ist vor allem die Steigerung der Importe aus West-Deutschland um 3,2\% $(+13,9 \%)$

\section{Internationales Farbensymposium 11th International Colour Symposium}

23.-26. September 1991

Montreux

Schweiz/Switzerland

Der Schweizerische Chemiker-Verband, die Schweizerische Chemische Gesellschaft und die Gesellschaft Deutscher Chemiker laden ein zum 11. Internationalen Farbensymposium. Das Farbensymposium wird seit 1960 von deutschen und schweizerischen Farbenchemikern veranstaltet. Es setzt sich zum Ziel, anhand von Erkenntnissen und Entwicklungen die Bedeutung de Farbenchemie auf den verschiedenen Gebieten von Wissenschaft und Praxis darzustellen.

The Swiss Association of Chemists, the Swiss Chemical Society and the Society of German Chemists ar organizing the 11 th International Colour Symposium. The Colour Symposium has been organized by German and Swiss chemical scientists since 1960. The ain is to present the importance of the dyestuff chemistry in science and technology by means of new research results and developments.
Wissenschaftliches Komitec Scientific Committee:

Dr. D. Wyrsch (Chairman), Ciba-Geigy AG Basel Prof. Dr. H Balli, Institut für Farbenchemic Basel; Dr. H. H. Bosshard, Ciba-Geigy AG Basel: Dr. R. Entschel, Sandoz AG Basel; Prof. Dr. P. Müller, Schweiz. Chemiker-Verband: PD Dr. R. Naef, Ciba-Geigy AG Basel:

Dr. R.H. Rupp, Hoechst AG Frankfurt: Prof. Dr. P. Rys, ETH Zürich

Das definitive Programm sowie die Anmeldeunterlagen sind im April 1991 crhältlich bei: The definitive programme and registration documents will be availsble in April 1991 at

Sekretariat Symposien SChV, Instilut für Organische Chemie, Frciestrasse 3, CH 3012 Bern (Tel. 031) 654311 , Fax 031654499 , Telex 912406 unich).

\section{Kurzvorträge und Posters/}

\section{Short Contributions and Posters}

Es ist vorgesehen. Kurzvorträge (20 Minuten) und eine Postersession zu präsenticren. Interessenten für einen Kurzyortrag oder einen Poster sind gebetch. Anmeldung und Abstract (max. I A4-Seite) bis 31. Januar 1991 zu schicken an:

It is planned to present short contributions $(20 \mathrm{minu}$ tes) and a postersession. Applications for a short contribution or a poster and an abstract (max. 1 A4-page) should be sent before January 31, 1991 to:

Prof. Dr. H. Balli

Institute of Colour Chemistry, University of Basle St. Johannsvorstadt 10

$\mathrm{CH}-4056$ Basle

\section{Bei der Redaktion eingetroffene Bücher}

Horst lbelgaufts, Gentechnologie von $A$ bis $Z$. Studienausgabe, VCH, Weinheim-New York- Basel Cambridge, 1990, VIII, 486 S., 290 Abb., 15 Tab., DM 64. -

Robert J. Hurtubise, Phosphorimetry, Theory, Instrumentation, and Applications, VCH, WeinheimNew York-Basel Cambridge, 1990, XII, 370 p., 62 figs., 45 tables, DM 114.-, $£ 45.00$.

Instrumental Surface Analysis of Geologic Materials, Dale L. Perry, VCH, Weinheim New York-Basel-Cambridge, 1990, IX, 373 p., 116 figs., 10 tables. DM 112,--, £40.50

Gerhard Schomburg, Gas Chromatography, A Practical Course, VCH, Weinheim-New York-BaselCambridge, 1990, 318 p., 126 figs., DM 76.-

\section{Ehrungen}

Den Doktortitel ehrenhalber erhielten am ETH-Tag in Zürich (17. November 1990) u. a. Prof. Dr. André Dreiding (Organische Chemie, Universität Zürich) und Prof. Dr. Ernst Schumacher (Anorganische und physikalische Chemie, Universität Bern).

\section{Glossary of bioanalytical nomenclature}

\section{Synopsis}

Many disciplines are involved in the practice of clinical laboratory medicine, with each having its own set of technical terminology. Consequently, the terminology used in the clinical laboratory is often vague, inexact, and in some cases, even in discord with conventional and officially-approved terminology. In order to help rectify this situation, a general set of bioanalytical definitions have been compiled and collated from documents from several national and international organiations with the emphasis on those prepared by the International Federation of Clinical Chemistry (IFCC), the International Union of Pure and Applied Chemistry (IUPAC), and the International Union of Biochemistry (IUB). References are included for each definition included. This document includes section on General Terminology, Body Fluids, Enzymology and Immunology. Other topics will be included in sub- 
Die schweizerische chemische Industrie ist vorerst für den Vollzug der geltenden Luftreinhalte-Verordnung

I.C. - Die geltende Luftreinhalte-Verordnung (LRV) ist seit gut viereinhalb Jahren in Kraft. Dic Unternehmen der chemischen Industrie der Schweiz haben sich von Beginn an voll hinter diese Verordnung gestellt. Sie sind bereit, die notwendigen lnvestitionen von einigen hundert Millionen Franken vorzunehmen Sie benötigen dazu aber die in der Verordnung vorgesehenen Sanierungsfristen von bis zu zehn Jahren und müssen sich auf Rechtsgrundlagen abstützen können dic während der üblichen Abschreibungsfristen ihre Gültigkeit bewahren.

Die chemische Industrie der Schweiz steht voll hinter den Zielen des Umweltschutzes als Ganzem und der Luftreinhaltung im besonderen. Sie bekennt sich auch zum Verursacher- und Vorsorgeprinzip. Beim Vollzus der kostspieligen Verordnungen muss sic sich jedoch auf Rechtsgrundlagen und Normen abstützen können. die mindestens während der landläufig üblichen $\mathrm{Ab}$ schreibungsfristen gültig bleiben.

Die jetzl geltende LRV wurde auf den I. März 1986 in Kraft gesetzt. Je nach dem Mass der Überschreitung der Emissionsgrenzwerte sieht sic realistischerweise Sanierungsfristen von bis zu zehn Jahren vor. Den Kantonen wurde eine Frist für den Erlass der Sanierungsverfügungen von bis zu zwei Jahren eingeräumt. Es kann also bis 1998 dauern, bis Industrie und Gewerbe alle notwendigen, auch die unbedeutenden, Massnahmen vollzogen haben.

Die Zicle der LRV können heule, mitten in der Vollzugsphase, noch gar nicht erreicht sein. Allgemein ist auch bekannt, dass erst etwa ein Drittel der Kantone mit dem Vollzug der LRV auf gutem Weg ist. Zwe Drittel hinken zum Teil noch weit hintennach. Die Schweizerische Gesellschaft für Chemische Industrie (SGCI) vertritt die Auffassung, dass der Vollzug der bestehenden Verordnung in allen Landesteilen etwa den gleichen Stand erreicht haben sollte, bevor neue Vorschriften erlassen werden. Dies gilt in unserem kleinräumigen Land vor allem für die Massnahmen zur Luftreinhaltung.

Dic SGCl erachtet es als falsch, die Luftreinhaltung als isoliertes Ziel des Umweltschutzes zu betrachten Umweltschutz als Ganzes muss der Zweek der Übung sein. Viele der im Entwurf zur Revision der LRV vorgeschlagenen Massnahmen lassen einen solchen gesamtheitlichen Blick jedoch vermissen. Je geringer die $\mathrm{zu}$ entfernenden Schadstoffanteile nämlich sind und je inlensiver Abgase und Waschflüssigkeiten umgewälz werden, desto grösser ist der Stromverbrauch zum Antrieb der Pumpen und Ventilatoren.

Die Schweiz besitzt, auch nach Meinung der Behörden, bereits jetzt eine im internationalen Vergleich sehr strenge Luftreinhalte-Verordnung. Die Frist für deren gänzlichen Vollzug ist aber noch nicht einmal zur Hälfte verstrichen. Im Interesse der Rechtssicherheit verlangt daher die $\mathrm{SGCl}$, es sei mit Revisionen, soweit sie festgeschriebene Grenzwerte betreffen, zuzuwarten, bis die vorgesehenen Fristen abgelaufen sind.

\section{Personalia}

\section{Geburtstage}

Hans Felix, Chemiker HTL, Muttenz, Mitglied des SChV, feiert am 1.1.91 seinen 65. Geburtstag.

Norbert Herzog. Dr. sc.techn., dipl. Ing. Chem., Witterswil, Mitglied des SChV, feiert am 14.1.91 seinen 65. Geburtstag.

Kurt Lew, Dr. phil., Riehen, Mitglied des SChV, feiert am 16.1.91 seinen 70. Geburtstag.

Ernest Merian, Dr. Ing. Chem., Therwil, Mitglied des $\mathrm{SChV}$, feiert am 19.1.91 seinen 70. Geburtstag.

Peter Ludwig, Chemiker HTL, Flüelen, Mitglied des SChV, feiert am 28.1.91 seinen 65. Geburtstag.

R.M. Kunz, Dr., Binningen, Mitglied des SChV, feiert am 2.2.91 seinen 80. Geburtstag.

Max Cruchaud, Dr. ċs sci., Thun, Mitglied des SChV, feiert am 15.2.91 seinen 80. Geburtstag.
Willi G. Stoll, Dr. Ing. Chem., Dr. h.c., Bottmingen, Mitglied des SChV, feiert am 25.2.91 seinen 80. Geburtstag.

\section{Neue Mitglieder}

Hans-Frieder Beer, Dipl. Chem., Dr. phil. nat., Ze]glistrasse 36, 5417 Untersiggenthal.

Cosimo De Caro, Dipl. Chem. ETH, Hofwiesenstrasse, 8050 Zürich.

Peter Hauser, Dr., Hönggerstrasse 10, 8037 Zürich.

Rohert Kuhn, Dr chem., Wiesendamm 10b, 4057 Basel.

André Peter, Cheniker HTL, Bruggwiesenstrasse 8 8307 Effretikon.

Veronique Nery, Ingenieur en chimie ETS, Bugnon 37. 1020 Renens.

\section{Chemie-Aussenhandel Januar bis September 1990}

I.C. - Die Exporte von chemischen Erzeugnissen haben in den ersten neun Monaten dieses Jahres gegen über der entsprechenden Vorjahresperiode um 5,2\% auf SFr. 14,0 Mrd. zugenommen. Gleichzeitig sind di Importe um $0,3 \%$ auf SFr. 8,0 Mrd. gesunken. Im Vergleich mit den Wachstumsraten der Vorjahresperiode (Exporte: $12,8 \%$, Importe: $16,7 \%$ ) ergibt sich eine deutliche Abschwächung der Aussenhandelsdynamik. Der Exportüberschuss der chemischen Industric steigerte sich weiter um 13,3\% auf SFr. 6,0 Mrd.

Infolge der international schwächeren Konjunktu und des wiedererstarkten Schweizer Frankens hat das Ausfuhrwachstum wesentlich an Dynamik eingebüsst. Dies trifft insbesondere für die Ausfuhren nach den USA $(0,1 \%$ nach $15,4 \%$ im Vorjahr) und nach Japan ( $2 \%$ nach $17,1 \%$ im Vorjahr) zu. In geringerem Aus mass hat sich auch das Wachstum der Ausfuhren nach der EG $(7,5 \%$ nach $16,1 \%$ im Vorjahr $)$ abgeschwächt. Eine bemerkenswerte Ausnahme von dieser generellcn Entwicklung bilden die Exporte nach West-Deutschland, die eine mit einem Zuwachs von $11,1 \%$ im Vergleich zum Vorjahr $(7,6 \%)$ sogar steigende Tendenz aufwiesen.

Die Importe von chemischen Produkten haben in der Berichtsperiode um 0,3\% aur SFr. 8,0 Mrd. abgenommen, während sie in der Vorjahresperiode noch um $16.7 \%$ zugenommen haben. Einzig der Import aus dem europäischen Raum weist noch positive Wachs tumsraten auf. Bemerkenswert ist vor allem die Steigerung der Importe aus West-Deutschland um 3,2\% $(+13,9 \%)$

\section{Internationales Farbensymposium 11th International Colour Symposium}

23.-26. September 1991

Montreux

Schweiz/Switzerland

Der Schweizerische Chemiker-Verband, die Schweizerische Chemische Gesellschaft und die Gesellschaft Deutscher Chemiker laden ein zum 11. Internationalen Farbensymposium. Das Farbensymposium wird seit 1960 von deutschen und schweizerischen Farbenchemikern veranstaltet. Es setzt sich zum Ziel, anhand von Erkenntnissen und Entwicklungen die Bedeutung de Farbenchemie auf den verschiedenen Gebieten von Wissenschaft und Praxis darzustellen.

The Swiss Association of Chemists, the Swiss Chemical Society and the Society of German Chemists ar organizing the 11 th International Colour Symposium. The Colour Symposium has been organized by German and Swiss chemical scientists since 1960. The ain is to present the importance of the dyestuff chemistry in science and technology by means of new research results and developments.
Wissenschaftliches Komitec Scientific Committee:

Dr. D. Wyrsch (Chairman), Ciba-Geigy AG Basel Prof. Dr. H Balli, Institut für Farbenchemic Basel; Dr. H. H. Bosshard, Ciba-Geigy AG Basel: Dr. R. Entschel, Sandoz AG Basel; Prof. Dr. P. Müller, Schweiz. Chemiker-Verband: PD Dr. R. Naef, Ciba-Geigy AG Basel:

Dr. R.H. Rupp, Hoechst AG Frankfurt: Prof. Dr. P. Rys, ETH Zürich

Das definitive Programm sowie die Anmeldeunterlagen sind im April 1991 crhältlich bei: The definitive programme and registration documents will be availsble in April 1991 at

Sekretariat Symposien SChV, Instilut für Organische Chemie, Frciestrasse 3, CH 3012 Bern (Tel. 031) 654311 , Fax 031654499 , Telex 912406 unich).

\section{Kurzvorträge und Posters/}

\section{Short Contributions and Posters}

Es ist vorgesehen. Kurzvorträge (20 Minuten) und eine Postersession zu präsenticren. Interessenten für einen Kurzyortrag oder einen Poster sind gebetch. Anmeldung und Abstract (max. I A4-Seite) bis 31. Januar 1991 zu schicken an:

It is planned to present short contributions $(20 \mathrm{minu}$ tes) and a postersession. Applications for a short contribution or a poster and an abstract (max. 1 A4-page) should be sent before January 31, 1991 to:

Prof. Dr. H. Balli

Institute of Colour Chemistry, University of Basle St. Johannsvorstadt 10

$\mathrm{CH}-4056$ Basle

\section{Bei der Redaktion eingetroffene Bücher}

Horst lbelgaufts, Gentechnologie von $A$ bis $Z$. Studienausgabe, VCH, Weinheim-New York- Basel Cambridge, 1990, VIII, 486 S., 290 Abb., 15 Tab., DM 64. -

Robert J. Hurtubise, Phosphorimetry, Theory, Instrumentation, and Applications, VCH, WeinheimNew York-Basel Cambridge, 1990, XII, 370 p., 62 figs., 45 tables, DM 114.-, $£ 45.00$.

Instrumental Surface Analysis of Geologic Materials, Dale L. Perry, VCH, Weinheim New York-Basel-Cambridge, 1990, IX, 373 p., 116 figs., 10 tables. DM 112,--, £40.50

Gerhard Schomburg, Gas Chromatography, A Practical Course, VCH, Weinheim-New York-BaselCambridge, 1990, 318 p., 126 figs., DM 76.-

\section{Ehrungen}

Den Doktortitel ehrenhalber erhielten am ETH-Tag in Zürich (17. November 1990) u. a. Prof. Dr. André Dreiding (Organische Chemie, Universität Zürich) und Prof. Dr. Ernst Schumacher (Anorganische und physikalische Chemie, Universität Bern).

\section{Glossary of bioanalytical nomenclature}

\section{Synopsis}

Many disciplines are involved in the practice of clinical laboratory medicine, with each having its own set of technical terminology. Consequently, the terminology used in the clinical laboratory is often vague, inexact, and in some cases, even in discord with conventional and officially-approved terminology. In order to help rectify this situation, a general set of bioanalytical definitions have been compiled and collated from documents from several national and international organiations with the emphasis on those prepared by the International Federation of Clinical Chemistry (IFCC), the International Union of Pure and Applied Chemistry (IUPAC), and the International Union of Biochemistry (IUB). References are included for each definition included. This document includes section on General Terminology, Body Fluids, Enzymology and Immunology. Other topics will be included in sub- 
Die schweizerische chemische Industrie ist vorerst für den Vollzug der geltenden Luftreinhalte-Verordnung

I.C. - Die geltende Luftreinhalte-Verordnung (LRV) ist seit gut viereinhalb Jahren in Kraft. Dic Unternehmen der chemischen Industrie der Schweiz haben sich von Beginn an voll hinter diese Verordnung gestellt. Sie sind bereit, die notwendigen lnvestitionen von einigen hundert Millionen Franken vorzunehmen Sie benötigen dazu aber die in der Verordnung vorgesehenen Sanierungsfristen von bis zu zehn Jahren und müssen sich auf Rechtsgrundlagen abstützen können dic während der üblichen Abschreibungsfristen ihre Gültigkeit bewahren.

Die chemische Industrie der Schweiz steht voll hinter den Zielen des Umweltschutzes als Ganzem und der Luftreinhaltung im besonderen. Sie bekennt sich auch zum Verursacher- und Vorsorgeprinzip. Beim Vollzus der kostspieligen Verordnungen muss sic sich jedoch auf Rechtsgrundlagen und Normen abstützen können. die mindestens während der landläufig üblichen $\mathrm{Ab}$ schreibungsfristen gültig bleiben.

Die jetzl geltende LRV wurde auf den I. März 1986 in Kraft gesetzt. Je nach dem Mass der Überschreitung der Emissionsgrenzwerte sieht sic realistischerweise Sanierungsfristen von bis zu zehn Jahren vor. Den Kantonen wurde eine Frist für den Erlass der Sanierungsverfügungen von bis zu zwei Jahren eingeräumt. Es kann also bis 1998 dauern, bis Industrie und Gewerbe alle notwendigen, auch die unbedeutenden, Massnahmen vollzogen haben.

Die Zicle der LRV können heule, mitten in der Vollzugsphase, noch gar nicht erreicht sein. Allgemein ist auch bekannt, dass erst etwa ein Drittel der Kantone mit dem Vollzug der LRV auf gutem Weg ist. Zwe Drittel hinken zum Teil noch weit hintennach. Die Schweizerische Gesellschaft für Chemische Industrie (SGCI) vertritt die Auffassung, dass der Vollzug der bestehenden Verordnung in allen Landesteilen etwa den gleichen Stand erreicht haben sollte, bevor neue Vorschriften erlassen werden. Dies gilt in unserem kleinräumigen Land vor allem für die Massnahmen zur Luftreinhaltung.

Dic SGCl erachtet es als falsch, die Luftreinhaltung als isoliertes Ziel des Umweltschutzes zu betrachten Umweltschutz als Ganzes muss der Zweek der Übung sein. Viele der im Entwurf zur Revision der LRV vorgeschlagenen Massnahmen lassen einen solchen gesamtheitlichen Blick jedoch vermissen. Je geringer die $\mathrm{zu}$ entfernenden Schadstoffanteile nämlich sind und je inlensiver Abgase und Waschflüssigkeiten umgewälz werden, desto grösser ist der Stromverbrauch zum Antrieb der Pumpen und Ventilatoren.

Die Schweiz besitzt, auch nach Meinung der Behörden, bereits jetzt eine im internationalen Vergleich sehr strenge Luftreinhalte-Verordnung. Die Frist für deren gänzlichen Vollzug ist aber noch nicht einmal zur Hälfte verstrichen. Im Interesse der Rechtssicherheit verlangt daher die $\mathrm{SGCl}$, es sei mit Revisionen, soweit sie festgeschriebene Grenzwerte betreffen, zuzuwarten, bis die vorgesehenen Fristen abgelaufen sind.

\section{Personalia}

\section{Geburtstage}

Hans Felix, Chemiker HTL, Muttenz, Mitglied des SChV, feiert am 1.1.91 seinen 65. Geburtstag.

Norbert Herzog. Dr. sc.techn., dipl. Ing. Chem., Witterswil, Mitglied des SChV, feiert am 14.1.91 seinen 65. Geburtstag.

Kurt Lew, Dr. phil., Riehen, Mitglied des SChV, feiert am 16.1.91 seinen 70. Geburtstag.

Ernest Merian, Dr. Ing. Chem., Therwil, Mitglied des $\mathrm{SChV}$, feiert am 19.1.91 seinen 70. Geburtstag.

Peter Ludwig, Chemiker HTL, Flüelen, Mitglied des SChV, feiert am 28.1.91 seinen 65. Geburtstag.

R.M. Kunz, Dr., Binningen, Mitglied des SChV, feiert am 2.2.91 seinen 80. Geburtstag.

Max Cruchaud, Dr. ċs sci., Thun, Mitglied des SChV, feiert am 15.2.91 seinen 80. Geburtstag.
Willi G. Stoll, Dr. Ing. Chem., Dr. h.c., Bottmingen, Mitglied des SChV, feiert am 25.2.91 seinen 80. Geburtstag.

\section{Neue Mitglieder}

Hans-Frieder Beer, Dipl. Chem., Dr. phil. nat., Ze]glistrasse 36, 5417 Untersiggenthal.

Cosimo De Caro, Dipl. Chem. ETH, Hofwiesenstrasse, 8050 Zürich.

Peter Hauser, Dr., Hönggerstrasse 10, 8037 Zürich.

Rohert Kuhn, Dr chem., Wiesendamm 10b, 4057 Basel.

André Peter, Cheniker HTL, Bruggwiesenstrasse 8 8307 Effretikon.

Veronique Nery, Ingenieur en chimie ETS, Bugnon 37. 1020 Renens.

\section{Chemie-Aussenhandel Januar bis September 1990}

I.C. - Die Exporte von chemischen Erzeugnissen haben in den ersten neun Monaten dieses Jahres gegen über der entsprechenden Vorjahresperiode um 5,2\% auf SFr. 14,0 Mrd. zugenommen. Gleichzeitig sind di Importe um $0,3 \%$ auf SFr. 8,0 Mrd. gesunken. Im Vergleich mit den Wachstumsraten der Vorjahresperiode (Exporte: $12,8 \%$, Importe: $16,7 \%$ ) ergibt sich eine deutliche Abschwächung der Aussenhandelsdynamik. Der Exportüberschuss der chemischen Industric steigerte sich weiter um 13,3\% auf SFr. 6,0 Mrd.

Infolge der international schwächeren Konjunktu und des wiedererstarkten Schweizer Frankens hat das Ausfuhrwachstum wesentlich an Dynamik eingebüsst. Dies trifft insbesondere für die Ausfuhren nach den USA $(0,1 \%$ nach $15,4 \%$ im Vorjahr) und nach Japan ( $2 \%$ nach $17,1 \%$ im Vorjahr) zu. In geringerem Aus mass hat sich auch das Wachstum der Ausfuhren nach der EG $(7,5 \%$ nach $16,1 \%$ im Vorjahr $)$ abgeschwächt. Eine bemerkenswerte Ausnahme von dieser generellcn Entwicklung bilden die Exporte nach West-Deutschland, die eine mit einem Zuwachs von $11,1 \%$ im Vergleich zum Vorjahr $(7,6 \%)$ sogar steigende Tendenz aufwiesen.

Die Importe von chemischen Produkten haben in der Berichtsperiode um 0,3\% aur SFr. 8,0 Mrd. abgenommen, während sie in der Vorjahresperiode noch um $16.7 \%$ zugenommen haben. Einzig der Import aus dem europäischen Raum weist noch positive Wachs tumsraten auf. Bemerkenswert ist vor allem die Steigerung der Importe aus West-Deutschland um 3,2\% $(+13,9 \%)$

\section{Internationales Farbensymposium 11th International Colour Symposium}

23.-26. September 1991

Montreux

Schweiz/Switzerland

Der Schweizerische Chemiker-Verband, die Schweizerische Chemische Gesellschaft und die Gesellschaft Deutscher Chemiker laden ein zum 11. Internationalen Farbensymposium. Das Farbensymposium wird seit 1960 von deutschen und schweizerischen Farbenchemikern veranstaltet. Es setzt sich zum Ziel, anhand von Erkenntnissen und Entwicklungen die Bedeutung de Farbenchemie auf den verschiedenen Gebieten von Wissenschaft und Praxis darzustellen.

The Swiss Association of Chemists, the Swiss Chemical Society and the Society of German Chemists ar organizing the 11 th International Colour Symposium. The Colour Symposium has been organized by German and Swiss chemical scientists since 1960. The ain is to present the importance of the dyestuff chemistry in science and technology by means of new research results and developments.
Wissenschaftliches Komitec Scientific Committee:

Dr. D. Wyrsch (Chairman), Ciba-Geigy AG Basel Prof. Dr. H Balli, Institut für Farbenchemic Basel; Dr. H. H. Bosshard, Ciba-Geigy AG Basel: Dr. R. Entschel, Sandoz AG Basel; Prof. Dr. P. Müller, Schweiz. Chemiker-Verband: PD Dr. R. Naef, Ciba-Geigy AG Basel:

Dr. R.H. Rupp, Hoechst AG Frankfurt: Prof. Dr. P. Rys, ETH Zürich

Das definitive Programm sowie die Anmeldeunterlagen sind im April 1991 crhältlich bei: The definitive programme and registration documents will be availsble in April 1991 at

Sekretariat Symposien SChV, Instilut für Organische Chemie, Frciestrasse 3, CH 3012 Bern (Tel. 031) 654311 , Fax 031654499 , Telex 912406 unich).

\section{Kurzvorträge und Posters/}

\section{Short Contributions and Posters}

Es ist vorgesehen. Kurzvorträge (20 Minuten) und eine Postersession zu präsenticren. Interessenten für einen Kurzyortrag oder einen Poster sind gebetch. Anmeldung und Abstract (max. I A4-Seite) bis 31. Januar 1991 zu schicken an:

It is planned to present short contributions $(20 \mathrm{minu}$ tes) and a postersession. Applications for a short contribution or a poster and an abstract (max. 1 A4-page) should be sent before January 31, 1991 to:

Prof. Dr. H. Balli

Institute of Colour Chemistry, University of Basle St. Johannsvorstadt 10

$\mathrm{CH}-4056$ Basle

\section{Bei der Redaktion eingetroffene Bücher}

Horst lbelgaufts, Gentechnologie von $A$ bis $Z$. Studienausgabe, VCH, Weinheim-New York- Basel Cambridge, 1990, VIII, 486 S., 290 Abb., 15 Tab., DM 64. -

Robert J. Hurtubise, Phosphorimetry, Theory, Instrumentation, and Applications, VCH, WeinheimNew York-Basel Cambridge, 1990, XII, 370 p., 62 figs., 45 tables, DM 114.-, $£ 45.00$.

Instrumental Surface Analysis of Geologic Materials, Dale L. Perry, VCH, Weinheim New York-Basel-Cambridge, 1990, IX, 373 p., 116 figs., 10 tables. DM 112,--, £40.50

Gerhard Schomburg, Gas Chromatography, A Practical Course, VCH, Weinheim-New York-BaselCambridge, 1990, 318 p., 126 figs., DM 76.-

\section{Ehrungen}

Den Doktortitel ehrenhalber erhielten am ETH-Tag in Zürich (17. November 1990) u. a. Prof. Dr. André Dreiding (Organische Chemie, Universität Zürich) und Prof. Dr. Ernst Schumacher (Anorganische und physikalische Chemie, Universität Bern).

\section{Glossary of bioanalytical nomenclature}

\section{Synopsis}

Many disciplines are involved in the practice of clinical laboratory medicine, with each having its own set of technical terminology. Consequently, the terminology used in the clinical laboratory is often vague, inexact, and in some cases, even in discord with conventional and officially-approved terminology. In order to help rectify this situation, a general set of bioanalytical definitions have been compiled and collated from documents from several national and international organiations with the emphasis on those prepared by the International Federation of Clinical Chemistry (IFCC), the International Union of Pure and Applied Chemistry (IUPAC), and the International Union of Biochemistry (IUB). References are included for each definition included. This document includes section on General Terminology, Body Fluids, Enzymology and Immunology. Other topics will be included in sub- 
Die schweizerische chemische Industrie ist vorerst für den Vollzug der geltenden Luftreinhalte-Verordnung

I.C. - Die geltende Luftreinhalte-Verordnung (LRV) ist seit gut viereinhalb Jahren in Kraft. Dic Unternehmen der chemischen Industrie der Schweiz haben sich von Beginn an voll hinter diese Verordnung gestellt. Sie sind bereit, die notwendigen lnvestitionen von einigen hundert Millionen Franken vorzunehmen Sie benötigen dazu aber die in der Verordnung vorgesehenen Sanierungsfristen von bis zu zehn Jahren und müssen sich auf Rechtsgrundlagen abstützen können dic während der üblichen Abschreibungsfristen ihre Gültigkeit bewahren.

Die chemische Industrie der Schweiz steht voll hinter den Zielen des Umweltschutzes als Ganzem und der Luftreinhaltung im besonderen. Sie bekennt sich auch zum Verursacher- und Vorsorgeprinzip. Beim Vollzus der kostspieligen Verordnungen muss sic sich jedoch auf Rechtsgrundlagen und Normen abstützen können. die mindestens während der landläufig üblichen $\mathrm{Ab}$ schreibungsfristen gültig bleiben.

Die jetzl geltende LRV wurde auf den I. März 1986 in Kraft gesetzt. Je nach dem Mass der Überschreitung der Emissionsgrenzwerte sieht sic realistischerweise Sanierungsfristen von bis zu zehn Jahren vor. Den Kantonen wurde eine Frist für den Erlass der Sanierungsverfügungen von bis zu zwei Jahren eingeräumt. Es kann also bis 1998 dauern, bis Industrie und Gewerbe alle notwendigen, auch die unbedeutenden, Massnahmen vollzogen haben.

Die Zicle der LRV können heule, mitten in der Vollzugsphase, noch gar nicht erreicht sein. Allgemein ist auch bekannt, dass erst etwa ein Drittel der Kantone mit dem Vollzug der LRV auf gutem Weg ist. Zwe Drittel hinken zum Teil noch weit hintennach. Die Schweizerische Gesellschaft für Chemische Industrie (SGCI) vertritt die Auffassung, dass der Vollzug der bestehenden Verordnung in allen Landesteilen etwa den gleichen Stand erreicht haben sollte, bevor neue Vorschriften erlassen werden. Dies gilt in unserem kleinräumigen Land vor allem für die Massnahmen zur Luftreinhaltung.

Dic SGCl erachtet es als falsch, die Luftreinhaltung als isoliertes Ziel des Umweltschutzes zu betrachten Umweltschutz als Ganzes muss der Zweek der Übung sein. Viele der im Entwurf zur Revision der LRV vorgeschlagenen Massnahmen lassen einen solchen gesamtheitlichen Blick jedoch vermissen. Je geringer die $\mathrm{zu}$ entfernenden Schadstoffanteile nämlich sind und je inlensiver Abgase und Waschflüssigkeiten umgewälz werden, desto grösser ist der Stromverbrauch zum Antrieb der Pumpen und Ventilatoren.

Die Schweiz besitzt, auch nach Meinung der Behörden, bereits jetzt eine im internationalen Vergleich sehr strenge Luftreinhalte-Verordnung. Die Frist für deren gänzlichen Vollzug ist aber noch nicht einmal zur Hälfte verstrichen. Im Interesse der Rechtssicherheit verlangt daher die $\mathrm{SGCl}$, es sei mit Revisionen, soweit sie festgeschriebene Grenzwerte betreffen, zuzuwarten, bis die vorgesehenen Fristen abgelaufen sind.

\section{Personalia}

\section{Geburtstage}

Hans Felix, Chemiker HTL, Muttenz, Mitglied des SChV, feiert am 1.1.91 seinen 65. Geburtstag.

Norbert Herzog. Dr. sc.techn., dipl. Ing. Chem., Witterswil, Mitglied des SChV, feiert am 14.1.91 seinen 65. Geburtstag.

Kurt Lew, Dr. phil., Riehen, Mitglied des SChV, feiert am 16.1.91 seinen 70. Geburtstag.

Ernest Merian, Dr. Ing. Chem., Therwil, Mitglied des $\mathrm{SChV}$, feiert am 19.1.91 seinen 70. Geburtstag.

Peter Ludwig, Chemiker HTL, Flüelen, Mitglied des SChV, feiert am 28.1.91 seinen 65. Geburtstag.

R.M. Kunz, Dr., Binningen, Mitglied des SChV, feiert am 2.2.91 seinen 80. Geburtstag.

Max Cruchaud, Dr. ċs sci., Thun, Mitglied des SChV, feiert am 15.2.91 seinen 80. Geburtstag.
Willi G. Stoll, Dr. Ing. Chem., Dr. h.c., Bottmingen, Mitglied des SChV, feiert am 25.2.91 seinen 80. Geburtstag.

\section{Neue Mitglieder}

Hans-Frieder Beer, Dipl. Chem., Dr. phil. nat., Ze]glistrasse 36, 5417 Untersiggenthal.

Cosimo De Caro, Dipl. Chem. ETH, Hofwiesenstrasse, 8050 Zürich.

Peter Hauser, Dr., Hönggerstrasse 10, 8037 Zürich.

Rohert Kuhn, Dr chem., Wiesendamm 10b, 4057 Basel.

André Peter, Cheniker HTL, Bruggwiesenstrasse 8 8307 Effretikon.

Veronique Nery, Ingenieur en chimie ETS, Bugnon 37. 1020 Renens.

\section{Chemie-Aussenhandel Januar bis September 1990}

I.C. - Die Exporte von chemischen Erzeugnissen haben in den ersten neun Monaten dieses Jahres gegen über der entsprechenden Vorjahresperiode um 5,2\% auf SFr. 14,0 Mrd. zugenommen. Gleichzeitig sind di Importe um $0,3 \%$ auf SFr. 8,0 Mrd. gesunken. Im Vergleich mit den Wachstumsraten der Vorjahresperiode (Exporte: $12,8 \%$, Importe: $16,7 \%$ ) ergibt sich eine deutliche Abschwächung der Aussenhandelsdynamik. Der Exportüberschuss der chemischen Industric steigerte sich weiter um 13,3\% auf SFr. 6,0 Mrd.

Infolge der international schwächeren Konjunktu und des wiedererstarkten Schweizer Frankens hat das Ausfuhrwachstum wesentlich an Dynamik eingebüsst. Dies trifft insbesondere für die Ausfuhren nach den USA $(0,1 \%$ nach $15,4 \%$ im Vorjahr) und nach Japan ( $2 \%$ nach $17,1 \%$ im Vorjahr) zu. In geringerem Aus mass hat sich auch das Wachstum der Ausfuhren nach der EG $(7,5 \%$ nach $16,1 \%$ im Vorjahr $)$ abgeschwächt. Eine bemerkenswerte Ausnahme von dieser generellcn Entwicklung bilden die Exporte nach West-Deutschland, die eine mit einem Zuwachs von $11,1 \%$ im Vergleich zum Vorjahr $(7,6 \%)$ sogar steigende Tendenz aufwiesen.

Die Importe von chemischen Produkten haben in der Berichtsperiode um 0,3\% aur SFr. 8,0 Mrd. abgenommen, während sie in der Vorjahresperiode noch um $16.7 \%$ zugenommen haben. Einzig der Import aus dem europäischen Raum weist noch positive Wachs tumsraten auf. Bemerkenswert ist vor allem die Steigerung der Importe aus West-Deutschland um 3,2\% $(+13,9 \%)$

\section{Internationales Farbensymposium 11th International Colour Symposium}

23.-26. September 1991

Montreux

Schweiz/Switzerland

Der Schweizerische Chemiker-Verband, die Schweizerische Chemische Gesellschaft und die Gesellschaft Deutscher Chemiker laden ein zum 11. Internationalen Farbensymposium. Das Farbensymposium wird seit 1960 von deutschen und schweizerischen Farbenchemikern veranstaltet. Es setzt sich zum Ziel, anhand von Erkenntnissen und Entwicklungen die Bedeutung de Farbenchemie auf den verschiedenen Gebieten von Wissenschaft und Praxis darzustellen.

The Swiss Association of Chemists, the Swiss Chemical Society and the Society of German Chemists ar organizing the 11 th International Colour Symposium. The Colour Symposium has been organized by German and Swiss chemical scientists since 1960. The ain is to present the importance of the dyestuff chemistry in science and technology by means of new research results and developments.
Wissenschaftliches Komitec Scientific Committee:

Dr. D. Wyrsch (Chairman), Ciba-Geigy AG Basel Prof. Dr. H Balli, Institut für Farbenchemic Basel; Dr. H. H. Bosshard, Ciba-Geigy AG Basel: Dr. R. Entschel, Sandoz AG Basel; Prof. Dr. P. Müller, Schweiz. Chemiker-Verband: PD Dr. R. Naef, Ciba-Geigy AG Basel:

Dr. R.H. Rupp, Hoechst AG Frankfurt: Prof. Dr. P. Rys, ETH Zürich

Das definitive Programm sowie die Anmeldeunterlagen sind im April 1991 crhältlich bei: The definitive programme and registration documents will be availsble in April 1991 at

Sekretariat Symposien SChV, Instilut für Organische Chemie, Frciestrasse 3, CH 3012 Bern (Tel. 031) 654311 , Fax 031654499 , Telex 912406 unich).

\section{Kurzvorträge und Posters/}

\section{Short Contributions and Posters}

Es ist vorgesehen. Kurzvorträge (20 Minuten) und eine Postersession zu präsenticren. Interessenten für einen Kurzyortrag oder einen Poster sind gebetch. Anmeldung und Abstract (max. I A4-Seite) bis 31. Januar 1991 zu schicken an:

It is planned to present short contributions $(20 \mathrm{minu}$ tes) and a postersession. Applications for a short contribution or a poster and an abstract (max. 1 A4-page) should be sent before January 31, 1991 to:

Prof. Dr. H. Balli

Institute of Colour Chemistry, University of Basle St. Johannsvorstadt 10

$\mathrm{CH}-4056$ Basle

\section{Bei der Redaktion eingetroffene Bücher}

Horst lbelgaufts, Gentechnologie von $A$ bis $Z$. Studienausgabe, VCH, Weinheim-New York- Basel Cambridge, 1990, VIII, 486 S., 290 Abb., 15 Tab., DM 64. -

Robert J. Hurtubise, Phosphorimetry, Theory, Instrumentation, and Applications, VCH, WeinheimNew York-Basel Cambridge, 1990, XII, 370 p., 62 figs., 45 tables, DM 114.-, $£ 45.00$.

Instrumental Surface Analysis of Geologic Materials, Dale L. Perry, VCH, Weinheim New York-Basel-Cambridge, 1990, IX, 373 p., 116 figs., 10 tables. DM 112,--, £40.50

Gerhard Schomburg, Gas Chromatography, A Practical Course, VCH, Weinheim-New York-BaselCambridge, 1990, 318 p., 126 figs., DM 76.-

\section{Ehrungen}

Den Doktortitel ehrenhalber erhielten am ETH-Tag in Zürich (17. November 1990) u. a. Prof. Dr. André Dreiding (Organische Chemie, Universität Zürich) und Prof. Dr. Ernst Schumacher (Anorganische und physikalische Chemie, Universität Bern).

\section{Glossary of bioanalytical nomenclature}

\section{Synopsis}

Many disciplines are involved in the practice of clinical laboratory medicine, with each having its own set of technical terminology. Consequently, the terminology used in the clinical laboratory is often vague, inexact, and in some cases, even in discord with conventional and officially-approved terminology. In order to help rectify this situation, a general set of bioanalytical definitions have been compiled and collated from documents from several national and international organiations with the emphasis on those prepared by the International Federation of Clinical Chemistry (IFCC), the International Union of Pure and Applied Chemistry (IUPAC), and the International Union of Biochemistry (IUB). References are included for each definition included. This document includes section on General Terminology, Body Fluids, Enzymology and Immunology. Other topics will be included in sub- 
Die schweizerische chemische Industrie ist vorerst für den Vollzug der geltenden Luftreinhalte-Verordnung

I.C. - Die geltende Luftreinhalte-Verordnung (LRV) ist seit gut viereinhalb Jahren in Kraft. Dic Unternehmen der chemischen Industrie der Schweiz haben sich von Beginn an voll hinter diese Verordnung gestellt. Sie sind bereit, die notwendigen lnvestitionen von einigen hundert Millionen Franken vorzunehmen Sie benötigen dazu aber die in der Verordnung vorgesehenen Sanierungsfristen von bis zu zehn Jahren und müssen sich auf Rechtsgrundlagen abstützen können dic während der üblichen Abschreibungsfristen ihre Gültigkeit bewahren.

Die chemische Industrie der Schweiz steht voll hinter den Zielen des Umweltschutzes als Ganzem und der Luftreinhaltung im besonderen. Sie bekennt sich auch zum Verursacher- und Vorsorgeprinzip. Beim Vollzus der kostspieligen Verordnungen muss sic sich jedoch auf Rechtsgrundlagen und Normen abstützen können. die mindestens während der landläufig üblichen $\mathrm{Ab}$ schreibungsfristen gültig bleiben.

Die jetzl geltende LRV wurde auf den I. März 1986 in Kraft gesetzt. Je nach dem Mass der Überschreitung der Emissionsgrenzwerte sieht sic realistischerweise Sanierungsfristen von bis zu zehn Jahren vor. Den Kantonen wurde eine Frist für den Erlass der Sanierungsverfügungen von bis zu zwei Jahren eingeräumt. Es kann also bis 1998 dauern, bis Industrie und Gewerbe alle notwendigen, auch die unbedeutenden, Massnahmen vollzogen haben.

Die Zicle der LRV können heule, mitten in der Vollzugsphase, noch gar nicht erreicht sein. Allgemein ist auch bekannt, dass erst etwa ein Drittel der Kantone mit dem Vollzug der LRV auf gutem Weg ist. Zwe Drittel hinken zum Teil noch weit hintennach. Die Schweizerische Gesellschaft für Chemische Industrie (SGCI) vertritt die Auffassung, dass der Vollzug der bestehenden Verordnung in allen Landesteilen etwa den gleichen Stand erreicht haben sollte, bevor neue Vorschriften erlassen werden. Dies gilt in unserem kleinräumigen Land vor allem für die Massnahmen zur Luftreinhaltung.

Dic SGCl erachtet es als falsch, die Luftreinhaltung als isoliertes Ziel des Umweltschutzes zu betrachten Umweltschutz als Ganzes muss der Zweek der Übung sein. Viele der im Entwurf zur Revision der LRV vorgeschlagenen Massnahmen lassen einen solchen gesamtheitlichen Blick jedoch vermissen. Je geringer die $\mathrm{zu}$ entfernenden Schadstoffanteile nämlich sind und je inlensiver Abgase und Waschflüssigkeiten umgewälz werden, desto grösser ist der Stromverbrauch zum Antrieb der Pumpen und Ventilatoren.

Die Schweiz besitzt, auch nach Meinung der Behörden, bereits jetzt eine im internationalen Vergleich sehr strenge Luftreinhalte-Verordnung. Die Frist für deren gänzlichen Vollzug ist aber noch nicht einmal zur Hälfte verstrichen. Im Interesse der Rechtssicherheit verlangt daher die $\mathrm{SGCl}$, es sei mit Revisionen, soweit sie festgeschriebene Grenzwerte betreffen, zuzuwarten, bis die vorgesehenen Fristen abgelaufen sind.

\section{Personalia}

\section{Geburtstage}

Hans Felix, Chemiker HTL, Muttenz, Mitglied des SChV, feiert am 1.1.91 seinen 65. Geburtstag.

Norbert Herzog. Dr. sc.techn., dipl. Ing. Chem., Witterswil, Mitglied des SChV, feiert am 14.1.91 seinen 65. Geburtstag.

Kurt Lew, Dr. phil., Riehen, Mitglied des SChV, feiert am 16.1.91 seinen 70. Geburtstag.

Ernest Merian, Dr. Ing. Chem., Therwil, Mitglied des $\mathrm{SChV}$, feiert am 19.1.91 seinen 70. Geburtstag.

Peter Ludwig, Chemiker HTL, Flüelen, Mitglied des SChV, feiert am 28.1.91 seinen 65. Geburtstag.

R.M. Kunz, Dr., Binningen, Mitglied des SChV, feiert am 2.2.91 seinen 80. Geburtstag.

Max Cruchaud, Dr. ċs sci., Thun, Mitglied des SChV, feiert am 15.2.91 seinen 80. Geburtstag.
Willi G. Stoll, Dr. Ing. Chem., Dr. h.c., Bottmingen, Mitglied des SChV, feiert am 25.2.91 seinen 80. Geburtstag.

\section{Neue Mitglieder}

Hans-Frieder Beer, Dipl. Chem., Dr. phil. nat., Ze]glistrasse 36, 5417 Untersiggenthal.

Cosimo De Caro, Dipl. Chem. ETH, Hofwiesenstrasse, 8050 Zürich.

Peter Hauser, Dr., Hönggerstrasse 10, 8037 Zürich.

Rohert Kuhn, Dr chem., Wiesendamm 10b, 4057 Basel.

André Peter, Cheniker HTL, Bruggwiesenstrasse 8 8307 Effretikon.

Veronique Nery, Ingenieur en chimie ETS, Bugnon 37. 1020 Renens.

\section{Chemie-Aussenhandel Januar bis September 1990}

I.C. - Die Exporte von chemischen Erzeugnissen haben in den ersten neun Monaten dieses Jahres gegen über der entsprechenden Vorjahresperiode um 5,2\% auf SFr. 14,0 Mrd. zugenommen. Gleichzeitig sind di Importe um $0,3 \%$ auf SFr. 8,0 Mrd. gesunken. Im Vergleich mit den Wachstumsraten der Vorjahresperiode (Exporte: $12,8 \%$, Importe: $16,7 \%$ ) ergibt sich eine deutliche Abschwächung der Aussenhandelsdynamik. Der Exportüberschuss der chemischen Industric steigerte sich weiter um 13,3\% auf SFr. 6,0 Mrd.

Infolge der international schwächeren Konjunktu und des wiedererstarkten Schweizer Frankens hat das Ausfuhrwachstum wesentlich an Dynamik eingebüsst. Dies trifft insbesondere für die Ausfuhren nach den USA $(0,1 \%$ nach $15,4 \%$ im Vorjahr) und nach Japan ( $2 \%$ nach $17,1 \%$ im Vorjahr) zu. In geringerem Aus mass hat sich auch das Wachstum der Ausfuhren nach der EG $(7,5 \%$ nach $16,1 \%$ im Vorjahr $)$ abgeschwächt. Eine bemerkenswerte Ausnahme von dieser generellcn Entwicklung bilden die Exporte nach West-Deutschland, die eine mit einem Zuwachs von $11,1 \%$ im Vergleich zum Vorjahr $(7,6 \%)$ sogar steigende Tendenz aufwiesen.

Die Importe von chemischen Produkten haben in der Berichtsperiode um 0,3\% aur SFr. 8,0 Mrd. abgenommen, während sie in der Vorjahresperiode noch um $16.7 \%$ zugenommen haben. Einzig der Import aus dem europäischen Raum weist noch positive Wachs tumsraten auf. Bemerkenswert ist vor allem die Steigerung der Importe aus West-Deutschland um 3,2\% $(+13,9 \%)$

\section{Internationales Farbensymposium 11th International Colour Symposium}

23.-26. September 1991

Montreux

Schweiz/Switzerland

Der Schweizerische Chemiker-Verband, die Schweizerische Chemische Gesellschaft und die Gesellschaft Deutscher Chemiker laden ein zum 11. Internationalen Farbensymposium. Das Farbensymposium wird seit 1960 von deutschen und schweizerischen Farbenchemikern veranstaltet. Es setzt sich zum Ziel, anhand von Erkenntnissen und Entwicklungen die Bedeutung de Farbenchemie auf den verschiedenen Gebieten von Wissenschaft und Praxis darzustellen.

The Swiss Association of Chemists, the Swiss Chemical Society and the Society of German Chemists ar organizing the 11 th International Colour Symposium. The Colour Symposium has been organized by German and Swiss chemical scientists since 1960. The ain is to present the importance of the dyestuff chemistry in science and technology by means of new research results and developments.
Wissenschaftliches Komitec Scientific Committee:

Dr. D. Wyrsch (Chairman), Ciba-Geigy AG Basel Prof. Dr. H Balli, Institut für Farbenchemic Basel; Dr. H. H. Bosshard, Ciba-Geigy AG Basel: Dr. R. Entschel, Sandoz AG Basel; Prof. Dr. P. Müller, Schweiz. Chemiker-Verband: PD Dr. R. Naef, Ciba-Geigy AG Basel:

Dr. R.H. Rupp, Hoechst AG Frankfurt: Prof. Dr. P. Rys, ETH Zürich

Das definitive Programm sowie die Anmeldeunterlagen sind im April 1991 crhältlich bei: The definitive programme and registration documents will be availsble in April 1991 at

Sekretariat Symposien SChV, Instilut für Organische Chemie, Frciestrasse 3, CH 3012 Bern (Tel. 031) 654311 , Fax 031654499 , Telex 912406 unich).

\section{Kurzvorträge und Posters/}

\section{Short Contributions and Posters}

Es ist vorgesehen. Kurzvorträge (20 Minuten) und eine Postersession zu präsenticren. Interessenten für einen Kurzyortrag oder einen Poster sind gebetch. Anmeldung und Abstract (max. I A4-Seite) bis 31. Januar 1991 zu schicken an:

It is planned to present short contributions $(20 \mathrm{minu}$ tes) and a postersession. Applications for a short contribution or a poster and an abstract (max. 1 A4-page) should be sent before January 31, 1991 to:

Prof. Dr. H. Balli

Institute of Colour Chemistry, University of Basle St. Johannsvorstadt 10

$\mathrm{CH}-4056$ Basle

\section{Bei der Redaktion eingetroffene Bücher}

Horst lbelgaufts, Gentechnologie von $A$ bis $Z$. Studienausgabe, VCH, Weinheim-New York- Basel Cambridge, 1990, VIII, 486 S., 290 Abb., 15 Tab., DM 64. -

Robert J. Hurtubise, Phosphorimetry, Theory, Instrumentation, and Applications, VCH, WeinheimNew York-Basel Cambridge, 1990, XII, 370 p., 62 figs., 45 tables, DM 114.-, $£ 45.00$.

Instrumental Surface Analysis of Geologic Materials, Dale L. Perry, VCH, Weinheim New York-Basel-Cambridge, 1990, IX, 373 p., 116 figs., 10 tables. DM 112,--, £40.50

Gerhard Schomburg, Gas Chromatography, A Practical Course, VCH, Weinheim-New York-BaselCambridge, 1990, 318 p., 126 figs., DM 76.-

\section{Ehrungen}

Den Doktortitel ehrenhalber erhielten am ETH-Tag in Zürich (17. November 1990) u. a. Prof. Dr. André Dreiding (Organische Chemie, Universität Zürich) und Prof. Dr. Ernst Schumacher (Anorganische und physikalische Chemie, Universität Bern).

\section{Glossary of bioanalytical nomenclature}

\section{Synopsis}

Many disciplines are involved in the practice of clinical laboratory medicine, with each having its own set of technical terminology. Consequently, the terminology used in the clinical laboratory is often vague, inexact, and in some cases, even in discord with conventional and officially-approved terminology. In order to help rectify this situation, a general set of bioanalytical definitions have been compiled and collated from documents from several national and international organiations with the emphasis on those prepared by the International Federation of Clinical Chemistry (IFCC), the International Union of Pure and Applied Chemistry (IUPAC), and the International Union of Biochemistry (IUB). References are included for each definition included. This document includes section on General Terminology, Body Fluids, Enzymology and Immunology. Other topics will be included in sub- 
Die schweizerische chemische Industrie ist vorerst für den Vollzug der geltenden Luftreinhalte-Verordnung

I.C. - Die geltende Luftreinhalte-Verordnung (LRV) ist seit gut viereinhalb Jahren in Kraft. Dic Unternehmen der chemischen Industrie der Schweiz haben sich von Beginn an voll hinter diese Verordnung gestellt. Sie sind bereit, die notwendigen lnvestitionen von einigen hundert Millionen Franken vorzunehmen Sie benötigen dazu aber die in der Verordnung vorgesehenen Sanierungsfristen von bis zu zehn Jahren und müssen sich auf Rechtsgrundlagen abstützen können dic während der üblichen Abschreibungsfristen ihre Gültigkeit bewahren.

Die chemische Industrie der Schweiz steht voll hinter den Zielen des Umweltschutzes als Ganzem und der Luftreinhaltung im besonderen. Sie bekennt sich auch zum Verursacher- und Vorsorgeprinzip. Beim Vollzus der kostspieligen Verordnungen muss sic sich jedoch auf Rechtsgrundlagen und Normen abstützen können. die mindestens während der landläufig üblichen $\mathrm{Ab}$ schreibungsfristen gültig bleiben.

Die jetzl geltende LRV wurde auf den I. März 1986 in Kraft gesetzt. Je nach dem Mass der Überschreitung der Emissionsgrenzwerte sieht sic realistischerweise Sanierungsfristen von bis zu zehn Jahren vor. Den Kantonen wurde eine Frist für den Erlass der Sanierungsverfügungen von bis zu zwei Jahren eingeräumt. Es kann also bis 1998 dauern, bis Industrie und Gewerbe alle notwendigen, auch die unbedeutenden, Massnahmen vollzogen haben.

Die Zicle der LRV können heule, mitten in der Vollzugsphase, noch gar nicht erreicht sein. Allgemein ist auch bekannt, dass erst etwa ein Drittel der Kantone mit dem Vollzug der LRV auf gutem Weg ist. Zwe Drittel hinken zum Teil noch weit hintennach. Die Schweizerische Gesellschaft für Chemische Industrie (SGCI) vertritt die Auffassung, dass der Vollzug der bestehenden Verordnung in allen Landesteilen etwa den gleichen Stand erreicht haben sollte, bevor neue Vorschriften erlassen werden. Dies gilt in unserem kleinräumigen Land vor allem für die Massnahmen zur Luftreinhaltung.

Dic SGCl erachtet es als falsch, die Luftreinhaltung als isoliertes Ziel des Umweltschutzes zu betrachten Umweltschutz als Ganzes muss der Zweek der Übung sein. Viele der im Entwurf zur Revision der LRV vorgeschlagenen Massnahmen lassen einen solchen gesamtheitlichen Blick jedoch vermissen. Je geringer die $\mathrm{zu}$ entfernenden Schadstoffanteile nämlich sind und je inlensiver Abgase und Waschflüssigkeiten umgewälz werden, desto grösser ist der Stromverbrauch zum Antrieb der Pumpen und Ventilatoren.

Die Schweiz besitzt, auch nach Meinung der Behörden, bereits jetzt eine im internationalen Vergleich sehr strenge Luftreinhalte-Verordnung. Die Frist für deren gänzlichen Vollzug ist aber noch nicht einmal zur Hälfte verstrichen. Im Interesse der Rechtssicherheit verlangt daher die $\mathrm{SGCl}$, es sei mit Revisionen, soweit sie festgeschriebene Grenzwerte betreffen, zuzuwarten, bis die vorgesehenen Fristen abgelaufen sind.

\section{Personalia}

\section{Geburtstage}

Hans Felix, Chemiker HTL, Muttenz, Mitglied des SChV, feiert am 1.1.91 seinen 65. Geburtstag.

Norbert Herzog. Dr. sc.techn., dipl. Ing. Chem., Witterswil, Mitglied des SChV, feiert am 14.1.91 seinen 65. Geburtstag.

Kurt Lew, Dr. phil., Riehen, Mitglied des SChV, feiert am 16.1.91 seinen 70. Geburtstag.

Ernest Merian, Dr. Ing. Chem., Therwil, Mitglied des $\mathrm{SChV}$, feiert am 19.1.91 seinen 70. Geburtstag.

Peter Ludwig, Chemiker HTL, Flüelen, Mitglied des SChV, feiert am 28.1.91 seinen 65. Geburtstag.

R.M. Kunz, Dr., Binningen, Mitglied des SChV, feiert am 2.2.91 seinen 80. Geburtstag.

Max Cruchaud, Dr. ċs sci., Thun, Mitglied des SChV, feiert am 15.2.91 seinen 80. Geburtstag.
Willi G. Stoll, Dr. Ing. Chem., Dr. h.c., Bottmingen, Mitglied des SChV, feiert am 25.2.91 seinen 80. Geburtstag.

\section{Neue Mitglieder}

Hans-Frieder Beer, Dipl. Chem., Dr. phil. nat., Ze]glistrasse 36, 5417 Untersiggenthal.

Cosimo De Caro, Dipl. Chem. ETH, Hofwiesenstrasse, 8050 Zürich.

Peter Hauser, Dr., Hönggerstrasse 10, 8037 Zürich.

Rohert Kuhn, Dr chem., Wiesendamm 10b, 4057 Basel.

André Peter, Cheniker HTL, Bruggwiesenstrasse 8 8307 Effretikon.

Veronique Nery, Ingenieur en chimie ETS, Bugnon 37. 1020 Renens.

\section{Chemie-Aussenhandel Januar bis September 1990}

I.C. - Die Exporte von chemischen Erzeugnissen haben in den ersten neun Monaten dieses Jahres gegen über der entsprechenden Vorjahresperiode um 5,2\% auf SFr. 14,0 Mrd. zugenommen. Gleichzeitig sind di Importe um $0,3 \%$ auf SFr. 8,0 Mrd. gesunken. Im Vergleich mit den Wachstumsraten der Vorjahresperiode (Exporte: $12,8 \%$, Importe: $16,7 \%$ ) ergibt sich eine deutliche Abschwächung der Aussenhandelsdynamik. Der Exportüberschuss der chemischen Industric steigerte sich weiter um 13,3\% auf SFr. 6,0 Mrd.

Infolge der international schwächeren Konjunktu und des wiedererstarkten Schweizer Frankens hat das Ausfuhrwachstum wesentlich an Dynamik eingebüsst. Dies trifft insbesondere für die Ausfuhren nach den USA $(0,1 \%$ nach $15,4 \%$ im Vorjahr) und nach Japan ( $2 \%$ nach $17,1 \%$ im Vorjahr) zu. In geringerem Aus mass hat sich auch das Wachstum der Ausfuhren nach der EG $(7,5 \%$ nach $16,1 \%$ im Vorjahr $)$ abgeschwächt. Eine bemerkenswerte Ausnahme von dieser generellcn Entwicklung bilden die Exporte nach West-Deutschland, die eine mit einem Zuwachs von $11,1 \%$ im Vergleich zum Vorjahr $(7,6 \%)$ sogar steigende Tendenz aufwiesen.

Die Importe von chemischen Produkten haben in der Berichtsperiode um 0,3\% aur SFr. 8,0 Mrd. abgenommen, während sie in der Vorjahresperiode noch um $16.7 \%$ zugenommen haben. Einzig der Import aus dem europäischen Raum weist noch positive Wachs tumsraten auf. Bemerkenswert ist vor allem die Steigerung der Importe aus West-Deutschland um 3,2\% $(+13,9 \%)$

\section{Internationales Farbensymposium 11th International Colour Symposium}

23.-26. September 1991

Montreux

Schweiz/Switzerland

Der Schweizerische Chemiker-Verband, die Schweizerische Chemische Gesellschaft und die Gesellschaft Deutscher Chemiker laden ein zum 11. Internationalen Farbensymposium. Das Farbensymposium wird seit 1960 von deutschen und schweizerischen Farbenchemikern veranstaltet. Es setzt sich zum Ziel, anhand von Erkenntnissen und Entwicklungen die Bedeutung de Farbenchemie auf den verschiedenen Gebieten von Wissenschaft und Praxis darzustellen.

The Swiss Association of Chemists, the Swiss Chemical Society and the Society of German Chemists ar organizing the 11 th International Colour Symposium. The Colour Symposium has been organized by German and Swiss chemical scientists since 1960. The ain is to present the importance of the dyestuff chemistry in science and technology by means of new research results and developments.
Wissenschaftliches Komitec Scientific Committee:

Dr. D. Wyrsch (Chairman), Ciba-Geigy AG Basel Prof. Dr. H Balli, Institut für Farbenchemic Basel; Dr. H. H. Bosshard, Ciba-Geigy AG Basel: Dr. R. Entschel, Sandoz AG Basel; Prof. Dr. P. Müller, Schweiz. Chemiker-Verband: PD Dr. R. Naef, Ciba-Geigy AG Basel:

Dr. R.H. Rupp, Hoechst AG Frankfurt: Prof. Dr. P. Rys, ETH Zürich

Das definitive Programm sowie die Anmeldeunterlagen sind im April 1991 crhältlich bei: The definitive programme and registration documents will be availsble in April 1991 at

Sekretariat Symposien SChV, Instilut für Organische Chemie, Frciestrasse 3, CH 3012 Bern (Tel. 031) 654311 , Fax 031654499 , Telex 912406 unich).

\section{Kurzvorträge und Posters/}

\section{Short Contributions and Posters}

Es ist vorgesehen. Kurzvorträge (20 Minuten) und eine Postersession zu präsenticren. Interessenten für einen Kurzyortrag oder einen Poster sind gebetch. Anmeldung und Abstract (max. I A4-Seite) bis 31. Januar 1991 zu schicken an:

It is planned to present short contributions $(20 \mathrm{minu}$ tes) and a postersession. Applications for a short contribution or a poster and an abstract (max. 1 A4-page) should be sent before January 31, 1991 to:

Prof. Dr. H. Balli

Institute of Colour Chemistry, University of Basle St. Johannsvorstadt 10

$\mathrm{CH}-4056$ Basle

\section{Bei der Redaktion eingetroffene Bücher}

Horst lbelgaufts, Gentechnologie von $A$ bis $Z$. Studienausgabe, VCH, Weinheim-New York- Basel Cambridge, 1990, VIII, 486 S., 290 Abb., 15 Tab., DM 64. -

Robert J. Hurtubise, Phosphorimetry, Theory, Instrumentation, and Applications, VCH, WeinheimNew York-Basel Cambridge, 1990, XII, 370 p., 62 figs., 45 tables, DM 114.-, $£ 45.00$.

Instrumental Surface Analysis of Geologic Materials, Dale L. Perry, VCH, Weinheim New York-Basel-Cambridge, 1990, IX, 373 p., 116 figs., 10 tables. DM 112,--, £40.50

Gerhard Schomburg, Gas Chromatography, A Practical Course, VCH, Weinheim-New York-BaselCambridge, 1990, 318 p., 126 figs., DM 76.-

\section{Ehrungen}

Den Doktortitel ehrenhalber erhielten am ETH-Tag in Zürich (17. November 1990) u. a. Prof. Dr. André Dreiding (Organische Chemie, Universität Zürich) und Prof. Dr. Ernst Schumacher (Anorganische und physikalische Chemie, Universität Bern).

\section{Glossary of bioanalytical nomenclature}

\section{Synopsis}

Many disciplines are involved in the practice of clinical laboratory medicine, with each having its own set of technical terminology. Consequently, the terminology used in the clinical laboratory is often vague, inexact, and in some cases, even in discord with conventional and officially-approved terminology. In order to help rectify this situation, a general set of bioanalytical definitions have been compiled and collated from documents from several national and international organiations with the emphasis on those prepared by the International Federation of Clinical Chemistry (IFCC), the International Union of Pure and Applied Chemistry (IUPAC), and the International Union of Biochemistry (IUB). References are included for each definition included. This document includes section on General Terminology, Body Fluids, Enzymology and Immunology. Other topics will be included in sub- 
sequent documents. It is hoped that this set of bioanalytical definitions will be useful to the practitioners of clinical chemistry and will foster improved communications and understanding between them.

Comments on the document are welcome and should be sent by 31st October 1991 to: Dr Carl A. Burtis, Oak Ridge National Laboratory, P. O. Box 2008, Bldg. 4500-N, MS 6194, Oak Ridge, Tennessee 37831, USA

\section{Chemie-Sicherheitspreis der ESCIS 1990}

Die ESCIS (Expertenkommission für Sicherheit in der chemischen Industrie der Schweiz) ist ein unabhängiges Gremium, das sich aus Persönlichkeiten der chemischen Industric, des Bundes (BIGA), der SUVA und von Hochschulen zusammensetzt. Dieses Gremium be fasst sich mit ciner Vielfalt von Sicherheitsfragen und praxisnahcn Lösungsmöglichkeiten für Sicherheitsprobleme und tritt mit verschiedenen technisch orientierten Publikationen sowie Ausbildungskursen an die Öffentlichkeit. Eines der wesentlichsten Anliegen der ESCIS ist die Förderung des Sicherheitsdenkens und insbesondere der Einbezug der Sicherheitsbelange in die Unterrichtsprogramme an Ausbildungsstätten.

Anlässlich ihres 25-Jahr-Jubiläums im Jahre 1981 beschloss die ESCIS, einen Preis auszusetzen zur Aus zeichnung von Arbeiten bzw. von besonderen Verdiensten im Sinne dieser Anliegen. Nach 1983 und 1987 wird nunmehr 1990 zum dritten Mal der ESCIS-Preis, der mit 10000 Franken dotiert ist, verliehen

Nach umfangreichen Abklärungen und der Prüfung verschicdener Anträgc hat sich die ESCIS-Iury ent schieden, den für 1990 ausgesetzten ESCIS-Preis in voller Höhe Herrn Dr. Gérard Killé, Dozent an der Ecole Nationale Supérieure de Chimie de Mulhouse, zuzu sprechen. Herr Dr. Killé ist seit Jahren mit grossem Erfolg auf dem Gebiet der wissenschaftlich-technischen Sicherheitsausbildung tätig und verleiht diese Ausbildung an der Ecole Nationale Supérieure de Chimic de Muthouse insbesondere mit Spezialkursen starke Jmpulse.

Die offizielle Übergabe des ESCIS-Preises an Herrn Dr. Killé hat anlässlich der ILMAC-Eröffnung am 23. Oktober 1990 in Basel stattgefunden.

\section{Wissenschaftlerin des}

\section{Max-Planck-Institutes erhält}

Roche-Auszeichnung in den USA

Dr. Christiane Nüsslein-Volhard, Direktorin des Tübinger Friedrich-Miescher-Laboratoriums in der MaxPlanck-Gesellschaft, ist die diesjährige Preisträgerin des V.D. Mattia Preises von Hoffmann-La Roche Inc. Nutley, USA. Sie erhielt die Auszeichnung für ihre hervorragenden Beiträge zur biomedizinischen Forschung auf dem Gebiet der Entwicklungsgenetik. Dr. Nüsslein-Volhard nahm den Preis kürzlich im Roche Institute for Molecular Biology (RIMB), dem unabhängigen Zentrum für Grundlagenforschung von Hoffmann-La Roche USA, entgegen.

Zu den wichtigsten Forschungsergebnissen von Frau Nüsslein-Volhard gehört der Nachweis, dass mütterliche Gene (sogenannte mütterliche Effekt-Gene) im Ei der Frucht Iliege ausschlaggebend sind für die Ausbildung von Organen und Körpern des Insektes. Durch diese Untersuchungen hat Dr. Nüsslein-Volhard wichtige Prinzipien der Genetik geklärt, die möglicherweise auch für Entwicklungsprozesse anderer Lebewesen Gültigkeit haben.

Christiane Nüsslein-Volhard, in Magdeburg geboren, crwarb 1968 das Diplom für Biochemie und 1973 den Doktor der Biologie an der Universität in Tübingen. Sie hat zahlreiche Ehrungen und Auszeichnungen erhalten, darunter die Carus-Medaille der Deutschen Akademie der Wissenschaften, die Rosenstiel-Medaille sowie den Ehrendoktor der Yale University. Sie is ausserdem Mitglied der U.S. National Academy of Science und der British Royal Society. Seit 1985 leitet Dr. Nüsslein-Volhard die Abteilung für Entwicklungsbiologie am Friedrich-Miescher-Laboratorium in der Max-Planck-Gesellschaft in Tübingen.

Der V. D. Mattia Preis ist nach dem früheren Präsidenten von Hoffmann-La Roche Inc., Nutley und Gründer des RIMB benannt. Unter den bisherigen Prcisträgern finden sich acht spätere Nobelpreisträger.
Zufriedene Besucher und Aussteller an der

24.1.91 ILMAC 90

Nach viertägiger Messedauer schloss die ILMAC 90, die 11. Internationale Fachmesse für Laboratoriumsund Verfahrenstechnik, Messtechnik und Automatik am Freitag 26. Oktober ihrc Tore. Die Aussteller der Chemie-Fachmesse, die in den Hallen der Schweizer Mustermesse durchgeführt wurde, zeigten sich mit dem Messeverlauf durchwegs zufrieden.

Knapp 23750 verkaufte Eintritte bedeuten für die ILMAC 90 ein sehr gutes Besucherergebnis. Liegt doch diescs Resultat im Bereich der vergleichbaren Zahlen von 1987, wobei im damaligen Ergebnis die Besucher der gleichzeitig durchgeführten Apothekerfachmesse lpharmex 87 enthalten sind.

Seitens der rund 480 Aussteller, die auf $16000 \mathrm{~m}^{2}$ Nettostandfläche ihre Dienstleistungen und Produkte anboten, wurde denn auch betont, dass die Besucher nicht nur zahlreicher, sondern vor allem sehr interessiert und kompetent waren. Dies bestitigt auch die von de KONSO, Basel, durchgeführte Besucherumfrage, wonach zwei Drittel der Besucher bei Investitionen mindestens mitentscheidend sind. Die Besucher ihrerseits erteilten auch der Messe gute Noten. So beurteilten fast $60 \%$ der Befragten die ILMAC als eine der wichtigsten Fachmessen der Branche. Der Besucheranteil aus dem Ausland betrug $18 \%$

Reges Interesse fand auch die Sonderschau zum Them 'Explosionsschutz', wo man sich von fachkundige Seite her über die Leistungen der Industrie im Explosionsschutz informieren lassen konnte.

\section{Société vaudoise des sciences naturelles}

Mercredi à $17.15 \mathrm{~h}$, Auditoire C, Collège Propedeutique, Université de Lausanne, Dorigny

1991

9 janvier Prof. A. Storck, ENSIC à Nancy (F)

23 janvier Prof, Dr. P.J. Crutzen, Otto Hahn Institut, Chimie de l'atmosphère à Mainz (D)

7.2 .91 H. Schwarz "Crofitut für Org Chemie. TU Berlin 'Chemie nackter Moleküle'

Prof. Dr. A. Pfalt Institut für Org. Chemie, Universität Base

'Enantioselektive Katalyse mit chiralen Metallkomplexen'

\section{Laboratorium für anorg. Chemie der ETH Zürich}

\section{Koordinationschemie und homogene Katalyse}

Mittwoch, 9.00-10.15, CAB B9

Universitätstrasse 6

9. Januar Prof. Jolm A. Oshorn, Universiti Louis Pasteur, Strasbourg 'Aspects of Enantioselective Hydrogenation with Metal Complexes'

Ende Januar Prof. Lars I. Elding, University of Lund

Der Titel wird später bekanntgegeben

20. Februar Prol, A. Ludi, Universität Bern Struktur und Reaktivität von Kom plexen als Funktion der Ligandenperipherie'

\section{Chemische Gesellschaft Zürich}

Alle Vorträge finden statt: Mittwoch, 17.15 Uhr, Hörsaal CAB D2 im Chemie-Altbau ETH, Universitätstrasse 6, 8092 Zürich.

9. Jan. 1991

Prof. Dr. H. Oeschger Physikalisches Institut Universität Bern, Bern Die sich ändernde Almosphäre; aus der Perspektive der $\mathrm{CO}_{2}$ - und $\mathrm{Kli}$ maschwankungen der Vergangenheit

\section{Institut für Polymere, ETH Zürich}

30. Januar 91

altes Chemiegebäude ETHZ, D28

Prof. Dr. C. D. Eisenbach, Universität Bayreuth

Polymere mit massgeschneiderten supramolekularen Strukturen und Eigenschaften

13. Februar 91

altes Chemiegebäude ETHZ, D28

Prof. Dr. S. Russo, Istituto di Chimica Industriale CNR, Università di Genova

A Novel Synthetic Approach to Poly(caprolactam)-based Materials

20. Februar 91

altes Chemiegebäude ETHZ, D28

Prof. Dr. W. Helfrich, Institut für Theoretische Physik, Freie Universität Berlin

Spontane Vesikulation und kubische Phasen von $\mathrm{Li}$ piddoppelschichten

\section{Basler Chemische Gesellschaft}

(Donnerstag, 16.45 Uhr, im kleinen Hörsaal des Instituts für Organische Chemie)
PD Dr. R. Schwesinger

Institut für Organische Chemie und Biochemie

Universität Freiburg, Freiburg, i. Br., BRD

Extrem starke, ungeladene Phosphazenbasen, 'Komplementüre Metallorganica"

30. Jan. 1991 Prof. Dr. St.G. Daries Department of Organic Chemistry University of Oxford, Oxford, GB Exploiting the law of mass action for synthesis

Prof. Dr. H. Werner

Institut für anorganische Chemio Universität Würzburg, Würzburg, BRD

Aktivierung gesättigter und ungesättigter Kohlenwasserstoffe durch elektronenreiche Ubergangsmetallkomplexe: Der Weg von der Synthese zur Katalyse

rof, Dr. C.W. Hilhers Laboratory of Biophysical ChemisUniversity of Nijmegen, Nijmegen, NMR studies of regularities in unusual DNA struclures 
sequent documents. It is hoped that this set of bioanalytical definitions will be useful to the practitioners of clinical chemistry and will foster improved communications and understanding between them.

Comments on the document are welcome and should be sent by 31st October 1991 to: Dr Carl A. Burtis, Oak Ridge National Laboratory, P. O. Box 2008, Bldg. 4500-N, MS 6194, Oak Ridge, Tennessee 37831, USA

\section{Chemie-Sicherheitspreis der ESCIS 1990}

Die ESCIS (Expertenkommission für Sicherheit in der chemischen Industrie der Schweiz) ist ein unabhängiges Gremium, das sich aus Persönlichkeiten der chemischen Industric, des Bundes (BIGA), der SUVA und von Hochschulen zusammensetzt. Dieses Gremium be fasst sich mit ciner Vielfalt von Sicherheitsfragen und praxisnahcn Lösungsmöglichkeiten für Sicherheitsprobleme und tritt mit verschiedenen technisch orientierten Publikationen sowie Ausbildungskursen an die Öffentlichkeit. Eines der wesentlichsten Anliegen der ESCIS ist die Förderung des Sicherheitsdenkens und insbesondere der Einbezug der Sicherheitsbelange in die Unterrichtsprogramme an Ausbildungsstätten.

Anlässlich ihres 25-Jahr-Jubiläums im Jahre 1981 beschloss die ESCIS, einen Preis auszusetzen zur Aus zeichnung von Arbeiten bzw. von besonderen Verdiensten im Sinne dieser Anliegen. Nach 1983 und 1987 wird nunmehr 1990 zum dritten Mal der ESCIS-Preis, der mit 10000 Franken dotiert ist, verliehen

Nach umfangreichen Abklärungen und der Prüfung verschicdener Anträgc hat sich die ESCIS-Iury ent schieden, den für 1990 ausgesetzten ESCIS-Preis in voller Höhe Herrn Dr. Gérard Killé, Dozent an der Ecole Nationale Supérieure de Chimie de Mulhouse, zuzu sprechen. Herr Dr. Killé ist seit Jahren mit grossem Erfolg auf dem Gebiet der wissenschaftlich-technischen Sicherheitsausbildung tätig und verleiht diese Ausbildung an der Ecole Nationale Supérieure de Chimic de Muthouse insbesondere mit Spezialkursen starke Jmpulse.

Die offizielle Übergabe des ESCIS-Preises an Herrn Dr. Killé hat anlässlich der ILMAC-Eröffnung am 23. Oktober 1990 in Basel stattgefunden.

\section{Wissenschaftlerin des}

\section{Max-Planck-Institutes erhält}

Roche-Auszeichnung in den USA

Dr. Christiane Nüsslein-Volhard, Direktorin des Tübinger Friedrich-Miescher-Laboratoriums in der MaxPlanck-Gesellschaft, ist die diesjährige Preisträgerin des V.D. Mattia Preises von Hoffmann-La Roche Inc. Nutley, USA. Sie erhielt die Auszeichnung für ihre hervorragenden Beiträge zur biomedizinischen Forschung auf dem Gebiet der Entwicklungsgenetik. Dr. Nüsslein-Volhard nahm den Preis kürzlich im Roche Institute for Molecular Biology (RIMB), dem unabhängigen Zentrum für Grundlagenforschung von Hoffmann-La Roche USA, entgegen.

Zu den wichtigsten Forschungsergebnissen von Frau Nüsslein-Volhard gehört der Nachweis, dass mütterliche Gene (sogenannte mütterliche Effekt-Gene) im Ei der Frucht Iliege ausschlaggebend sind für die Ausbildung von Organen und Körpern des Insektes. Durch diese Untersuchungen hat Dr. Nüsslein-Volhard wichtige Prinzipien der Genetik geklärt, die möglicherweise auch für Entwicklungsprozesse anderer Lebewesen Gültigkeit haben.

Christiane Nüsslein-Volhard, in Magdeburg geboren, crwarb 1968 das Diplom für Biochemie und 1973 den Doktor der Biologie an der Universität in Tübingen. Sie hat zahlreiche Ehrungen und Auszeichnungen erhalten, darunter die Carus-Medaille der Deutschen Akademie der Wissenschaften, die Rosenstiel-Medaille sowie den Ehrendoktor der Yale University. Sie is ausserdem Mitglied der U.S. National Academy of Science und der British Royal Society. Seit 1985 leitet Dr. Nüsslein-Volhard die Abteilung für Entwicklungsbiologie am Friedrich-Miescher-Laboratorium in der Max-Planck-Gesellschaft in Tübingen.

Der V. D. Mattia Preis ist nach dem früheren Präsidenten von Hoffmann-La Roche Inc., Nutley und Gründer des RIMB benannt. Unter den bisherigen Prcisträgern finden sich acht spätere Nobelpreisträger.
Zufriedene Besucher und Aussteller an der

24.1.91 ILMAC 90

Nach viertägiger Messedauer schloss die ILMAC 90, die 11. Internationale Fachmesse für Laboratoriumsund Verfahrenstechnik, Messtechnik und Automatik am Freitag 26. Oktober ihrc Tore. Die Aussteller der Chemie-Fachmesse, die in den Hallen der Schweizer Mustermesse durchgeführt wurde, zeigten sich mit dem Messeverlauf durchwegs zufrieden.

Knapp 23750 verkaufte Eintritte bedeuten für die ILMAC 90 ein sehr gutes Besucherergebnis. Liegt doch diescs Resultat im Bereich der vergleichbaren Zahlen von 1987, wobei im damaligen Ergebnis die Besucher der gleichzeitig durchgeführten Apothekerfachmesse lpharmex 87 enthalten sind.

Seitens der rund 480 Aussteller, die auf $16000 \mathrm{~m}^{2}$ Nettostandfläche ihre Dienstleistungen und Produkte anboten, wurde denn auch betont, dass die Besucher nicht nur zahlreicher, sondern vor allem sehr interessiert und kompetent waren. Dies bestitigt auch die von de KONSO, Basel, durchgeführte Besucherumfrage, wonach zwei Drittel der Besucher bei Investitionen mindestens mitentscheidend sind. Die Besucher ihrerseits erteilten auch der Messe gute Noten. So beurteilten fast $60 \%$ der Befragten die ILMAC als eine der wichtigsten Fachmessen der Branche. Der Besucheranteil aus dem Ausland betrug $18 \%$

Reges Interesse fand auch die Sonderschau zum Them 'Explosionsschutz', wo man sich von fachkundige Seite her über die Leistungen der Industrie im Explosionsschutz informieren lassen konnte.

\section{Société vaudoise des sciences naturelles}

Mercredi à $17.15 \mathrm{~h}$, Auditoire C, Collège Propedeutique, Université de Lausanne, Dorigny

1991

9 janvier Prof. A. Storck, ENSIC à Nancy (F)

23 janvier Prof, Dr. P.J. Crutzen, Otto Hahn Institut, Chimie de l'atmosphère à Mainz (D)

7.2 .91 H. Schwarz "Crofitut für Org Chemie. TU Berlin 'Chemie nackter Moleküle'

Prof. Dr. A. Pfalt Institut für Org. Chemie, Universität Base

'Enantioselektive Katalyse mit chiralen Metallkomplexen'

\section{Laboratorium für anorg. Chemie der ETH Zürich}

\section{Koordinationschemie und homogene Katalyse}

Mittwoch, 9.00-10.15, CAB B9

Universitätstrasse 6

9. Januar Prof. Jolm A. Oshorn, Universiti Louis Pasteur, Strasbourg 'Aspects of Enantioselective Hydrogenation with Metal Complexes'

Ende Januar Prof. Lars I. Elding, University of Lund

Der Titel wird später bekanntgegeben

20. Februar Prol, A. Ludi, Universität Bern Struktur und Reaktivität von Kom plexen als Funktion der Ligandenperipherie'

\section{Chemische Gesellschaft Zürich}

Alle Vorträge finden statt: Mittwoch, 17.15 Uhr, Hörsaal CAB D2 im Chemie-Altbau ETH, Universitätstrasse 6, 8092 Zürich.

9. Jan. 1991

Prof. Dr. H. Oeschger Physikalisches Institut Universität Bern, Bern Die sich ändernde Almosphäre; aus der Perspektive der $\mathrm{CO}_{2}$ - und $\mathrm{Kli}$ maschwankungen der Vergangenheit

\section{Institut für Polymere, ETH Zürich}

30. Januar 91

altes Chemiegebäude ETHZ, D28

Prof. Dr. C. D. Eisenbach, Universität Bayreuth

Polymere mit massgeschneiderten supramolekularen Strukturen und Eigenschaften

13. Februar 91

altes Chemiegebäude ETHZ, D28

Prof. Dr. S. Russo, Istituto di Chimica Industriale CNR, Università di Genova

A Novel Synthetic Approach to Poly(caprolactam)-based Materials

20. Februar 91

altes Chemiegebäude ETHZ, D28

Prof. Dr. W. Helfrich, Institut für Theoretische Physik, Freie Universität Berlin

Spontane Vesikulation und kubische Phasen von $\mathrm{Li}$ piddoppelschichten

\section{Basler Chemische Gesellschaft}

(Donnerstag, 16.45 Uhr, im kleinen Hörsaal des Instituts für Organische Chemie)
PD Dr. R. Schwesinger

Institut für Organische Chemie und Biochemie

Universität Freiburg, Freiburg, i. Br., BRD

Extrem starke, ungeladene Phosphazenbasen, 'Komplementüre Metallorganica"

30. Jan. 1991 Prof. Dr. St.G. Daries Department of Organic Chemistry University of Oxford, Oxford, GB Exploiting the law of mass action for synthesis

Prof. Dr. H. Werner

Institut für anorganische Chemio Universität Würzburg, Würzburg, BRD

Aktivierung gesättigter und ungesättigter Kohlenwasserstoffe durch elektronenreiche Ubergangsmetallkomplexe: Der Weg von der Synthese zur Katalyse

rof, Dr. C.W. Hilhers Laboratory of Biophysical ChemisUniversity of Nijmegen, Nijmegen, NMR studies of regularities in unusual DNA struclures 
sequent documents. It is hoped that this set of bioanalytical definitions will be useful to the practitioners of clinical chemistry and will foster improved communications and understanding between them.

Comments on the document are welcome and should be sent by 31st October 1991 to: Dr Carl A. Burtis, Oak Ridge National Laboratory, P. O. Box 2008, Bldg. 4500-N, MS 6194, Oak Ridge, Tennessee 37831, USA

\section{Chemie-Sicherheitspreis der ESCIS 1990}

Die ESCIS (Expertenkommission für Sicherheit in der chemischen Industrie der Schweiz) ist ein unabhängiges Gremium, das sich aus Persönlichkeiten der chemischen Industric, des Bundes (BIGA), der SUVA und von Hochschulen zusammensetzt. Dieses Gremium be fasst sich mit ciner Vielfalt von Sicherheitsfragen und praxisnahcn Lösungsmöglichkeiten für Sicherheitsprobleme und tritt mit verschiedenen technisch orientierten Publikationen sowie Ausbildungskursen an die Öffentlichkeit. Eines der wesentlichsten Anliegen der ESCIS ist die Förderung des Sicherheitsdenkens und insbesondere der Einbezug der Sicherheitsbelange in die Unterrichtsprogramme an Ausbildungsstätten.

Anlässlich ihres 25-Jahr-Jubiläums im Jahre 1981 beschloss die ESCIS, einen Preis auszusetzen zur Aus zeichnung von Arbeiten bzw. von besonderen Verdiensten im Sinne dieser Anliegen. Nach 1983 und 1987 wird nunmehr 1990 zum dritten Mal der ESCIS-Preis, der mit 10000 Franken dotiert ist, verliehen

Nach umfangreichen Abklärungen und der Prüfung verschicdener Anträgc hat sich die ESCIS-Iury ent schieden, den für 1990 ausgesetzten ESCIS-Preis in voller Höhe Herrn Dr. Gérard Killé, Dozent an der Ecole Nationale Supérieure de Chimie de Mulhouse, zuzu sprechen. Herr Dr. Killé ist seit Jahren mit grossem Erfolg auf dem Gebiet der wissenschaftlich-technischen Sicherheitsausbildung tätig und verleiht diese Ausbildung an der Ecole Nationale Supérieure de Chimic de Muthouse insbesondere mit Spezialkursen starke Jmpulse.

Die offizielle Übergabe des ESCIS-Preises an Herrn Dr. Killé hat anlässlich der ILMAC-Eröffnung am 23. Oktober 1990 in Basel stattgefunden.

\section{Wissenschaftlerin des}

\section{Max-Planck-Institutes erhält}

Roche-Auszeichnung in den USA

Dr. Christiane Nüsslein-Volhard, Direktorin des Tübinger Friedrich-Miescher-Laboratoriums in der MaxPlanck-Gesellschaft, ist die diesjährige Preisträgerin des V.D. Mattia Preises von Hoffmann-La Roche Inc. Nutley, USA. Sie erhielt die Auszeichnung für ihre hervorragenden Beiträge zur biomedizinischen Forschung auf dem Gebiet der Entwicklungsgenetik. Dr. Nüsslein-Volhard nahm den Preis kürzlich im Roche Institute for Molecular Biology (RIMB), dem unabhängigen Zentrum für Grundlagenforschung von Hoffmann-La Roche USA, entgegen.

Zu den wichtigsten Forschungsergebnissen von Frau Nüsslein-Volhard gehört der Nachweis, dass mütterliche Gene (sogenannte mütterliche Effekt-Gene) im Ei der Frucht Iliege ausschlaggebend sind für die Ausbildung von Organen und Körpern des Insektes. Durch diese Untersuchungen hat Dr. Nüsslein-Volhard wichtige Prinzipien der Genetik geklärt, die möglicherweise auch für Entwicklungsprozesse anderer Lebewesen Gültigkeit haben.

Christiane Nüsslein-Volhard, in Magdeburg geboren, crwarb 1968 das Diplom für Biochemie und 1973 den Doktor der Biologie an der Universität in Tübingen. Sie hat zahlreiche Ehrungen und Auszeichnungen erhalten, darunter die Carus-Medaille der Deutschen Akademie der Wissenschaften, die Rosenstiel-Medaille sowie den Ehrendoktor der Yale University. Sie is ausserdem Mitglied der U.S. National Academy of Science und der British Royal Society. Seit 1985 leitet Dr. Nüsslein-Volhard die Abteilung für Entwicklungsbiologie am Friedrich-Miescher-Laboratorium in der Max-Planck-Gesellschaft in Tübingen.

Der V. D. Mattia Preis ist nach dem früheren Präsidenten von Hoffmann-La Roche Inc., Nutley und Gründer des RIMB benannt. Unter den bisherigen Prcisträgern finden sich acht spätere Nobelpreisträger.
Zufriedene Besucher und Aussteller an der

24.1.91 ILMAC 90

Nach viertägiger Messedauer schloss die ILMAC 90, die 11. Internationale Fachmesse für Laboratoriumsund Verfahrenstechnik, Messtechnik und Automatik am Freitag 26. Oktober ihrc Tore. Die Aussteller der Chemie-Fachmesse, die in den Hallen der Schweizer Mustermesse durchgeführt wurde, zeigten sich mit dem Messeverlauf durchwegs zufrieden.

Knapp 23750 verkaufte Eintritte bedeuten für die ILMAC 90 ein sehr gutes Besucherergebnis. Liegt doch diescs Resultat im Bereich der vergleichbaren Zahlen von 1987, wobei im damaligen Ergebnis die Besucher der gleichzeitig durchgeführten Apothekerfachmesse lpharmex 87 enthalten sind.

Seitens der rund 480 Aussteller, die auf $16000 \mathrm{~m}^{2}$ Nettostandfläche ihre Dienstleistungen und Produkte anboten, wurde denn auch betont, dass die Besucher nicht nur zahlreicher, sondern vor allem sehr interessiert und kompetent waren. Dies bestitigt auch die von de KONSO, Basel, durchgeführte Besucherumfrage, wonach zwei Drittel der Besucher bei Investitionen mindestens mitentscheidend sind. Die Besucher ihrerseits erteilten auch der Messe gute Noten. So beurteilten fast $60 \%$ der Befragten die ILMAC als eine der wichtigsten Fachmessen der Branche. Der Besucheranteil aus dem Ausland betrug $18 \%$

Reges Interesse fand auch die Sonderschau zum Them 'Explosionsschutz', wo man sich von fachkundige Seite her über die Leistungen der Industrie im Explosionsschutz informieren lassen konnte.

\section{Société vaudoise des sciences naturelles}

Mercredi à $17.15 \mathrm{~h}$, Auditoire C, Collège Propedeutique, Université de Lausanne, Dorigny

1991

9 janvier Prof. A. Storck, ENSIC à Nancy (F)

23 janvier Prof, Dr. P.J. Crutzen, Otto Hahn Institut, Chimie de l'atmosphère à Mainz (D)

7.2 .91 H. Schwarz "Crofitut für Org Chemie. TU Berlin 'Chemie nackter Moleküle'

Prof. Dr. A. Pfalt Institut für Org. Chemie, Universität Base

'Enantioselektive Katalyse mit chiralen Metallkomplexen'

\section{Laboratorium für anorg. Chemie der ETH Zürich}

\section{Koordinationschemie und homogene Katalyse}

Mittwoch, 9.00-10.15, CAB B9

Universitätstrasse 6

9. Januar Prof. Jolm A. Oshorn, Universiti Louis Pasteur, Strasbourg 'Aspects of Enantioselective Hydrogenation with Metal Complexes'

Ende Januar Prof. Lars I. Elding, University of Lund

Der Titel wird später bekanntgegeben

20. Februar Prol, A. Ludi, Universität Bern Struktur und Reaktivität von Kom plexen als Funktion der Ligandenperipherie'

\section{Chemische Gesellschaft Zürich}

Alle Vorträge finden statt: Mittwoch, 17.15 Uhr, Hörsaal CAB D2 im Chemie-Altbau ETH, Universitätstrasse 6, 8092 Zürich.

9. Jan. 1991

Prof. Dr. H. Oeschger Physikalisches Institut Universität Bern, Bern Die sich ändernde Almosphäre; aus der Perspektive der $\mathrm{CO}_{2}$ - und $\mathrm{Kli}$ maschwankungen der Vergangenheit

\section{Institut für Polymere, ETH Zürich}

30. Januar 91

altes Chemiegebäude ETHZ, D28

Prof. Dr. C. D. Eisenbach, Universität Bayreuth

Polymere mit massgeschneiderten supramolekularen Strukturen und Eigenschaften

13. Februar 91

altes Chemiegebäude ETHZ, D28

Prof. Dr. S. Russo, Istituto di Chimica Industriale CNR, Università di Genova

A Novel Synthetic Approach to Poly(caprolactam)-based Materials

20. Februar 91

altes Chemiegebäude ETHZ, D28

Prof. Dr. W. Helfrich, Institut für Theoretische Physik, Freie Universität Berlin

Spontane Vesikulation und kubische Phasen von $\mathrm{Li}$ piddoppelschichten

\section{Basler Chemische Gesellschaft}

(Donnerstag, 16.45 Uhr, im kleinen Hörsaal des Instituts für Organische Chemie)
PD Dr. R. Schwesinger

Institut für Organische Chemie und Biochemie

Universität Freiburg, Freiburg, i. Br., BRD

Extrem starke, ungeladene Phosphazenbasen, 'Komplementüre Metallorganica"

30. Jan. 1991 Prof. Dr. St.G. Daries Department of Organic Chemistry University of Oxford, Oxford, GB Exploiting the law of mass action for synthesis

Prof. Dr. H. Werner

Institut für anorganische Chemio Universität Würzburg, Würzburg, BRD

Aktivierung gesättigter und ungesättigter Kohlenwasserstoffe durch elektronenreiche Ubergangsmetallkomplexe: Der Weg von der Synthese zur Katalyse

rof, Dr. C.W. Hilhers Laboratory of Biophysical ChemisUniversity of Nijmegen, Nijmegen, NMR studies of regularities in unusual DNA struclures 
sequent documents. It is hoped that this set of bioanalytical definitions will be useful to the practitioners of clinical chemistry and will foster improved communications and understanding between them.

Comments on the document are welcome and should be sent by 31st October 1991 to: Dr Carl A. Burtis, Oak Ridge National Laboratory, P. O. Box 2008, Bldg. 4500-N, MS 6194, Oak Ridge, Tennessee 37831, USA

\section{Chemie-Sicherheitspreis der ESCIS 1990}

Die ESCIS (Expertenkommission für Sicherheit in der chemischen Industrie der Schweiz) ist ein unabhängiges Gremium, das sich aus Persönlichkeiten der chemischen Industric, des Bundes (BIGA), der SUVA und von Hochschulen zusammensetzt. Dieses Gremium be fasst sich mit ciner Vielfalt von Sicherheitsfragen und praxisnahcn Lösungsmöglichkeiten für Sicherheitsprobleme und tritt mit verschiedenen technisch orientierten Publikationen sowie Ausbildungskursen an die Öffentlichkeit. Eines der wesentlichsten Anliegen der ESCIS ist die Förderung des Sicherheitsdenkens und insbesondere der Einbezug der Sicherheitsbelange in die Unterrichtsprogramme an Ausbildungsstätten.

Anlässlich ihres 25-Jahr-Jubiläums im Jahre 1981 beschloss die ESCIS, einen Preis auszusetzen zur Aus zeichnung von Arbeiten bzw. von besonderen Verdiensten im Sinne dieser Anliegen. Nach 1983 und 1987 wird nunmehr 1990 zum dritten Mal der ESCIS-Preis, der mit 10000 Franken dotiert ist, verliehen

Nach umfangreichen Abklärungen und der Prüfung verschicdener Anträgc hat sich die ESCIS-Iury ent schieden, den für 1990 ausgesetzten ESCIS-Preis in voller Höhe Herrn Dr. Gérard Killé, Dozent an der Ecole Nationale Supérieure de Chimie de Mulhouse, zuzu sprechen. Herr Dr. Killé ist seit Jahren mit grossem Erfolg auf dem Gebiet der wissenschaftlich-technischen Sicherheitsausbildung tätig und verleiht diese Ausbildung an der Ecole Nationale Supérieure de Chimic de Muthouse insbesondere mit Spezialkursen starke Jmpulse.

Die offizielle Übergabe des ESCIS-Preises an Herrn Dr. Killé hat anlässlich der ILMAC-Eröffnung am 23. Oktober 1990 in Basel stattgefunden.

\section{Wissenschaftlerin des}

\section{Max-Planck-Institutes erhält}

Roche-Auszeichnung in den USA

Dr. Christiane Nüsslein-Volhard, Direktorin des Tübinger Friedrich-Miescher-Laboratoriums in der MaxPlanck-Gesellschaft, ist die diesjährige Preisträgerin des V.D. Mattia Preises von Hoffmann-La Roche Inc. Nutley, USA. Sie erhielt die Auszeichnung für ihre hervorragenden Beiträge zur biomedizinischen Forschung auf dem Gebiet der Entwicklungsgenetik. Dr. Nüsslein-Volhard nahm den Preis kürzlich im Roche Institute for Molecular Biology (RIMB), dem unabhängigen Zentrum für Grundlagenforschung von Hoffmann-La Roche USA, entgegen.

Zu den wichtigsten Forschungsergebnissen von Frau Nüsslein-Volhard gehört der Nachweis, dass mütterliche Gene (sogenannte mütterliche Effekt-Gene) im Ei der Frucht Iliege ausschlaggebend sind für die Ausbildung von Organen und Körpern des Insektes. Durch diese Untersuchungen hat Dr. Nüsslein-Volhard wichtige Prinzipien der Genetik geklärt, die möglicherweise auch für Entwicklungsprozesse anderer Lebewesen Gültigkeit haben.

Christiane Nüsslein-Volhard, in Magdeburg geboren, crwarb 1968 das Diplom für Biochemie und 1973 den Doktor der Biologie an der Universität in Tübingen. Sie hat zahlreiche Ehrungen und Auszeichnungen erhalten, darunter die Carus-Medaille der Deutschen Akademie der Wissenschaften, die Rosenstiel-Medaille sowie den Ehrendoktor der Yale University. Sie is ausserdem Mitglied der U.S. National Academy of Science und der British Royal Society. Seit 1985 leitet Dr. Nüsslein-Volhard die Abteilung für Entwicklungsbiologie am Friedrich-Miescher-Laboratorium in der Max-Planck-Gesellschaft in Tübingen.

Der V. D. Mattia Preis ist nach dem früheren Präsidenten von Hoffmann-La Roche Inc., Nutley und Gründer des RIMB benannt. Unter den bisherigen Prcisträgern finden sich acht spätere Nobelpreisträger.
Zufriedene Besucher und Aussteller an der

24.1.91 ILMAC 90

Nach viertägiger Messedauer schloss die ILMAC 90, die 11. Internationale Fachmesse für Laboratoriumsund Verfahrenstechnik, Messtechnik und Automatik am Freitag 26. Oktober ihrc Tore. Die Aussteller der Chemie-Fachmesse, die in den Hallen der Schweizer Mustermesse durchgeführt wurde, zeigten sich mit dem Messeverlauf durchwegs zufrieden.

Knapp 23750 verkaufte Eintritte bedeuten für die ILMAC 90 ein sehr gutes Besucherergebnis. Liegt doch diescs Resultat im Bereich der vergleichbaren Zahlen von 1987, wobei im damaligen Ergebnis die Besucher der gleichzeitig durchgeführten Apothekerfachmesse lpharmex 87 enthalten sind.

Seitens der rund 480 Aussteller, die auf $16000 \mathrm{~m}^{2}$ Nettostandfläche ihre Dienstleistungen und Produkte anboten, wurde denn auch betont, dass die Besucher nicht nur zahlreicher, sondern vor allem sehr interessiert und kompetent waren. Dies bestitigt auch die von de KONSO, Basel, durchgeführte Besucherumfrage, wonach zwei Drittel der Besucher bei Investitionen mindestens mitentscheidend sind. Die Besucher ihrerseits erteilten auch der Messe gute Noten. So beurteilten fast $60 \%$ der Befragten die ILMAC als eine der wichtigsten Fachmessen der Branche. Der Besucheranteil aus dem Ausland betrug $18 \%$

Reges Interesse fand auch die Sonderschau zum Them 'Explosionsschutz', wo man sich von fachkundige Seite her über die Leistungen der Industrie im Explosionsschutz informieren lassen konnte.

\section{Société vaudoise des sciences naturelles}

Mercredi à $17.15 \mathrm{~h}$, Auditoire C, Collège Propedeutique, Université de Lausanne, Dorigny

1991

9 janvier Prof. A. Storck, ENSIC à Nancy (F)

23 janvier Prof, Dr. P.J. Crutzen, Otto Hahn Institut, Chimie de l'atmosphère à Mainz (D)

7.2 .91 H. Schwarz "Crofitut für Org Chemie. TU Berlin 'Chemie nackter Moleküle'

Prof. Dr. A. Pfalt Institut für Org. Chemie, Universität Base

'Enantioselektive Katalyse mit chiralen Metallkomplexen'

\section{Laboratorium für anorg. Chemie der ETH Zürich}

\section{Koordinationschemie und homogene Katalyse}

Mittwoch, 9.00-10.15, CAB B9

Universitätstrasse 6

9. Januar Prof. Jolm A. Oshorn, Universiti Louis Pasteur, Strasbourg 'Aspects of Enantioselective Hydrogenation with Metal Complexes'

Ende Januar Prof. Lars I. Elding, University of Lund

Der Titel wird später bekanntgegeben

20. Februar Prol, A. Ludi, Universität Bern Struktur und Reaktivität von Kom plexen als Funktion der Ligandenperipherie'

\section{Chemische Gesellschaft Zürich}

Alle Vorträge finden statt: Mittwoch, 17.15 Uhr, Hörsaal CAB D2 im Chemie-Altbau ETH, Universitätstrasse 6, 8092 Zürich.

9. Jan. 1991

Prof. Dr. H. Oeschger Physikalisches Institut Universität Bern, Bern Die sich ändernde Almosphäre; aus der Perspektive der $\mathrm{CO}_{2}$ - und $\mathrm{Kli}$ maschwankungen der Vergangenheit

\section{Institut für Polymere, ETH Zürich}

30. Januar 91

altes Chemiegebäude ETHZ, D28

Prof. Dr. C. D. Eisenbach, Universität Bayreuth

Polymere mit massgeschneiderten supramolekularen Strukturen und Eigenschaften

13. Februar 91

altes Chemiegebäude ETHZ, D28

Prof. Dr. S. Russo, Istituto di Chimica Industriale CNR, Università di Genova

A Novel Synthetic Approach to Poly(caprolactam)-based Materials

20. Februar 91

altes Chemiegebäude ETHZ, D28

Prof. Dr. W. Helfrich, Institut für Theoretische Physik, Freie Universität Berlin

Spontane Vesikulation und kubische Phasen von $\mathrm{Li}$ piddoppelschichten

\section{Basler Chemische Gesellschaft}

(Donnerstag, 16.45 Uhr, im kleinen Hörsaal des Instituts für Organische Chemie)
PD Dr. R. Schwesinger

Institut für Organische Chemie und Biochemie

Universität Freiburg, Freiburg, i. Br., BRD

Extrem starke, ungeladene Phosphazenbasen, 'Komplementüre Metallorganica"

30. Jan. 1991 Prof. Dr. St.G. Daries Department of Organic Chemistry University of Oxford, Oxford, GB Exploiting the law of mass action for synthesis

Prof. Dr. H. Werner

Institut für anorganische Chemio Universität Würzburg, Würzburg, BRD

Aktivierung gesättigter und ungesättigter Kohlenwasserstoffe durch elektronenreiche Ubergangsmetallkomplexe: Der Weg von der Synthese zur Katalyse

rof, Dr. C.W. Hilhers Laboratory of Biophysical ChemisUniversity of Nijmegen, Nijmegen, NMR studies of regularities in unusual DNA struclures 
sequent documents. It is hoped that this set of bioanalytical definitions will be useful to the practitioners of clinical chemistry and will foster improved communications and understanding between them.

Comments on the document are welcome and should be sent by 31st October 1991 to: Dr Carl A. Burtis, Oak Ridge National Laboratory, P. O. Box 2008, Bldg. 4500-N, MS 6194, Oak Ridge, Tennessee 37831, USA

\section{Chemie-Sicherheitspreis der ESCIS 1990}

Die ESCIS (Expertenkommission für Sicherheit in der chemischen Industrie der Schweiz) ist ein unabhängiges Gremium, das sich aus Persönlichkeiten der chemischen Industric, des Bundes (BIGA), der SUVA und von Hochschulen zusammensetzt. Dieses Gremium be fasst sich mit ciner Vielfalt von Sicherheitsfragen und praxisnahcn Lösungsmöglichkeiten für Sicherheitsprobleme und tritt mit verschiedenen technisch orientierten Publikationen sowie Ausbildungskursen an die Öffentlichkeit. Eines der wesentlichsten Anliegen der ESCIS ist die Förderung des Sicherheitsdenkens und insbesondere der Einbezug der Sicherheitsbelange in die Unterrichtsprogramme an Ausbildungsstätten.

Anlässlich ihres 25-Jahr-Jubiläums im Jahre 1981 beschloss die ESCIS, einen Preis auszusetzen zur Aus zeichnung von Arbeiten bzw. von besonderen Verdiensten im Sinne dieser Anliegen. Nach 1983 und 1987 wird nunmehr 1990 zum dritten Mal der ESCIS-Preis, der mit 10000 Franken dotiert ist, verliehen

Nach umfangreichen Abklärungen und der Prüfung verschicdener Anträgc hat sich die ESCIS-Iury ent schieden, den für 1990 ausgesetzten ESCIS-Preis in voller Höhe Herrn Dr. Gérard Killé, Dozent an der Ecole Nationale Supérieure de Chimie de Mulhouse, zuzu sprechen. Herr Dr. Killé ist seit Jahren mit grossem Erfolg auf dem Gebiet der wissenschaftlich-technischen Sicherheitsausbildung tätig und verleiht diese Ausbildung an der Ecole Nationale Supérieure de Chimic de Muthouse insbesondere mit Spezialkursen starke Jmpulse.

Die offizielle Übergabe des ESCIS-Preises an Herrn Dr. Killé hat anlässlich der ILMAC-Eröffnung am 23. Oktober 1990 in Basel stattgefunden.

\section{Wissenschaftlerin des}

\section{Max-Planck-Institutes erhält}

Roche-Auszeichnung in den USA

Dr. Christiane Nüsslein-Volhard, Direktorin des Tübinger Friedrich-Miescher-Laboratoriums in der MaxPlanck-Gesellschaft, ist die diesjährige Preisträgerin des V.D. Mattia Preises von Hoffmann-La Roche Inc. Nutley, USA. Sie erhielt die Auszeichnung für ihre hervorragenden Beiträge zur biomedizinischen Forschung auf dem Gebiet der Entwicklungsgenetik. Dr. Nüsslein-Volhard nahm den Preis kürzlich im Roche Institute for Molecular Biology (RIMB), dem unabhängigen Zentrum für Grundlagenforschung von Hoffmann-La Roche USA, entgegen.

Zu den wichtigsten Forschungsergebnissen von Frau Nüsslein-Volhard gehört der Nachweis, dass mütterliche Gene (sogenannte mütterliche Effekt-Gene) im Ei der Frucht Iliege ausschlaggebend sind für die Ausbildung von Organen und Körpern des Insektes. Durch diese Untersuchungen hat Dr. Nüsslein-Volhard wichtige Prinzipien der Genetik geklärt, die möglicherweise auch für Entwicklungsprozesse anderer Lebewesen Gültigkeit haben.

Christiane Nüsslein-Volhard, in Magdeburg geboren, crwarb 1968 das Diplom für Biochemie und 1973 den Doktor der Biologie an der Universität in Tübingen. Sie hat zahlreiche Ehrungen und Auszeichnungen erhalten, darunter die Carus-Medaille der Deutschen Akademie der Wissenschaften, die Rosenstiel-Medaille sowie den Ehrendoktor der Yale University. Sie is ausserdem Mitglied der U.S. National Academy of Science und der British Royal Society. Seit 1985 leitet Dr. Nüsslein-Volhard die Abteilung für Entwicklungsbiologie am Friedrich-Miescher-Laboratorium in der Max-Planck-Gesellschaft in Tübingen.

Der V. D. Mattia Preis ist nach dem früheren Präsidenten von Hoffmann-La Roche Inc., Nutley und Gründer des RIMB benannt. Unter den bisherigen Prcisträgern finden sich acht spätere Nobelpreisträger.
Zufriedene Besucher und Aussteller an der

24.1.91 ILMAC 90

Nach viertägiger Messedauer schloss die ILMAC 90, die 11. Internationale Fachmesse für Laboratoriumsund Verfahrenstechnik, Messtechnik und Automatik am Freitag 26. Oktober ihrc Tore. Die Aussteller der Chemie-Fachmesse, die in den Hallen der Schweizer Mustermesse durchgeführt wurde, zeigten sich mit dem Messeverlauf durchwegs zufrieden.

Knapp 23750 verkaufte Eintritte bedeuten für die ILMAC 90 ein sehr gutes Besucherergebnis. Liegt doch diescs Resultat im Bereich der vergleichbaren Zahlen von 1987, wobei im damaligen Ergebnis die Besucher der gleichzeitig durchgeführten Apothekerfachmesse lpharmex 87 enthalten sind.

Seitens der rund 480 Aussteller, die auf $16000 \mathrm{~m}^{2}$ Nettostandfläche ihre Dienstleistungen und Produkte anboten, wurde denn auch betont, dass die Besucher nicht nur zahlreicher, sondern vor allem sehr interessiert und kompetent waren. Dies bestitigt auch die von de KONSO, Basel, durchgeführte Besucherumfrage, wonach zwei Drittel der Besucher bei Investitionen mindestens mitentscheidend sind. Die Besucher ihrerseits erteilten auch der Messe gute Noten. So beurteilten fast $60 \%$ der Befragten die ILMAC als eine der wichtigsten Fachmessen der Branche. Der Besucheranteil aus dem Ausland betrug $18 \%$

Reges Interesse fand auch die Sonderschau zum Them 'Explosionsschutz', wo man sich von fachkundige Seite her über die Leistungen der Industrie im Explosionsschutz informieren lassen konnte.

\section{Société vaudoise des sciences naturelles}

Mercredi à $17.15 \mathrm{~h}$, Auditoire C, Collège Propedeutique, Université de Lausanne, Dorigny

1991

9 janvier Prof. A. Storck, ENSIC à Nancy (F)

23 janvier Prof, Dr. P.J. Crutzen, Otto Hahn Institut, Chimie de l'atmosphère à Mainz (D)

7.2 .91 H. Schwarz "Crofitut für Org Chemie. TU Berlin 'Chemie nackter Moleküle'

Prof. Dr. A. Pfalt Institut für Org. Chemie, Universität Base

'Enantioselektive Katalyse mit chiralen Metallkomplexen'

\section{Laboratorium für anorg. Chemie der ETH Zürich}

\section{Koordinationschemie und homogene Katalyse}

Mittwoch, 9.00-10.15, CAB B9

Universitätstrasse 6

9. Januar Prof. Jolm A. Oshorn, Universiti Louis Pasteur, Strasbourg 'Aspects of Enantioselective Hydrogenation with Metal Complexes'

Ende Januar Prof. Lars I. Elding, University of Lund

Der Titel wird später bekanntgegeben

20. Februar Prol, A. Ludi, Universität Bern Struktur und Reaktivität von Kom plexen als Funktion der Ligandenperipherie'

\section{Chemische Gesellschaft Zürich}

Alle Vorträge finden statt: Mittwoch, 17.15 Uhr, Hörsaal CAB D2 im Chemie-Altbau ETH, Universitätstrasse 6, 8092 Zürich.

9. Jan. 1991

Prof. Dr. H. Oeschger Physikalisches Institut Universität Bern, Bern Die sich ändernde Almosphäre; aus der Perspektive der $\mathrm{CO}_{2}$ - und $\mathrm{Kli}$ maschwankungen der Vergangenheit

\section{Institut für Polymere, ETH Zürich}

30. Januar 91

altes Chemiegebäude ETHZ, D28

Prof. Dr. C. D. Eisenbach, Universität Bayreuth

Polymere mit massgeschneiderten supramolekularen Strukturen und Eigenschaften

13. Februar 91

altes Chemiegebäude ETHZ, D28

Prof. Dr. S. Russo, Istituto di Chimica Industriale CNR, Università di Genova

A Novel Synthetic Approach to Poly(caprolactam)-based Materials

20. Februar 91

altes Chemiegebäude ETHZ, D28

Prof. Dr. W. Helfrich, Institut für Theoretische Physik, Freie Universität Berlin

Spontane Vesikulation und kubische Phasen von $\mathrm{Li}$ piddoppelschichten

\section{Basler Chemische Gesellschaft}

(Donnerstag, 16.45 Uhr, im kleinen Hörsaal des Instituts für Organische Chemie)
PD Dr. R. Schwesinger

Institut für Organische Chemie und Biochemie

Universität Freiburg, Freiburg, i. Br., BRD

Extrem starke, ungeladene Phosphazenbasen, 'Komplementüre Metallorganica"

30. Jan. 1991 Prof. Dr. St.G. Daries Department of Organic Chemistry University of Oxford, Oxford, GB Exploiting the law of mass action for synthesis

Prof. Dr. H. Werner

Institut für anorganische Chemio Universität Würzburg, Würzburg, BRD

Aktivierung gesättigter und ungesättigter Kohlenwasserstoffe durch elektronenreiche Ubergangsmetallkomplexe: Der Weg von der Synthese zur Katalyse

rof, Dr. C.W. Hilhers Laboratory of Biophysical ChemisUniversity of Nijmegen, Nijmegen, NMR studies of regularities in unusual DNA struclures 
sequent documents. It is hoped that this set of bioanalytical definitions will be useful to the practitioners of clinical chemistry and will foster improved communications and understanding between them.

Comments on the document are welcome and should be sent by 31st October 1991 to: Dr Carl A. Burtis, Oak Ridge National Laboratory, P. O. Box 2008, Bldg. 4500-N, MS 6194, Oak Ridge, Tennessee 37831, USA

\section{Chemie-Sicherheitspreis der ESCIS 1990}

Die ESCIS (Expertenkommission für Sicherheit in der chemischen Industrie der Schweiz) ist ein unabhängiges Gremium, das sich aus Persönlichkeiten der chemischen Industric, des Bundes (BIGA), der SUVA und von Hochschulen zusammensetzt. Dieses Gremium be fasst sich mit ciner Vielfalt von Sicherheitsfragen und praxisnahcn Lösungsmöglichkeiten für Sicherheitsprobleme und tritt mit verschiedenen technisch orientierten Publikationen sowie Ausbildungskursen an die Öffentlichkeit. Eines der wesentlichsten Anliegen der ESCIS ist die Förderung des Sicherheitsdenkens und insbesondere der Einbezug der Sicherheitsbelange in die Unterrichtsprogramme an Ausbildungsstätten.

Anlässlich ihres 25-Jahr-Jubiläums im Jahre 1981 beschloss die ESCIS, einen Preis auszusetzen zur Aus zeichnung von Arbeiten bzw. von besonderen Verdiensten im Sinne dieser Anliegen. Nach 1983 und 1987 wird nunmehr 1990 zum dritten Mal der ESCIS-Preis, der mit 10000 Franken dotiert ist, verliehen

Nach umfangreichen Abklärungen und der Prüfung verschicdener Anträgc hat sich die ESCIS-Iury ent schieden, den für 1990 ausgesetzten ESCIS-Preis in voller Höhe Herrn Dr. Gérard Killé, Dozent an der Ecole Nationale Supérieure de Chimie de Mulhouse, zuzu sprechen. Herr Dr. Killé ist seit Jahren mit grossem Erfolg auf dem Gebiet der wissenschaftlich-technischen Sicherheitsausbildung tätig und verleiht diese Ausbildung an der Ecole Nationale Supérieure de Chimic de Muthouse insbesondere mit Spezialkursen starke Jmpulse.

Die offizielle Übergabe des ESCIS-Preises an Herrn Dr. Killé hat anlässlich der ILMAC-Eröffnung am 23. Oktober 1990 in Basel stattgefunden.

\section{Wissenschaftlerin des}

\section{Max-Planck-Institutes erhält}

Roche-Auszeichnung in den USA

Dr. Christiane Nüsslein-Volhard, Direktorin des Tübinger Friedrich-Miescher-Laboratoriums in der MaxPlanck-Gesellschaft, ist die diesjährige Preisträgerin des V.D. Mattia Preises von Hoffmann-La Roche Inc. Nutley, USA. Sie erhielt die Auszeichnung für ihre hervorragenden Beiträge zur biomedizinischen Forschung auf dem Gebiet der Entwicklungsgenetik. Dr. Nüsslein-Volhard nahm den Preis kürzlich im Roche Institute for Molecular Biology (RIMB), dem unabhängigen Zentrum für Grundlagenforschung von Hoffmann-La Roche USA, entgegen.

Zu den wichtigsten Forschungsergebnissen von Frau Nüsslein-Volhard gehört der Nachweis, dass mütterliche Gene (sogenannte mütterliche Effekt-Gene) im Ei der Frucht Iliege ausschlaggebend sind für die Ausbildung von Organen und Körpern des Insektes. Durch diese Untersuchungen hat Dr. Nüsslein-Volhard wichtige Prinzipien der Genetik geklärt, die möglicherweise auch für Entwicklungsprozesse anderer Lebewesen Gültigkeit haben.

Christiane Nüsslein-Volhard, in Magdeburg geboren, crwarb 1968 das Diplom für Biochemie und 1973 den Doktor der Biologie an der Universität in Tübingen. Sie hat zahlreiche Ehrungen und Auszeichnungen erhalten, darunter die Carus-Medaille der Deutschen Akademie der Wissenschaften, die Rosenstiel-Medaille sowie den Ehrendoktor der Yale University. Sie is ausserdem Mitglied der U.S. National Academy of Science und der British Royal Society. Seit 1985 leitet Dr. Nüsslein-Volhard die Abteilung für Entwicklungsbiologie am Friedrich-Miescher-Laboratorium in der Max-Planck-Gesellschaft in Tübingen.

Der V. D. Mattia Preis ist nach dem früheren Präsidenten von Hoffmann-La Roche Inc., Nutley und Gründer des RIMB benannt. Unter den bisherigen Prcisträgern finden sich acht spätere Nobelpreisträger.
Zufriedene Besucher und Aussteller an der

24.1.91 ILMAC 90

Nach viertägiger Messedauer schloss die ILMAC 90, die 11. Internationale Fachmesse für Laboratoriumsund Verfahrenstechnik, Messtechnik und Automatik am Freitag 26. Oktober ihrc Tore. Die Aussteller der Chemie-Fachmesse, die in den Hallen der Schweizer Mustermesse durchgeführt wurde, zeigten sich mit dem Messeverlauf durchwegs zufrieden.

Knapp 23750 verkaufte Eintritte bedeuten für die ILMAC 90 ein sehr gutes Besucherergebnis. Liegt doch diescs Resultat im Bereich der vergleichbaren Zahlen von 1987, wobei im damaligen Ergebnis die Besucher der gleichzeitig durchgeführten Apothekerfachmesse lpharmex 87 enthalten sind.

Seitens der rund 480 Aussteller, die auf $16000 \mathrm{~m}^{2}$ Nettostandfläche ihre Dienstleistungen und Produkte anboten, wurde denn auch betont, dass die Besucher nicht nur zahlreicher, sondern vor allem sehr interessiert und kompetent waren. Dies bestitigt auch die von de KONSO, Basel, durchgeführte Besucherumfrage, wonach zwei Drittel der Besucher bei Investitionen mindestens mitentscheidend sind. Die Besucher ihrerseits erteilten auch der Messe gute Noten. So beurteilten fast $60 \%$ der Befragten die ILMAC als eine der wichtigsten Fachmessen der Branche. Der Besucheranteil aus dem Ausland betrug $18 \%$

Reges Interesse fand auch die Sonderschau zum Them 'Explosionsschutz', wo man sich von fachkundige Seite her über die Leistungen der Industrie im Explosionsschutz informieren lassen konnte.

\section{Société vaudoise des sciences naturelles}

Mercredi à $17.15 \mathrm{~h}$, Auditoire C, Collège Propedeutique, Université de Lausanne, Dorigny

1991

9 janvier Prof. A. Storck, ENSIC à Nancy (F)

23 janvier Prof, Dr. P.J. Crutzen, Otto Hahn Institut, Chimie de l'atmosphère à Mainz (D)

7.2 .91 H. Schwarz "Crofitut für Org Chemie. TU Berlin 'Chemie nackter Moleküle'

Prof. Dr. A. Pfalt Institut für Org. Chemie, Universität Base

'Enantioselektive Katalyse mit chiralen Metallkomplexen'

\section{Laboratorium für anorg. Chemie der ETH Zürich}

\section{Koordinationschemie und homogene Katalyse}

Mittwoch, 9.00-10.15, CAB B9

Universitätstrasse 6

9. Januar Prof. Jolm A. Oshorn, Universiti Louis Pasteur, Strasbourg 'Aspects of Enantioselective Hydrogenation with Metal Complexes'

Ende Januar Prof. Lars I. Elding, University of Lund

Der Titel wird später bekanntgegeben

20. Februar Prol, A. Ludi, Universität Bern Struktur und Reaktivität von Kom plexen als Funktion der Ligandenperipherie'

\section{Chemische Gesellschaft Zürich}

Alle Vorträge finden statt: Mittwoch, 17.15 Uhr, Hörsaal CAB D2 im Chemie-Altbau ETH, Universitätstrasse 6, 8092 Zürich.

9. Jan. 1991

Prof. Dr. H. Oeschger Physikalisches Institut Universität Bern, Bern Die sich ändernde Almosphäre; aus der Perspektive der $\mathrm{CO}_{2}$ - und $\mathrm{Kli}$ maschwankungen der Vergangenheit

\section{Institut für Polymere, ETH Zürich}

30. Januar 91

altes Chemiegebäude ETHZ, D28

Prof. Dr. C. D. Eisenbach, Universität Bayreuth

Polymere mit massgeschneiderten supramolekularen Strukturen und Eigenschaften

13. Februar 91

altes Chemiegebäude ETHZ, D28

Prof. Dr. S. Russo, Istituto di Chimica Industriale CNR, Università di Genova

A Novel Synthetic Approach to Poly(caprolactam)-based Materials

20. Februar 91

altes Chemiegebäude ETHZ, D28

Prof. Dr. W. Helfrich, Institut für Theoretische Physik, Freie Universität Berlin

Spontane Vesikulation und kubische Phasen von $\mathrm{Li}$ piddoppelschichten

\section{Basler Chemische Gesellschaft}

(Donnerstag, 16.45 Uhr, im kleinen Hörsaal des Instituts für Organische Chemie)
PD Dr. R. Schwesinger

Institut für Organische Chemie und Biochemie

Universität Freiburg, Freiburg, i. Br., BRD

Extrem starke, ungeladene Phosphazenbasen, 'Komplementüre Metallorganica"

30. Jan. 1991 Prof. Dr. St.G. Daries Department of Organic Chemistry University of Oxford, Oxford, GB Exploiting the law of mass action for synthesis

Prof. Dr. H. Werner

Institut für anorganische Chemio Universität Würzburg, Würzburg, BRD

Aktivierung gesättigter und ungesättigter Kohlenwasserstoffe durch elektronenreiche Ubergangsmetallkomplexe: Der Weg von der Synthese zur Katalyse

rof, Dr. C.W. Hilhers Laboratory of Biophysical ChemisUniversity of Nijmegen, Nijmegen, NMR studies of regularities in unusual DNA struclures 
sequent documents. It is hoped that this set of bioanalytical definitions will be useful to the practitioners of clinical chemistry and will foster improved communications and understanding between them.

Comments on the document are welcome and should be sent by 31st October 1991 to: Dr Carl A. Burtis, Oak Ridge National Laboratory, P. O. Box 2008, Bldg. 4500-N, MS 6194, Oak Ridge, Tennessee 37831, USA

\section{Chemie-Sicherheitspreis der ESCIS 1990}

Die ESCIS (Expertenkommission für Sicherheit in der chemischen Industrie der Schweiz) ist ein unabhängiges Gremium, das sich aus Persönlichkeiten der chemischen Industric, des Bundes (BIGA), der SUVA und von Hochschulen zusammensetzt. Dieses Gremium be fasst sich mit ciner Vielfalt von Sicherheitsfragen und praxisnahcn Lösungsmöglichkeiten für Sicherheitsprobleme und tritt mit verschiedenen technisch orientierten Publikationen sowie Ausbildungskursen an die Öffentlichkeit. Eines der wesentlichsten Anliegen der ESCIS ist die Förderung des Sicherheitsdenkens und insbesondere der Einbezug der Sicherheitsbelange in die Unterrichtsprogramme an Ausbildungsstätten.

Anlässlich ihres 25-Jahr-Jubiläums im Jahre 1981 beschloss die ESCIS, einen Preis auszusetzen zur Aus zeichnung von Arbeiten bzw. von besonderen Verdiensten im Sinne dieser Anliegen. Nach 1983 und 1987 wird nunmehr 1990 zum dritten Mal der ESCIS-Preis, der mit 10000 Franken dotiert ist, verliehen

Nach umfangreichen Abklärungen und der Prüfung verschicdener Anträgc hat sich die ESCIS-Iury ent schieden, den für 1990 ausgesetzten ESCIS-Preis in voller Höhe Herrn Dr. Gérard Killé, Dozent an der Ecole Nationale Supérieure de Chimie de Mulhouse, zuzu sprechen. Herr Dr. Killé ist seit Jahren mit grossem Erfolg auf dem Gebiet der wissenschaftlich-technischen Sicherheitsausbildung tätig und verleiht diese Ausbildung an der Ecole Nationale Supérieure de Chimic de Muthouse insbesondere mit Spezialkursen starke Jmpulse.

Die offizielle Übergabe des ESCIS-Preises an Herrn Dr. Killé hat anlässlich der ILMAC-Eröffnung am 23. Oktober 1990 in Basel stattgefunden.

\section{Wissenschaftlerin des}

\section{Max-Planck-Institutes erhält}

Roche-Auszeichnung in den USA

Dr. Christiane Nüsslein-Volhard, Direktorin des Tübinger Friedrich-Miescher-Laboratoriums in der MaxPlanck-Gesellschaft, ist die diesjährige Preisträgerin des V.D. Mattia Preises von Hoffmann-La Roche Inc. Nutley, USA. Sie erhielt die Auszeichnung für ihre hervorragenden Beiträge zur biomedizinischen Forschung auf dem Gebiet der Entwicklungsgenetik. Dr. Nüsslein-Volhard nahm den Preis kürzlich im Roche Institute for Molecular Biology (RIMB), dem unabhängigen Zentrum für Grundlagenforschung von Hoffmann-La Roche USA, entgegen.

Zu den wichtigsten Forschungsergebnissen von Frau Nüsslein-Volhard gehört der Nachweis, dass mütterliche Gene (sogenannte mütterliche Effekt-Gene) im Ei der Frucht Iliege ausschlaggebend sind für die Ausbildung von Organen und Körpern des Insektes. Durch diese Untersuchungen hat Dr. Nüsslein-Volhard wichtige Prinzipien der Genetik geklärt, die möglicherweise auch für Entwicklungsprozesse anderer Lebewesen Gültigkeit haben.

Christiane Nüsslein-Volhard, in Magdeburg geboren, crwarb 1968 das Diplom für Biochemie und 1973 den Doktor der Biologie an der Universität in Tübingen. Sie hat zahlreiche Ehrungen und Auszeichnungen erhalten, darunter die Carus-Medaille der Deutschen Akademie der Wissenschaften, die Rosenstiel-Medaille sowie den Ehrendoktor der Yale University. Sie is ausserdem Mitglied der U.S. National Academy of Science und der British Royal Society. Seit 1985 leitet Dr. Nüsslein-Volhard die Abteilung für Entwicklungsbiologie am Friedrich-Miescher-Laboratorium in der Max-Planck-Gesellschaft in Tübingen.

Der V. D. Mattia Preis ist nach dem früheren Präsidenten von Hoffmann-La Roche Inc., Nutley und Gründer des RIMB benannt. Unter den bisherigen Prcisträgern finden sich acht spätere Nobelpreisträger.
Zufriedene Besucher und Aussteller an der

24.1.91 ILMAC 90

Nach viertägiger Messedauer schloss die ILMAC 90, die 11. Internationale Fachmesse für Laboratoriumsund Verfahrenstechnik, Messtechnik und Automatik am Freitag 26. Oktober ihrc Tore. Die Aussteller der Chemie-Fachmesse, die in den Hallen der Schweizer Mustermesse durchgeführt wurde, zeigten sich mit dem Messeverlauf durchwegs zufrieden.

Knapp 23750 verkaufte Eintritte bedeuten für die ILMAC 90 ein sehr gutes Besucherergebnis. Liegt doch diescs Resultat im Bereich der vergleichbaren Zahlen von 1987, wobei im damaligen Ergebnis die Besucher der gleichzeitig durchgeführten Apothekerfachmesse lpharmex 87 enthalten sind.

Seitens der rund 480 Aussteller, die auf $16000 \mathrm{~m}^{2}$ Nettostandfläche ihre Dienstleistungen und Produkte anboten, wurde denn auch betont, dass die Besucher nicht nur zahlreicher, sondern vor allem sehr interessiert und kompetent waren. Dies bestitigt auch die von de KONSO, Basel, durchgeführte Besucherumfrage, wonach zwei Drittel der Besucher bei Investitionen mindestens mitentscheidend sind. Die Besucher ihrerseits erteilten auch der Messe gute Noten. So beurteilten fast $60 \%$ der Befragten die ILMAC als eine der wichtigsten Fachmessen der Branche. Der Besucheranteil aus dem Ausland betrug $18 \%$

Reges Interesse fand auch die Sonderschau zum Them 'Explosionsschutz', wo man sich von fachkundige Seite her über die Leistungen der Industrie im Explosionsschutz informieren lassen konnte.

\section{Société vaudoise des sciences naturelles}

Mercredi à $17.15 \mathrm{~h}$, Auditoire C, Collège Propedeutique, Université de Lausanne, Dorigny

1991

9 janvier Prof. A. Storck, ENSIC à Nancy (F)

23 janvier Prof, Dr. P.J. Crutzen, Otto Hahn Institut, Chimie de l'atmosphère à Mainz (D)

7.2 .91 H. Schwarz "Crofitut für Org Chemie. TU Berlin 'Chemie nackter Moleküle'

Prof. Dr. A. Pfalt Institut für Org. Chemie, Universität Base

'Enantioselektive Katalyse mit chiralen Metallkomplexen'

\section{Laboratorium für anorg. Chemie der ETH Zürich}

\section{Koordinationschemie und homogene Katalyse}

Mittwoch, 9.00-10.15, CAB B9

Universitätstrasse 6

9. Januar Prof. Jolm A. Oshorn, Universiti Louis Pasteur, Strasbourg 'Aspects of Enantioselective Hydrogenation with Metal Complexes'

Ende Januar Prof. Lars I. Elding, University of Lund

Der Titel wird später bekanntgegeben

20. Februar Prol, A. Ludi, Universität Bern Struktur und Reaktivität von Kom plexen als Funktion der Ligandenperipherie'

\section{Chemische Gesellschaft Zürich}

Alle Vorträge finden statt: Mittwoch, 17.15 Uhr, Hörsaal CAB D2 im Chemie-Altbau ETH, Universitätstrasse 6, 8092 Zürich.

9. Jan. 1991

Prof. Dr. H. Oeschger Physikalisches Institut Universität Bern, Bern Die sich ändernde Almosphäre; aus der Perspektive der $\mathrm{CO}_{2}$ - und $\mathrm{Kli}$ maschwankungen der Vergangenheit

\section{Institut für Polymere, ETH Zürich}

30. Januar 91

altes Chemiegebäude ETHZ, D28

Prof. Dr. C. D. Eisenbach, Universität Bayreuth

Polymere mit massgeschneiderten supramolekularen Strukturen und Eigenschaften

13. Februar 91

altes Chemiegebäude ETHZ, D28

Prof. Dr. S. Russo, Istituto di Chimica Industriale CNR, Università di Genova

A Novel Synthetic Approach to Poly(caprolactam)-based Materials

20. Februar 91

altes Chemiegebäude ETHZ, D28

Prof. Dr. W. Helfrich, Institut für Theoretische Physik, Freie Universität Berlin

Spontane Vesikulation und kubische Phasen von $\mathrm{Li}$ piddoppelschichten

\section{Basler Chemische Gesellschaft}

(Donnerstag, 16.45 Uhr, im kleinen Hörsaal des Instituts für Organische Chemie)
PD Dr. R. Schwesinger

Institut für Organische Chemie und Biochemie

Universität Freiburg, Freiburg, i. Br., BRD

Extrem starke, ungeladene Phosphazenbasen, 'Komplementüre Metallorganica"

30. Jan. 1991 Prof. Dr. St.G. Daries Department of Organic Chemistry University of Oxford, Oxford, GB Exploiting the law of mass action for synthesis

Prof. Dr. H. Werner

Institut für anorganische Chemio Universität Würzburg, Würzburg, BRD

Aktivierung gesättigter und ungesättigter Kohlenwasserstoffe durch elektronenreiche Ubergangsmetallkomplexe: Der Weg von der Synthese zur Katalyse

rof, Dr. C.W. Hilhers Laboratory of Biophysical ChemisUniversity of Nijmegen, Nijmegen, NMR studies of regularities in unusual DNA struclures 
sequent documents. It is hoped that this set of bioanalytical definitions will be useful to the practitioners of clinical chemistry and will foster improved communications and understanding between them.

Comments on the document are welcome and should be sent by 31st October 1991 to: Dr Carl A. Burtis, Oak Ridge National Laboratory, P. O. Box 2008, Bldg. 4500-N, MS 6194, Oak Ridge, Tennessee 37831, USA

\section{Chemie-Sicherheitspreis der ESCIS 1990}

Die ESCIS (Expertenkommission für Sicherheit in der chemischen Industrie der Schweiz) ist ein unabhängiges Gremium, das sich aus Persönlichkeiten der chemischen Industric, des Bundes (BIGA), der SUVA und von Hochschulen zusammensetzt. Dieses Gremium be fasst sich mit ciner Vielfalt von Sicherheitsfragen und praxisnahcn Lösungsmöglichkeiten für Sicherheitsprobleme und tritt mit verschiedenen technisch orientierten Publikationen sowie Ausbildungskursen an die Öffentlichkeit. Eines der wesentlichsten Anliegen der ESCIS ist die Förderung des Sicherheitsdenkens und insbesondere der Einbezug der Sicherheitsbelange in die Unterrichtsprogramme an Ausbildungsstätten.

Anlässlich ihres 25-Jahr-Jubiläums im Jahre 1981 beschloss die ESCIS, einen Preis auszusetzen zur Aus zeichnung von Arbeiten bzw. von besonderen Verdiensten im Sinne dieser Anliegen. Nach 1983 und 1987 wird nunmehr 1990 zum dritten Mal der ESCIS-Preis, der mit 10000 Franken dotiert ist, verliehen

Nach umfangreichen Abklärungen und der Prüfung verschicdener Anträgc hat sich die ESCIS-Iury ent schieden, den für 1990 ausgesetzten ESCIS-Preis in voller Höhe Herrn Dr. Gérard Killé, Dozent an der Ecole Nationale Supérieure de Chimie de Mulhouse, zuzu sprechen. Herr Dr. Killé ist seit Jahren mit grossem Erfolg auf dem Gebiet der wissenschaftlich-technischen Sicherheitsausbildung tätig und verleiht diese Ausbildung an der Ecole Nationale Supérieure de Chimic de Muthouse insbesondere mit Spezialkursen starke Jmpulse.

Die offizielle Übergabe des ESCIS-Preises an Herrn Dr. Killé hat anlässlich der ILMAC-Eröffnung am 23. Oktober 1990 in Basel stattgefunden.

\section{Wissenschaftlerin des}

\section{Max-Planck-Institutes erhält}

Roche-Auszeichnung in den USA

Dr. Christiane Nüsslein-Volhard, Direktorin des Tübinger Friedrich-Miescher-Laboratoriums in der MaxPlanck-Gesellschaft, ist die diesjährige Preisträgerin des V.D. Mattia Preises von Hoffmann-La Roche Inc. Nutley, USA. Sie erhielt die Auszeichnung für ihre hervorragenden Beiträge zur biomedizinischen Forschung auf dem Gebiet der Entwicklungsgenetik. Dr. Nüsslein-Volhard nahm den Preis kürzlich im Roche Institute for Molecular Biology (RIMB), dem unabhängigen Zentrum für Grundlagenforschung von Hoffmann-La Roche USA, entgegen.

Zu den wichtigsten Forschungsergebnissen von Frau Nüsslein-Volhard gehört der Nachweis, dass mütterliche Gene (sogenannte mütterliche Effekt-Gene) im Ei der Frucht Iliege ausschlaggebend sind für die Ausbildung von Organen und Körpern des Insektes. Durch diese Untersuchungen hat Dr. Nüsslein-Volhard wichtige Prinzipien der Genetik geklärt, die möglicherweise auch für Entwicklungsprozesse anderer Lebewesen Gültigkeit haben.

Christiane Nüsslein-Volhard, in Magdeburg geboren, crwarb 1968 das Diplom für Biochemie und 1973 den Doktor der Biologie an der Universität in Tübingen. Sie hat zahlreiche Ehrungen und Auszeichnungen erhalten, darunter die Carus-Medaille der Deutschen Akademie der Wissenschaften, die Rosenstiel-Medaille sowie den Ehrendoktor der Yale University. Sie is ausserdem Mitglied der U.S. National Academy of Science und der British Royal Society. Seit 1985 leitet Dr. Nüsslein-Volhard die Abteilung für Entwicklungsbiologie am Friedrich-Miescher-Laboratorium in der Max-Planck-Gesellschaft in Tübingen.

Der V. D. Mattia Preis ist nach dem früheren Präsidenten von Hoffmann-La Roche Inc., Nutley und Gründer des RIMB benannt. Unter den bisherigen Prcisträgern finden sich acht spätere Nobelpreisträger.
Zufriedene Besucher und Aussteller an der

24.1.91 ILMAC 90

Nach viertägiger Messedauer schloss die ILMAC 90, die 11. Internationale Fachmesse für Laboratoriumsund Verfahrenstechnik, Messtechnik und Automatik am Freitag 26. Oktober ihrc Tore. Die Aussteller der Chemie-Fachmesse, die in den Hallen der Schweizer Mustermesse durchgeführt wurde, zeigten sich mit dem Messeverlauf durchwegs zufrieden.

Knapp 23750 verkaufte Eintritte bedeuten für die ILMAC 90 ein sehr gutes Besucherergebnis. Liegt doch diescs Resultat im Bereich der vergleichbaren Zahlen von 1987, wobei im damaligen Ergebnis die Besucher der gleichzeitig durchgeführten Apothekerfachmesse lpharmex 87 enthalten sind.

Seitens der rund 480 Aussteller, die auf $16000 \mathrm{~m}^{2}$ Nettostandfläche ihre Dienstleistungen und Produkte anboten, wurde denn auch betont, dass die Besucher nicht nur zahlreicher, sondern vor allem sehr interessiert und kompetent waren. Dies bestitigt auch die von de KONSO, Basel, durchgeführte Besucherumfrage, wonach zwei Drittel der Besucher bei Investitionen mindestens mitentscheidend sind. Die Besucher ihrerseits erteilten auch der Messe gute Noten. So beurteilten fast $60 \%$ der Befragten die ILMAC als eine der wichtigsten Fachmessen der Branche. Der Besucheranteil aus dem Ausland betrug $18 \%$

Reges Interesse fand auch die Sonderschau zum Them 'Explosionsschutz', wo man sich von fachkundige Seite her über die Leistungen der Industrie im Explosionsschutz informieren lassen konnte.

\section{Société vaudoise des sciences naturelles}

Mercredi à $17.15 \mathrm{~h}$, Auditoire C, Collège Propedeutique, Université de Lausanne, Dorigny

1991

9 janvier Prof. A. Storck, ENSIC à Nancy (F)

23 janvier Prof, Dr. P.J. Crutzen, Otto Hahn Institut, Chimie de l'atmosphère à Mainz (D)

7.2 .91 H. Schwarz "Crofitut für Org Chemie. TU Berlin 'Chemie nackter Moleküle'

Prof. Dr. A. Pfalt Institut für Org. Chemie, Universität Base

'Enantioselektive Katalyse mit chiralen Metallkomplexen'

\section{Laboratorium für anorg. Chemie der ETH Zürich}

\section{Koordinationschemie und homogene Katalyse}

Mittwoch, 9.00-10.15, CAB B9

Universitätstrasse 6

9. Januar Prof. Jolm A. Oshorn, Universiti Louis Pasteur, Strasbourg 'Aspects of Enantioselective Hydrogenation with Metal Complexes'

Ende Januar Prof. Lars I. Elding, University of Lund

Der Titel wird später bekanntgegeben

20. Februar Prol, A. Ludi, Universität Bern Struktur und Reaktivität von Kom plexen als Funktion der Ligandenperipherie'

\section{Chemische Gesellschaft Zürich}

Alle Vorträge finden statt: Mittwoch, 17.15 Uhr, Hörsaal CAB D2 im Chemie-Altbau ETH, Universitätstrasse 6, 8092 Zürich.

9. Jan. 1991

Prof. Dr. H. Oeschger Physikalisches Institut Universität Bern, Bern Die sich ändernde Almosphäre; aus der Perspektive der $\mathrm{CO}_{2}$ - und $\mathrm{Kli}$ maschwankungen der Vergangenheit

\section{Institut für Polymere, ETH Zürich}

30. Januar 91

altes Chemiegebäude ETHZ, D28

Prof. Dr. C. D. Eisenbach, Universität Bayreuth

Polymere mit massgeschneiderten supramolekularen Strukturen und Eigenschaften

13. Februar 91

altes Chemiegebäude ETHZ, D28

Prof. Dr. S. Russo, Istituto di Chimica Industriale CNR, Università di Genova

A Novel Synthetic Approach to Poly(caprolactam)-based Materials

20. Februar 91

altes Chemiegebäude ETHZ, D28

Prof. Dr. W. Helfrich, Institut für Theoretische Physik, Freie Universität Berlin

Spontane Vesikulation und kubische Phasen von $\mathrm{Li}$ piddoppelschichten

\section{Basler Chemische Gesellschaft}

(Donnerstag, 16.45 Uhr, im kleinen Hörsaal des Instituts für Organische Chemie)
PD Dr. R. Schwesinger

Institut für Organische Chemie und Biochemie

Universität Freiburg, Freiburg, i. Br., BRD

Extrem starke, ungeladene Phosphazenbasen, 'Komplementüre Metallorganica"

30. Jan. 1991 Prof. Dr. St.G. Daries Department of Organic Chemistry University of Oxford, Oxford, GB Exploiting the law of mass action for synthesis

Prof. Dr. H. Werner

Institut für anorganische Chemio Universität Würzburg, Würzburg, BRD

Aktivierung gesättigter und ungesättigter Kohlenwasserstoffe durch elektronenreiche Ubergangsmetallkomplexe: Der Weg von der Synthese zur Katalyse

rof, Dr. C.W. Hilhers Laboratory of Biophysical ChemisUniversity of Nijmegen, Nijmegen, NMR studies of regularities in unusual DNA struclures 
sequent documents. It is hoped that this set of bioanalytical definitions will be useful to the practitioners of clinical chemistry and will foster improved communications and understanding between them.

Comments on the document are welcome and should be sent by 31st October 1991 to: Dr Carl A. Burtis, Oak Ridge National Laboratory, P. O. Box 2008, Bldg. 4500-N, MS 6194, Oak Ridge, Tennessee 37831, USA

\section{Chemie-Sicherheitspreis der ESCIS 1990}

Die ESCIS (Expertenkommission für Sicherheit in der chemischen Industrie der Schweiz) ist ein unabhängiges Gremium, das sich aus Persönlichkeiten der chemischen Industric, des Bundes (BIGA), der SUVA und von Hochschulen zusammensetzt. Dieses Gremium be fasst sich mit ciner Vielfalt von Sicherheitsfragen und praxisnahcn Lösungsmöglichkeiten für Sicherheitsprobleme und tritt mit verschiedenen technisch orientierten Publikationen sowie Ausbildungskursen an die Öffentlichkeit. Eines der wesentlichsten Anliegen der ESCIS ist die Förderung des Sicherheitsdenkens und insbesondere der Einbezug der Sicherheitsbelange in die Unterrichtsprogramme an Ausbildungsstätten.

Anlässlich ihres 25-Jahr-Jubiläums im Jahre 1981 beschloss die ESCIS, einen Preis auszusetzen zur Aus zeichnung von Arbeiten bzw. von besonderen Verdiensten im Sinne dieser Anliegen. Nach 1983 und 1987 wird nunmehr 1990 zum dritten Mal der ESCIS-Preis, der mit 10000 Franken dotiert ist, verliehen

Nach umfangreichen Abklärungen und der Prüfung verschicdener Anträgc hat sich die ESCIS-Iury ent schieden, den für 1990 ausgesetzten ESCIS-Preis in voller Höhe Herrn Dr. Gérard Killé, Dozent an der Ecole Nationale Supérieure de Chimie de Mulhouse, zuzu sprechen. Herr Dr. Killé ist seit Jahren mit grossem Erfolg auf dem Gebiet der wissenschaftlich-technischen Sicherheitsausbildung tätig und verleiht diese Ausbildung an der Ecole Nationale Supérieure de Chimic de Muthouse insbesondere mit Spezialkursen starke Jmpulse.

Die offizielle Übergabe des ESCIS-Preises an Herrn Dr. Killé hat anlässlich der ILMAC-Eröffnung am 23. Oktober 1990 in Basel stattgefunden.

\section{Wissenschaftlerin des}

\section{Max-Planck-Institutes erhält}

Roche-Auszeichnung in den USA

Dr. Christiane Nüsslein-Volhard, Direktorin des Tübinger Friedrich-Miescher-Laboratoriums in der MaxPlanck-Gesellschaft, ist die diesjährige Preisträgerin des V.D. Mattia Preises von Hoffmann-La Roche Inc. Nutley, USA. Sie erhielt die Auszeichnung für ihre hervorragenden Beiträge zur biomedizinischen Forschung auf dem Gebiet der Entwicklungsgenetik. Dr. Nüsslein-Volhard nahm den Preis kürzlich im Roche Institute for Molecular Biology (RIMB), dem unabhängigen Zentrum für Grundlagenforschung von Hoffmann-La Roche USA, entgegen.

Zu den wichtigsten Forschungsergebnissen von Frau Nüsslein-Volhard gehört der Nachweis, dass mütterliche Gene (sogenannte mütterliche Effekt-Gene) im Ei der Frucht Iliege ausschlaggebend sind für die Ausbildung von Organen und Körpern des Insektes. Durch diese Untersuchungen hat Dr. Nüsslein-Volhard wichtige Prinzipien der Genetik geklärt, die möglicherweise auch für Entwicklungsprozesse anderer Lebewesen Gültigkeit haben.

Christiane Nüsslein-Volhard, in Magdeburg geboren, crwarb 1968 das Diplom für Biochemie und 1973 den Doktor der Biologie an der Universität in Tübingen. Sie hat zahlreiche Ehrungen und Auszeichnungen erhalten, darunter die Carus-Medaille der Deutschen Akademie der Wissenschaften, die Rosenstiel-Medaille sowie den Ehrendoktor der Yale University. Sie is ausserdem Mitglied der U.S. National Academy of Science und der British Royal Society. Seit 1985 leitet Dr. Nüsslein-Volhard die Abteilung für Entwicklungsbiologie am Friedrich-Miescher-Laboratorium in der Max-Planck-Gesellschaft in Tübingen.

Der V. D. Mattia Preis ist nach dem früheren Präsidenten von Hoffmann-La Roche Inc., Nutley und Gründer des RIMB benannt. Unter den bisherigen Prcisträgern finden sich acht spätere Nobelpreisträger.
Zufriedene Besucher und Aussteller an der

24.1.91 ILMAC 90

Nach viertägiger Messedauer schloss die ILMAC 90, die 11. Internationale Fachmesse für Laboratoriumsund Verfahrenstechnik, Messtechnik und Automatik am Freitag 26. Oktober ihrc Tore. Die Aussteller der Chemie-Fachmesse, die in den Hallen der Schweizer Mustermesse durchgeführt wurde, zeigten sich mit dem Messeverlauf durchwegs zufrieden.

Knapp 23750 verkaufte Eintritte bedeuten für die ILMAC 90 ein sehr gutes Besucherergebnis. Liegt doch diescs Resultat im Bereich der vergleichbaren Zahlen von 1987, wobei im damaligen Ergebnis die Besucher der gleichzeitig durchgeführten Apothekerfachmesse lpharmex 87 enthalten sind.

Seitens der rund 480 Aussteller, die auf $16000 \mathrm{~m}^{2}$ Nettostandfläche ihre Dienstleistungen und Produkte anboten, wurde denn auch betont, dass die Besucher nicht nur zahlreicher, sondern vor allem sehr interessiert und kompetent waren. Dies bestitigt auch die von de KONSO, Basel, durchgeführte Besucherumfrage, wonach zwei Drittel der Besucher bei Investitionen mindestens mitentscheidend sind. Die Besucher ihrerseits erteilten auch der Messe gute Noten. So beurteilten fast $60 \%$ der Befragten die ILMAC als eine der wichtigsten Fachmessen der Branche. Der Besucheranteil aus dem Ausland betrug $18 \%$

Reges Interesse fand auch die Sonderschau zum Them 'Explosionsschutz', wo man sich von fachkundige Seite her über die Leistungen der Industrie im Explosionsschutz informieren lassen konnte.

\section{Société vaudoise des sciences naturelles}

Mercredi à $17.15 \mathrm{~h}$, Auditoire C, Collège Propedeutique, Université de Lausanne, Dorigny

1991

9 janvier Prof. A. Storck, ENSIC à Nancy (F)

23 janvier Prof, Dr. P.J. Crutzen, Otto Hahn Institut, Chimie de l'atmosphère à Mainz (D)

7.2 .91 H. Schwarz "Crofitut für Org Chemie. TU Berlin 'Chemie nackter Moleküle'

Prof. Dr. A. Pfalt Institut für Org. Chemie, Universität Base

'Enantioselektive Katalyse mit chiralen Metallkomplexen'

\section{Laboratorium für anorg. Chemie der ETH Zürich}

\section{Koordinationschemie und homogene Katalyse}

Mittwoch, 9.00-10.15, CAB B9

Universitätstrasse 6

9. Januar Prof. Jolm A. Oshorn, Universiti Louis Pasteur, Strasbourg 'Aspects of Enantioselective Hydrogenation with Metal Complexes'

Ende Januar Prof. Lars I. Elding, University of Lund

Der Titel wird später bekanntgegeben

20. Februar Prol, A. Ludi, Universität Bern Struktur und Reaktivität von Kom plexen als Funktion der Ligandenperipherie'

\section{Chemische Gesellschaft Zürich}

Alle Vorträge finden statt: Mittwoch, 17.15 Uhr, Hörsaal CAB D2 im Chemie-Altbau ETH, Universitätstrasse 6, 8092 Zürich.

9. Jan. 1991

Prof. Dr. H. Oeschger Physikalisches Institut Universität Bern, Bern Die sich ändernde Almosphäre; aus der Perspektive der $\mathrm{CO}_{2}$ - und $\mathrm{Kli}$ maschwankungen der Vergangenheit

\section{Institut für Polymere, ETH Zürich}

30. Januar 91

altes Chemiegebäude ETHZ, D28

Prof. Dr. C. D. Eisenbach, Universität Bayreuth

Polymere mit massgeschneiderten supramolekularen Strukturen und Eigenschaften

13. Februar 91

altes Chemiegebäude ETHZ, D28

Prof. Dr. S. Russo, Istituto di Chimica Industriale CNR, Università di Genova

A Novel Synthetic Approach to Poly(caprolactam)-based Materials

20. Februar 91

altes Chemiegebäude ETHZ, D28

Prof. Dr. W. Helfrich, Institut für Theoretische Physik, Freie Universität Berlin

Spontane Vesikulation und kubische Phasen von $\mathrm{Li}$ piddoppelschichten

\section{Basler Chemische Gesellschaft}

(Donnerstag, 16.45 Uhr, im kleinen Hörsaal des Instituts für Organische Chemie)
PD Dr. R. Schwesinger

Institut für Organische Chemie und Biochemie

Universität Freiburg, Freiburg, i. Br., BRD

Extrem starke, ungeladene Phosphazenbasen, 'Komplementüre Metallorganica"

30. Jan. 1991 Prof. Dr. St.G. Daries Department of Organic Chemistry University of Oxford, Oxford, GB Exploiting the law of mass action for synthesis

Prof. Dr. H. Werner

Institut für anorganische Chemio Universität Würzburg, Würzburg, BRD

Aktivierung gesättigter und ungesättigter Kohlenwasserstoffe durch elektronenreiche Ubergangsmetallkomplexe: Der Weg von der Synthese zur Katalyse

rof, Dr. C.W. Hilhers Laboratory of Biophysical ChemisUniversity of Nijmegen, Nijmegen, NMR studies of regularities in unusual DNA struclures 


\section{0-Jahr-Feier der Berner Chemischen Gesellschaft}

\section{2./23. Februar 1991}

Symposium: Chemie gestern-heute-morgen

22. Februar 1991

Grosser Hörsaal Chem. Institute

09.30-12.55 Uhr

Prof. H. Lübhe, Universität Zürich:

'Erfahrungsverluste. Überkulturelle und politische Folgen des wissenschaftlich-technischen Fortschritts' Prof. J. Drews, F. Hoffmann-La Roche AG:

'Krankheit, Diagnose und Therapie aus chemischer Sicht: die Rolle naturwissenschaftlicher Paradigmen in der Medizin

Prof. W. Stumm, EAWAG Dübendorf:

'Umweltchemische Forschung: vom Elektron zum globalen Kreislauf

Prof. E. Schumacher, Universität Bern

'Reflexion der Chemie im Computer'

\section{Februar 199}

Treppenhaus Chem. Inst.

14.00-18.00 Uhr

Ausstellung ehemaliger Berner Chemiestudentinnen und -studenten über ihre gegenwärtige berufliche Tätigkeit
23. Februar 1991

Chemische Institute

ab 09.00 Uhr Tag der offenen Tür

\section{Laboratorium für Organische Chemie der ETH Zürich}

\section{Organisch-chemische Kolloquien}

Hörsaal CHN A31 Universitätsstrasse 16,8092 Zürich Montags, jeweils $16.30 \mathrm{Uhr}$

7. Jan. 1991

\section{Prof. Dr. Georg Fuchs}

Angewandte Mikrobiologie, Universität Ulm/BRD

"Über die vollständige mikrobjelle Oxidation von Aromaten ohne Sauerstoff

14. Jan. 1991 Prof. Dr. Manfred C. Regitz FB Chemie, Organische Chemie, Universität Kaiserlautern/BRD

'Phosphaalkine - Neue Möglichkeiten in der Heteroatomchemie'

21. Jan. 1991 Prof. Dr. Pierre Vogel Institut de chimie organique, Université de Lausanne

"Asymmetric Synthesis of Biomolecules Using 'Naked Sugars'
28. Jan. 1991 Prof. Dr. Claude Hëlène Lab. de Biophysique, Muséum National d'Histoire Naturelle, Paris/F 'Rational Design of Sequence-specific Inhibitors of Gene Expression

31.Jan. 1991 Dr. Stephen G. Davies The Dyson Perrins Laboratory, University of Oxford/GB 'Small Chiral Auxiliaries'

4.Feb. 1991 Prof. Dr. Gernot Boche FB Chemie, Philipps-Universität Marburg/BRD

'Zur Struktur und Reaktivität Li-organischer Verbindungen: einige Mosaiksteine*

11. Feb. 1991 Prof. Dr. Eherhard Steckhan Institut für Organische Chemic und Biochemie, Universität Bonn/BRD 'Redoxkatalytische Verfahren zur nicht-enzymatischen Cofaktorregenerierung und Enzymaktivierung für enzymatische Synthesen'

18. Feb. 1991 Fält aus wegen Abtcilungskonferenz

25. Feb. 1991 Univ.-Doz. Dr. Christoph Kratky Institut für Physikalische Chemie, Universität $\mathrm{Graz} / \mathrm{A}$ 'B $B_{12}$-Kristallographie'

\section{Markt: Apparate, Chemikalien und Dienstleistungen}

Ex-geschützte Behälter und Rohrbegleitheizungen

Immer häufiger werden in Chemieanlagen elektrische Beheizungen in exgeschützter Ausführung installiert. Dank einem speziellen Computerprogramm können solche Heizsysteme für Behälter, Reaktoren, Silos, Trichter. Rohrleitungen usw, innert kürzester Zeit ausgelegt und geliefert werden. Je nach Anwendungsfall wird $z, B$. bei einem Behälter der gesamte oder nur der untere Teil des Mantels und der Boden beheizt. Um die Montagezeit zu verkürzen, können auch vorgefertigte Heizmatten verwendet werden. Viele der zu lagernden Medien sind temperaturempfindlich. Das entsprechende Regelsystem ist deshalb so ausgelegt, dass an der gesamten Behälterwand gleiche thermische Verhältnisse gegeben sind. Das Medium kann somit einwandfrei beheizt werden. Elektrische Beheizsysteme können für Temperaturen bis zu $1000^{\circ} \mathrm{C}$ (nicht exgeschützt) geliefert werden.

- WISAG, Wissenschaftliche Apparaturen und Industrieanlagen AG, Oerlikonerstrasse $88, \mathrm{CH} 8057$ Zürich, Tel. (01) 3114040

$$
\text { Leserdienst } 5 I
$$

\section{Druckunabhängiges}

Dosieren von Gasen

Mit dem neuen Gas-Dosiergerät FC300 ist es möglich, Gasströme, unabhängig von variablen Ein- oder Ausgangsdrücken, genau zu dosieren. Das Gerät bietet die Möglichkeit, den Gasstrom über einen Schreiber zu registrieren oder über eine bereits vorhandene Fremdsteuerung vorzuwählen. $1 \mathrm{~m}$ Falle von externen oder internen Störungen werden am Steuergerät Alarmmeldungen angezeigt, und auf Wunsch erfolgt ein automatisches Abschalten oder Weiterleiten.
Der Einsatz mit spezieller Ausführung ist ebenfalls im Ex-Bereich möglich Gas-Dosiergeräte Typ FC-300 DD sind für variable Ausgangsdrücke und de Typ FC-300 DU für variable Eingangsdrücke vorgesehen.

Wisag, Oerlikonerstrasse $88, \mathrm{CH}$ 8057 Zürich. Tel. (01) 3114040 . Leserdienst 52

\section{Ein gutes System verbessern}

Für das Messen und Dosieren von Gas- und Flüssigkeitsströmen sind die Messgeräte nach dem Schwebekörperprinzip vielfach auch aus preislichen Gründen eingesetzt. Um genau bestimmte Durchflusswerte überwachen zu können oder um Mini- und/oder MaxiAlarmwerte zu signalisieren, werden fremdlichtgeschützte Infrarot-Photozellen in die Durchflussmesser eingebaut. Dieses System erlaubt ein automatisches Überwachen von beliebigen Durchflussströmen. Die Photozellen sind auf Schienen montiert und auf der ganzen Skalenlänge sehr leicht und stufenlos fixierbar. Spezielle Ausführungen sind auch im ExBereich einsetzbar.

- Wisag, Oerlikonerstrasse $88, \mathrm{CH}-$ 8057 Zürich, Tel. (01) 3114040.

Leserdienst 53

\section{Neue Kalibrierstelle}

Die Revue Thommen AG wurde mi Wirkung ab Februar 1990 vom Eidgenössischen Amt für Messwesen (EAM) als Kalibrierstelle für die physikalische Grösse "Druck" anerkannt. Mit dieser Zulassung als Kalibrierstelle wurde ein weiterer Schritt zur Zukunftssicherung durchgeführt, um der erhöhten Nachfrage, den Anforderungen des Marktes in bezug auf die Qualitätssicherung bei
Druckmessinstrumenten, -geräten gerecht zu werden. Durch diese Massnahme beziehungsweise Dienstleistung als Kalibrierstelle für "Druck" wird die nationale und internationale Marktposition der Revue Thommen AG gestärkt und gefestigt.

Revue Thommen $\mathrm{AG}, \mathrm{CH}-4437 \mathrm{Wal}-$ denburg, Tel. (061) 9704 11, Telefax (061) 978171

Leserdienst 54

Immerwährende hohe

Messgenauigkeit

Messgenauigkeit bei Flüssigkeiten und Gasen gleich hoch - keine Beeinträchtigung durch Verunreinigungen des Mediums - keine Wartung - nahezu unbegrenzte Lebensdauer: Diese Merkmale der Durchflussmesser von Fluid Inventor haben sich in ausgeführten Anlagen immer wieder bestätigt. Die Gehäuse, wahlweise aus Gusseisen oder Edelstahl, werden serienmässig für die Nenndrücke PN 10, PN 16, PN 25 und PN 40 sowie für die Nennweiten DN 20 bis DN 400 gebaut. Grössere Nennweiten sind auch lieferbar. Die Durchflussmesser enthalten keine beweglichen Teile. Als Messwertgeber dient ein sogenannter Fluidistor-Oszillator. Das vom Medium durchströmte Gehäuse enthält eine Drossel mit dem gleichen Durchflusskoeffizienten wie der Messwertgeber selbst. Das Frequenz-Volumenstrom-Verhältnis wird durch die Viskosität bzw. Dichte des Mediums nicht beeinflusst. Die Schwingungszahl des Oszillators ist dem Volumenstrom im Messwertgeber und somit auch dem Durchfluss im Gehäuse direkt proportional. Ein kompletter Gerätesatz besteht aus dem eigentlichen Durchilussmesser und dem zugehörigen Signalumformer. Der Umformer steht in mehreren Ausführungen zur Verfügung:
Als Zählwerk (lmpulsverstärker), als lntegralmesswerk (Wärmemessungen) oder als sog. Durchflussrechner für $\mathrm{P}+\mathrm{T}$-kompensierte Gasdurchflussmessung. Die Durchflussmesser von Fluid Inventor erreichen praktisch unbegrenzte Lebensdauer.

Fluid Inventor AB, Box 81037 S-104 81 Stockholm. Tel. (46) 8440805 .

Fax (46) 844 1520, Telex: 13440

Leserdienst 55

Neues Farbsystem für MacIntosh optimiert die Farbwiedergabe auf Druckern

TekColor ermöglicht erstmals die Anpassung der Bildschirmfarben an Farbdrucker. Damit lassen sich auf dem Bildschirm erstellte Farbgrafiken auch in der Farbwiedergabe exakt auf dem angeschlossenen Farbdrucker reproduzieren. Das Softwarepaket TekColor besteh aus den drei folgenden Komponenten: inem Farbmodell, einer Benutzerschnittstelle und ciner Gerätedatenbank. Die erste Realisierung des Farbtreuesystems bietet Tektronix für Apple-MacIntosh-Il-Personalcomputer an. Ebenfalls unterstützt wird TekColor von PC-Software-Anbietern wie Aldus sowie den Bildschirmherstellern Radius, E-Machines und RasterOps. Durch die offene Schnittstellensperifikation in TekColor ermöglicht Tektronix auch anderen Anbietern den Zugriff auf das Farbwahlsystem. Tektronix geht davon aus, dass weitere Anbieter auf dem DTP-Mark das Farbwahlsystem einsetzen werden.

- Tektronix International AG, Kurt Mühlebach, Marketing Communications Manager, Gubelstrasse 11, CH $6300 \mathrm{Zug}$, Tel (042) 219192 


\section{0-Jahr-Feier der Berner Chemischen Gesellschaft}

\section{2./23. Februar 1991}

Symposium: Chemie gestern-heute-morgen

22. Februar 1991

Grosser Hörsaal Chem. Institute

09.30-12.55 Uhr

Prof. H. Lübhe, Universität Zürich:

'Erfahrungsverluste. Überkulturelle und politische Folgen des wissenschaftlich-technischen Fortschritts' Prof. J. Drews, F. Hoffmann-La Roche AG:

'Krankheit, Diagnose und Therapie aus chemischer Sicht: die Rolle naturwissenschaftlicher Paradigmen in der Medizin

Prof. W. Stumm, EAWAG Dübendorf:

'Umweltchemische Forschung: vom Elektron zum globalen Kreislauf

Prof. E. Schumacher, Universität Bern

'Reflexion der Chemie im Computer'

\section{Februar 199}

Treppenhaus Chem. Inst.

14.00-18.00 Uhr

Ausstellung ehemaliger Berner Chemiestudentinnen und -studenten über ihre gegenwärtige berufliche Tätigkeit
23. Februar 1991

Chemische Institute

ab 09.00 Uhr Tag der offenen Tür

\section{Laboratorium für Organische Chemie der ETH Zürich}

\section{Organisch-chemische Kolloquien}

Hörsaal CHN A31 Universitätsstrasse 16,8092 Zürich Montags, jeweils $16.30 \mathrm{Uhr}$

7. Jan. 1991

\section{Prof. Dr. Georg Fuchs}

Angewandte Mikrobiologie, Universität Ulm/BRD

"Über die vollständige mikrobjelle Oxidation von Aromaten ohne Sauerstoff

14. Jan. 1991 Prof. Dr. Manfred C. Regitz FB Chemie, Organische Chemie, Universität Kaiserlautern/BRD

'Phosphaalkine - Neue Möglichkeiten in der Heteroatomchemie'

21. Jan. 1991 Prof. Dr. Pierre Vogel Institut de chimie organique, Université de Lausanne

"Asymmetric Synthesis of Biomolecules Using 'Naked Sugars'
28. Jan. 1991 Prof. Dr. Claude Hëlène Lab. de Biophysique, Muséum National d'Histoire Naturelle, Paris/F 'Rational Design of Sequence-specific Inhibitors of Gene Expression

31.Jan. 1991 Dr. Stephen G. Davies The Dyson Perrins Laboratory, University of Oxford/GB 'Small Chiral Auxiliaries'

4.Feb. 1991 Prof. Dr. Gernot Boche FB Chemie, Philipps-Universität Marburg/BRD

'Zur Struktur und Reaktivität Li-organischer Verbindungen: einige Mosaiksteine*

11. Feb. 1991 Prof. Dr. Eherhard Steckhan Institut für Organische Chemic und Biochemie, Universität Bonn/BRD 'Redoxkatalytische Verfahren zur nicht-enzymatischen Cofaktorregenerierung und Enzymaktivierung für enzymatische Synthesen'

18. Feb. 1991 Fält aus wegen Abtcilungskonferenz

25. Feb. 1991 Univ.-Doz. Dr. Christoph Kratky Institut für Physikalische Chemie, Universität $\mathrm{Graz} / \mathrm{A}$ 'B $B_{12}$-Kristallographie'

\section{Markt: Apparate, Chemikalien und Dienstleistungen}

Ex-geschützte Behälter und Rohrbegleitheizungen

Immer häufiger werden in Chemieanlagen elektrische Beheizungen in exgeschützter Ausführung installiert. Dank einem speziellen Computerprogramm können solche Heizsysteme für Behälter, Reaktoren, Silos, Trichter. Rohrleitungen usw, innert kürzester Zeit ausgelegt und geliefert werden. Je nach Anwendungsfall wird $z, B$. bei einem Behälter der gesamte oder nur der untere Teil des Mantels und der Boden beheizt. Um die Montagezeit zu verkürzen, können auch vorgefertigte Heizmatten verwendet werden. Viele der zu lagernden Medien sind temperaturempfindlich. Das entsprechende Regelsystem ist deshalb so ausgelegt, dass an der gesamten Behälterwand gleiche thermische Verhältnisse gegeben sind. Das Medium kann somit einwandfrei beheizt werden. Elektrische Beheizsysteme können für Temperaturen bis zu $1000^{\circ} \mathrm{C}$ (nicht exgeschützt) geliefert werden.

- WISAG, Wissenschaftliche Apparaturen und Industrieanlagen AG, Oerlikonerstrasse $88, \mathrm{CH} 8057$ Zürich, Tel. (01) 3114040

$$
\text { Leserdienst } 5 I
$$

\section{Druckunabhängiges}

Dosieren von Gasen

Mit dem neuen Gas-Dosiergerät FC300 ist es möglich, Gasströme, unabhängig von variablen Ein- oder Ausgangsdrücken, genau zu dosieren. Das Gerät bietet die Möglichkeit, den Gasstrom über einen Schreiber zu registrieren oder über eine bereits vorhandene Fremdsteuerung vorzuwählen. $1 \mathrm{~m}$ Falle von externen oder internen Störungen werden am Steuergerät Alarmmeldungen angezeigt, und auf Wunsch erfolgt ein automatisches Abschalten oder Weiterleiten.
Der Einsatz mit spezieller Ausführung ist ebenfalls im Ex-Bereich möglich Gas-Dosiergeräte Typ FC-300 DD sind für variable Ausgangsdrücke und de Typ FC-300 DU für variable Eingangsdrücke vorgesehen.

Wisag, Oerlikonerstrasse $88, \mathrm{CH}$ 8057 Zürich. Tel. (01) 3114040 . Leserdienst 52

\section{Ein gutes System verbessern}

Für das Messen und Dosieren von Gas- und Flüssigkeitsströmen sind die Messgeräte nach dem Schwebekörperprinzip vielfach auch aus preislichen Gründen eingesetzt. Um genau bestimmte Durchflusswerte überwachen zu können oder um Mini- und/oder MaxiAlarmwerte zu signalisieren, werden fremdlichtgeschützte Infrarot-Photozellen in die Durchflussmesser eingebaut. Dieses System erlaubt ein automatisches Überwachen von beliebigen Durchflussströmen. Die Photozellen sind auf Schienen montiert und auf der ganzen Skalenlänge sehr leicht und stufenlos fixierbar. Spezielle Ausführungen sind auch im ExBereich einsetzbar.

- Wisag, Oerlikonerstrasse $88, \mathrm{CH}-$ 8057 Zürich, Tel. (01) 3114040.

Leserdienst 53

\section{Neue Kalibrierstelle}

Die Revue Thommen AG wurde mi Wirkung ab Februar 1990 vom Eidgenössischen Amt für Messwesen (EAM) als Kalibrierstelle für die physikalische Grösse "Druck" anerkannt. Mit dieser Zulassung als Kalibrierstelle wurde ein weiterer Schritt zur Zukunftssicherung durchgeführt, um der erhöhten Nachfrage, den Anforderungen des Marktes in bezug auf die Qualitätssicherung bei
Druckmessinstrumenten, -geräten gerecht zu werden. Durch diese Massnahme beziehungsweise Dienstleistung als Kalibrierstelle für "Druck" wird die nationale und internationale Marktposition der Revue Thommen AG gestärkt und gefestigt.

Revue Thommen $\mathrm{AG}, \mathrm{CH}-4437 \mathrm{Wal}-$ denburg, Tel. (061) 9704 11, Telefax (061) 978171

Leserdienst 54

Immerwährende hohe

Messgenauigkeit

Messgenauigkeit bei Flüssigkeiten und Gasen gleich hoch - keine Beeinträchtigung durch Verunreinigungen des Mediums - keine Wartung - nahezu unbegrenzte Lebensdauer: Diese Merkmale der Durchflussmesser von Fluid Inventor haben sich in ausgeführten Anlagen immer wieder bestätigt. Die Gehäuse, wahlweise aus Gusseisen oder Edelstahl, werden serienmässig für die Nenndrücke PN 10, PN 16, PN 25 und PN 40 sowie für die Nennweiten DN 20 bis DN 400 gebaut. Grössere Nennweiten sind auch lieferbar. Die Durchflussmesser enthalten keine beweglichen Teile. Als Messwertgeber dient ein sogenannter Fluidistor-Oszillator. Das vom Medium durchströmte Gehäuse enthält eine Drossel mit dem gleichen Durchflusskoeffizienten wie der Messwertgeber selbst. Das Frequenz-Volumenstrom-Verhältnis wird durch die Viskosität bzw. Dichte des Mediums nicht beeinflusst. Die Schwingungszahl des Oszillators ist dem Volumenstrom im Messwertgeber und somit auch dem Durchfluss im Gehäuse direkt proportional. Ein kompletter Gerätesatz besteht aus dem eigentlichen Durchilussmesser und dem zugehörigen Signalumformer. Der Umformer steht in mehreren Ausführungen zur Verfügung:
Als Zählwerk (lmpulsverstärker), als lntegralmesswerk (Wärmemessungen) oder als sog. Durchflussrechner für $\mathrm{P}+\mathrm{T}$-kompensierte Gasdurchflussmessung. Die Durchflussmesser von Fluid Inventor erreichen praktisch unbegrenzte Lebensdauer.

Fluid Inventor AB, Box 81037 S-104 81 Stockholm. Tel. (46) 8440805 .

Fax (46) 844 1520, Telex: 13440

Leserdienst 55

Neues Farbsystem für MacIntosh optimiert die Farbwiedergabe auf Druckern

TekColor ermöglicht erstmals die Anpassung der Bildschirmfarben an Farbdrucker. Damit lassen sich auf dem Bildschirm erstellte Farbgrafiken auch in der Farbwiedergabe exakt auf dem angeschlossenen Farbdrucker reproduzieren. Das Softwarepaket TekColor besteh aus den drei folgenden Komponenten: inem Farbmodell, einer Benutzerschnittstelle und ciner Gerätedatenbank. Die erste Realisierung des Farbtreuesystems bietet Tektronix für Apple-MacIntosh-Il-Personalcomputer an. Ebenfalls unterstützt wird TekColor von PC-Software-Anbietern wie Aldus sowie den Bildschirmherstellern Radius, E-Machines und RasterOps. Durch die offene Schnittstellensperifikation in TekColor ermöglicht Tektronix auch anderen Anbietern den Zugriff auf das Farbwahlsystem. Tektronix geht davon aus, dass weitere Anbieter auf dem DTP-Mark das Farbwahlsystem einsetzen werden.

- Tektronix International AG, Kurt Mühlebach, Marketing Communications Manager, Gubelstrasse 11, CH $6300 \mathrm{Zug}$, Tel (042) 219192 


\section{0-Jahr-Feier der Berner Chemischen Gesellschaft}

\section{2./23. Februar 1991}

Symposium: Chemie gestern-heute-morgen

22. Februar 1991

Grosser Hörsaal Chem. Institute

09.30-12.55 Uhr

Prof. H. Lübhe, Universität Zürich:

'Erfahrungsverluste. Überkulturelle und politische Folgen des wissenschaftlich-technischen Fortschritts' Prof. J. Drews, F. Hoffmann-La Roche AG:

'Krankheit, Diagnose und Therapie aus chemischer Sicht: die Rolle naturwissenschaftlicher Paradigmen in der Medizin

Prof. W. Stumm, EAWAG Dübendorf:

'Umweltchemische Forschung: vom Elektron zum globalen Kreislauf

Prof. E. Schumacher, Universität Bern

'Reflexion der Chemie im Computer'

\section{Februar 199}

Treppenhaus Chem. Inst.

14.00-18.00 Uhr

Ausstellung ehemaliger Berner Chemiestudentinnen und -studenten über ihre gegenwärtige berufliche Tätigkeit
23. Februar 1991

Chemische Institute

ab 09.00 Uhr Tag der offenen Tür

\section{Laboratorium für Organische Chemie der ETH Zürich}

\section{Organisch-chemische Kolloquien}

Hörsaal CHN A31 Universitätsstrasse 16,8092 Zürich Montags, jeweils $16.30 \mathrm{Uhr}$

7. Jan. 1991

\section{Prof. Dr. Georg Fuchs}

Angewandte Mikrobiologie, Universität Ulm/BRD

"Über die vollständige mikrobjelle Oxidation von Aromaten ohne Sauerstoff

14. Jan. 1991 Prof. Dr. Manfred C. Regitz FB Chemie, Organische Chemie, Universität Kaiserlautern/BRD

'Phosphaalkine - Neue Möglichkeiten in der Heteroatomchemie'

21. Jan. 1991 Prof. Dr. Pierre Vogel Institut de chimie organique, Université de Lausanne

"Asymmetric Synthesis of Biomolecules Using 'Naked Sugars'
28. Jan. 1991 Prof. Dr. Claude Hëlène Lab. de Biophysique, Muséum National d'Histoire Naturelle, Paris/F 'Rational Design of Sequence-specific Inhibitors of Gene Expression

31.Jan. 1991 Dr. Stephen G. Davies The Dyson Perrins Laboratory, University of Oxford/GB 'Small Chiral Auxiliaries'

4.Feb. 1991 Prof. Dr. Gernot Boche FB Chemie, Philipps-Universität Marburg/BRD

'Zur Struktur und Reaktivität Li-organischer Verbindungen: einige Mosaiksteine*

11. Feb. 1991 Prof. Dr. Eherhard Steckhan Institut für Organische Chemic und Biochemie, Universität Bonn/BRD 'Redoxkatalytische Verfahren zur nicht-enzymatischen Cofaktorregenerierung und Enzymaktivierung für enzymatische Synthesen'

18. Feb. 1991 Fält aus wegen Abtcilungskonferenz

25. Feb. 1991 Univ.-Doz. Dr. Christoph Kratky Institut für Physikalische Chemie, Universität $\mathrm{Graz} / \mathrm{A}$ 'B $B_{12}$-Kristallographie'

\section{Markt: Apparate, Chemikalien und Dienstleistungen}

Ex-geschützte Behälter und Rohrbegleitheizungen

Immer häufiger werden in Chemieanlagen elektrische Beheizungen in exgeschützter Ausführung installiert. Dank einem speziellen Computerprogramm können solche Heizsysteme für Behälter, Reaktoren, Silos, Trichter. Rohrleitungen usw, innert kürzester Zeit ausgelegt und geliefert werden. Je nach Anwendungsfall wird $z, B$. bei einem Behälter der gesamte oder nur der untere Teil des Mantels und der Boden beheizt. Um die Montagezeit zu verkürzen, können auch vorgefertigte Heizmatten verwendet werden. Viele der zu lagernden Medien sind temperaturempfindlich. Das entsprechende Regelsystem ist deshalb so ausgelegt, dass an der gesamten Behälterwand gleiche thermische Verhältnisse gegeben sind. Das Medium kann somit einwandfrei beheizt werden. Elektrische Beheizsysteme können für Temperaturen bis zu $1000^{\circ} \mathrm{C}$ (nicht exgeschützt) geliefert werden.

- WISAG, Wissenschaftliche Apparaturen und Industrieanlagen AG, Oerlikonerstrasse $88, \mathrm{CH} 8057$ Zürich, Tel. (01) 3114040

$$
\text { Leserdienst } 5 I
$$

\section{Druckunabhängiges}

Dosieren von Gasen

Mit dem neuen Gas-Dosiergerät FC300 ist es möglich, Gasströme, unabhängig von variablen Ein- oder Ausgangsdrücken, genau zu dosieren. Das Gerät bietet die Möglichkeit, den Gasstrom über einen Schreiber zu registrieren oder über eine bereits vorhandene Fremdsteuerung vorzuwählen. $1 \mathrm{~m}$ Falle von externen oder internen Störungen werden am Steuergerät Alarmmeldungen angezeigt, und auf Wunsch erfolgt ein automatisches Abschalten oder Weiterleiten.
Der Einsatz mit spezieller Ausführung ist ebenfalls im Ex-Bereich möglich Gas-Dosiergeräte Typ FC-300 DD sind für variable Ausgangsdrücke und de Typ FC-300 DU für variable Eingangsdrücke vorgesehen.

Wisag, Oerlikonerstrasse $88, \mathrm{CH}$ 8057 Zürich. Tel. (01) 3114040 . Leserdienst 52

\section{Ein gutes System verbessern}

Für das Messen und Dosieren von Gas- und Flüssigkeitsströmen sind die Messgeräte nach dem Schwebekörperprinzip vielfach auch aus preislichen Gründen eingesetzt. Um genau bestimmte Durchflusswerte überwachen zu können oder um Mini- und/oder MaxiAlarmwerte zu signalisieren, werden fremdlichtgeschützte Infrarot-Photozellen in die Durchflussmesser eingebaut. Dieses System erlaubt ein automatisches Überwachen von beliebigen Durchflussströmen. Die Photozellen sind auf Schienen montiert und auf der ganzen Skalenlänge sehr leicht und stufenlos fixierbar. Spezielle Ausführungen sind auch im ExBereich einsetzbar.

- Wisag, Oerlikonerstrasse $88, \mathrm{CH}-$ 8057 Zürich, Tel. (01) 3114040.

Leserdienst 53

\section{Neue Kalibrierstelle}

Die Revue Thommen AG wurde mi Wirkung ab Februar 1990 vom Eidgenössischen Amt für Messwesen (EAM) als Kalibrierstelle für die physikalische Grösse "Druck" anerkannt. Mit dieser Zulassung als Kalibrierstelle wurde ein weiterer Schritt zur Zukunftssicherung durchgeführt, um der erhöhten Nachfrage, den Anforderungen des Marktes in bezug auf die Qualitätssicherung bei
Druckmessinstrumenten, -geräten gerecht zu werden. Durch diese Massnahme beziehungsweise Dienstleistung als Kalibrierstelle für "Druck" wird die nationale und internationale Marktposition der Revue Thommen AG gestärkt und gefestigt.

Revue Thommen $\mathrm{AG}, \mathrm{CH}-4437 \mathrm{Wal}-$ denburg, Tel. (061) 9704 11, Telefax (061) 978171

Leserdienst 54

Immerwährende hohe

Messgenauigkeit

Messgenauigkeit bei Flüssigkeiten und Gasen gleich hoch - keine Beeinträchtigung durch Verunreinigungen des Mediums - keine Wartung - nahezu unbegrenzte Lebensdauer: Diese Merkmale der Durchflussmesser von Fluid Inventor haben sich in ausgeführten Anlagen immer wieder bestätigt. Die Gehäuse, wahlweise aus Gusseisen oder Edelstahl, werden serienmässig für die Nenndrücke PN 10, PN 16, PN 25 und PN 40 sowie für die Nennweiten DN 20 bis DN 400 gebaut. Grössere Nennweiten sind auch lieferbar. Die Durchflussmesser enthalten keine beweglichen Teile. Als Messwertgeber dient ein sogenannter Fluidistor-Oszillator. Das vom Medium durchströmte Gehäuse enthält eine Drossel mit dem gleichen Durchflusskoeffizienten wie der Messwertgeber selbst. Das Frequenz-Volumenstrom-Verhältnis wird durch die Viskosität bzw. Dichte des Mediums nicht beeinflusst. Die Schwingungszahl des Oszillators ist dem Volumenstrom im Messwertgeber und somit auch dem Durchfluss im Gehäuse direkt proportional. Ein kompletter Gerätesatz besteht aus dem eigentlichen Durchilussmesser und dem zugehörigen Signalumformer. Der Umformer steht in mehreren Ausführungen zur Verfügung:
Als Zählwerk (lmpulsverstärker), als lntegralmesswerk (Wärmemessungen) oder als sog. Durchflussrechner für $\mathrm{P}+\mathrm{T}$-kompensierte Gasdurchflussmessung. Die Durchflussmesser von Fluid Inventor erreichen praktisch unbegrenzte Lebensdauer.

Fluid Inventor AB, Box 81037 S-104 81 Stockholm. Tel. (46) 8440805 .

Fax (46) 844 1520, Telex: 13440

Leserdienst 55

Neues Farbsystem für MacIntosh optimiert die Farbwiedergabe auf Druckern

TekColor ermöglicht erstmals die Anpassung der Bildschirmfarben an Farbdrucker. Damit lassen sich auf dem Bildschirm erstellte Farbgrafiken auch in der Farbwiedergabe exakt auf dem angeschlossenen Farbdrucker reproduzieren. Das Softwarepaket TekColor besteh aus den drei folgenden Komponenten: inem Farbmodell, einer Benutzerschnittstelle und ciner Gerätedatenbank. Die erste Realisierung des Farbtreuesystems bietet Tektronix für Apple-MacIntosh-Il-Personalcomputer an. Ebenfalls unterstützt wird TekColor von PC-Software-Anbietern wie Aldus sowie den Bildschirmherstellern Radius, E-Machines und RasterOps. Durch die offene Schnittstellensperifikation in TekColor ermöglicht Tektronix auch anderen Anbietern den Zugriff auf das Farbwahlsystem. Tektronix geht davon aus, dass weitere Anbieter auf dem DTP-Mark das Farbwahlsystem einsetzen werden.

- Tektronix International AG, Kurt Mühlebach, Marketing Communications Manager, Gubelstrasse 11, CH $6300 \mathrm{Zug}$, Tel (042) 219192 